\title{
Therapies Against COVID-19: a Running to a Treatment
}

\author{
ISI-SENAI-CIMATEC Group ${ }^{1}$; Laboratory of Molecular Biology Group, Butantan Insitutite ${ }^{2}$ \\ ${ }^{1}$ Salvador, Bahia, Brazil; ${ }^{2}$ São Paulo, São Paulo, Brazil
}

\begin{abstract}
There is no specific drug or therapy against COVID-19. Since the beginning of the pandemic, scientists are running to discover a drug or therapy that can treat the disease. What we found until now are a combined drug and therapies that can mitigate the effects of the disease in the human body and how to manage the patient better. In this article, we tried to join the new discoveries and presented the drugs and therapies and their mechanisms to combat the SARS-CoV-2. We showed the immunomodulators, parasiticides, antiviral drugs (focused on Remdesivir), antimalarial drugs, anti-cytokine drugs focused on the role of IL-6, Reumathological drugs, inhibitors of cell-receptors, antiinflammatory drugs, especially the role of corticosteroids (dexamethasone), antibiotics (azithromycin), anti-thrombotic drugs, blood derivates therapies and alternative therapies currently used against COVID-19. Also, we listed the main results of clinical trials of new therapies presented by Recommended Panel Treatment Guidelines [NIAID-RML (USA)]. We searched the data in the main database (PubMed/Medline, Elsevier Science Direct, Scopus, Isi Web of Science, Embase, Excerpta Medica, UptoDate, Lilacs, Novel Coronavirus Resource Directory from Elsevier), in the high-impact international scientific Journals (Scimago Journal and Country Rank - SJR - and Journal Citation Reports - JCR), such as The Lancet, Science, Nature, The New England Journal of Medicine, Physiological Reviews, Journal of the American Medical Association, Plos One, Journal of Clinical Investigation, and in the data from Center for Disease Control (CDC), National Institutes of Health (NIH), National Institute of Allergy and Infectious Diseases (NIAID) and World Health Organization (WHO). We prior selected meta-analysis, systematic reviews, article reviews, and original articles in this order. We used 302 articles from March to June 2020, using the terms coronavirus, SARS-CoV-2, novel coronavirus, Wuhan coronavirus, severe acute respiratory syndrome, 2019-nCoV, 2019 novel coronavirus, n-CoV-2, covid, n-SARS-2, COVID-19, corona virus, coronaviruses, immunomodulators, parasiticides, antiviral, antimalarial, anti-thrombotic and anti-cytokine, antiinflammatory, Reumathological drugs, inhibitors of cell-receptors, antibiotics, blood derivates therapies and alternative therapies, with the tools MeSH (Medical Subject Headings), AND, OR, and the characters [,",; /., to ensure the best review topics. We concluded that despite there is no treatment or drugs against the COVID-19, a combined therapy can help and mitigate the effects of the disease, helping the immune system to combat the virus.
\end{abstract}

Keywords: COVID-19. SARS-CoV-2. Therapies. Treatments. New Discoveries.

\section{Introduction}

COVID-19 is defined as a sickness caused by the novel coronavirus SARS-CoV-2 (severe acute respiratory syndrome coronavirus 2), which was first identified in Wuhan City, Hubei Province, China [1]. It was originally reported to the World Health Organization (WHO) on December 31, 2019, and on March 11, 2020, the

Received on 2 March 2020; revised 9 June 2020.

Address for correspondence: ISI-SENAI CIMATEC. Av. Orlando Gomes, 1845, Piatã. Zip Code: 41650-010. Salvador, Bahia, Brazil. E-mail: jbth@jbth.com.

J Bioeng. Tech. Appl. Health

(D)2020 by SENAI CIMATEC.
WHO ed the COVID-19 outbreak as a global pandemic. The period since then has been one of the most challenging in recent history for doctors, researchers, health companies, and all the governments around the world. Scientists are running on to find treatments, drugs, and vaccines to save lives and cure people.

Notwithstanding, no drugs, biologics or vaccines have yet been approved by the health federal agencies worldwide for prevention or treatment of COVID-19. The drugs' arsenal we have available so far is destined for the management of COVID-19 patients. This article review brings a compilation of promising drugs, therapies and treatment against COVID-19, as well as the treatment guidelines panel from National Institutes of Health from the United States. 
SARS-CoV-2: Virology and Drug Targets [2] (Figures 1 and 2)

As already known, SARS-CoV-2 is able to target cells by viral structural spike (S) protein that attaches to the angiotensin-converting enzyme 2 (ACE2) receptor [3]. After the receptor attachment, the virus particle utilizes host cell receptors and endosomes to penetrate the host cells. A host type 2 transmembrane serine protease, TMPRSS2, aids cell entrance via the S protein [3]. Into the cell, viral polyproteins are synthesized that encode for the replicase-transcriptase complex. The virus then produces RNA by its RNAdependent RNA polymerase. Structural proteins are synthesized conducting to completion of arrangement and release of viral particles $[4,5]$. These steps of the viral lifecycle give possible targets for drug therapies. Assuring drug targets involve nonstructural proteins (eg, 3-chymotrypsin-like protease, papain-like protease, RNA-dependent RNA polymerase), which share homology with other novel coronaviruses (nCoVs). Added drug purposes include viral entrance and immune regulation pathways $[6,7]$.

The Figure 1 presents the main targets and drugs that have been used in attempt to treat the COVID-19, as well as Figure 2 presents the drugs target and immune response (Figure 3 ).

\section{Immunomodulators, Drugs of ARDS/ Anticytokines and Other Investigational Therapies [8] (Table 1 attached)}

\section{$\underline{\text { Anti-TNF Agents }}$}

TNF- $\alpha$ is one of the most potent proinflammatory cytokines with broad spectrum of actions. Marked elevations reported in many inflammatory conditions including cytokine release syndrome. Serum TNF- $\alpha$ levels found elevated in COVID-19 patients with being more pronounced in more severe patients [9]. SARS-CoV viral spike protein can modulate TNF- $\alpha$-converting enzyme (TACE)dependent shedding of the ACE2 ectodomain, required for the viral entry which is coupled to TNF- $\alpha$ production [10]. The hypothesis is that the use of TNF inhibitors might be effective in blocking viral entry and detrimental effects of exuberant TNF- $\alpha$, which is observed preclinical studies on severe respiratory syncytial virus and influenza infections [11]. Anti-TNFs lead to higher risks of bacterial, viral and fungal infections, thus their use in COVID-19 needs to be supported with preclinical and clinical studies.

\section{IL-1 Family Antagonists [12]}

During the cytokine storm (Figure 4), the three most important cytokines in the IL-1 family are released such as IL-1 $\beta$, IL-18, and IL-33 [12, 13]. Many studies have shown that a "cytokine storm" relief of IL-6, IL-1, IL-12, and IL-18, simultaneously with tumor necrosis factor-alpha (TNF $\alpha)$ and other inflammatory mediators. The elevated pulmonary inflammatory response may result in increased alveolar-capillary gas exchange, causing oxygenation difficult in patients with severe disease. Investigations that concentrate on the inhibition of IL- $1 \beta$ to decrease the cytokine storm have attracted attention. Anakinra, which is an antagonist of IL-1 $\beta$, can be applied to treat the cytokine storm caused by infection. Shakoory and colleagues demonstrated that Anakira significantly improved the 28-day survival rate of patients with severe sepsis [14]. According to the Center for Disease Control Guidelines for COVID-19 [15], the data is not sufficient to recommend for or against the use of interleukin (IL)-1 inhibitors for COVID-19 treatment.

\section{Anakira [5]}

Nod-like receptor family pyrin domaincontaining 3 (NLRP3) is a critical inflammasome in acute protection of the body against a wide variety of noxious stimuli, including RNA viruses [16]. NLRP3 activates caspase-1, a molecule responsible for the activation and exuberant release of IL- $1 \beta$ and IL-18. Previously SARS-CoV has been shown to induce NLRP3 by its ion channelforming M protein and ORF8b [17]. SARS-CoV-2 is known to induce various cytokines, including 
Figure 1. Currently tested therapeutic molecules targeting different steps of SARS-CoV-2 life cycle.

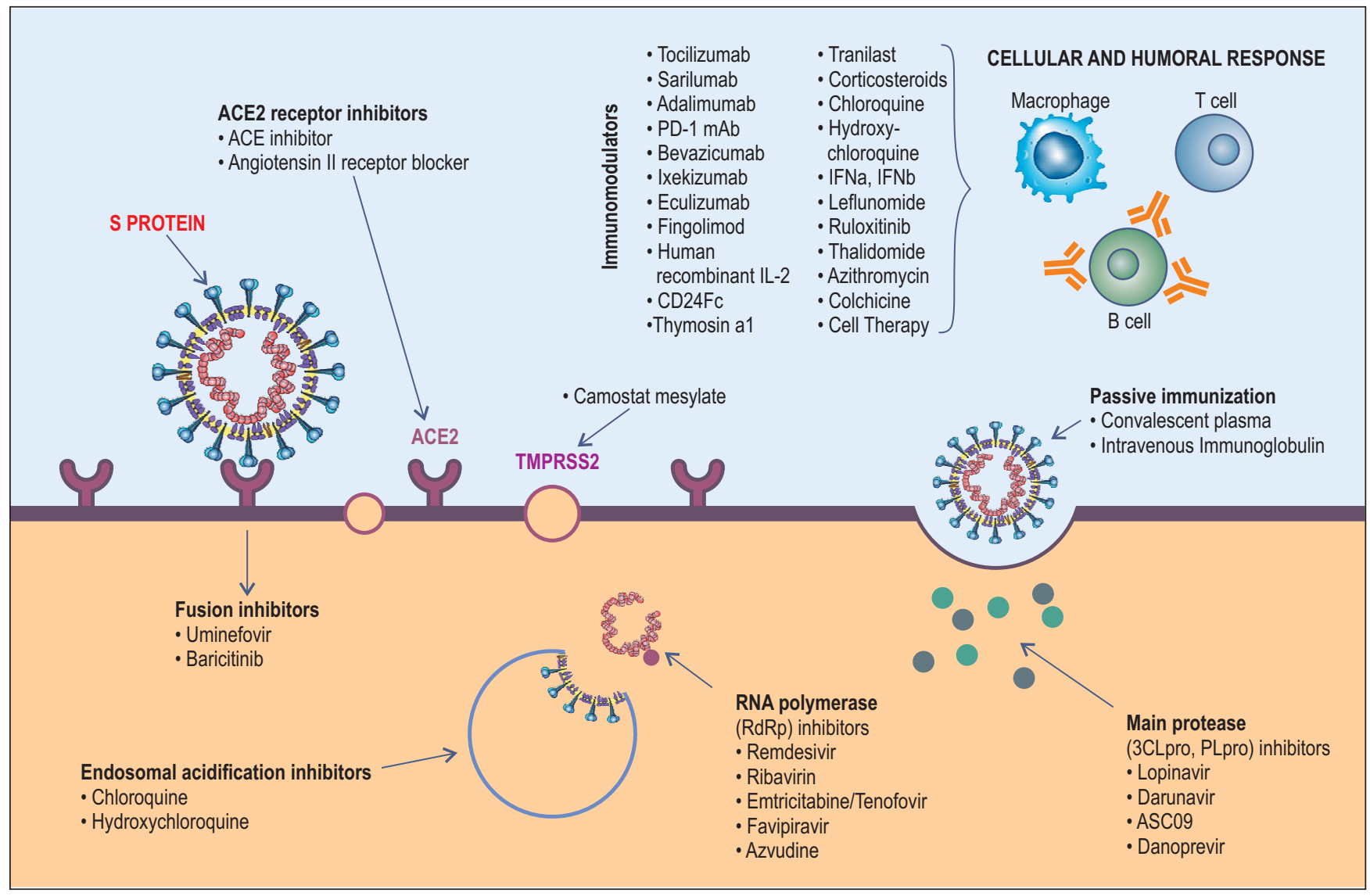

Credit/Source: Adapted from Fragkou and colleagues [7a].

the IL-1 family [18]. The IL-1 family is made up of pleiotropic cytokines, which have roles in inflammation, hematopoiesis, and fibrosis. IL-1 $\beta$ and TNF- $\alpha$ promote vascular permeability and leakage. Both IL-1 $\beta$ and IL-18 fuel cytokine storm and MAS and IL-1 cytokines (except IL-18) can be successfully inhibited by anakinra, as Conti and colleagues' study can attest [19].

Anakinra is a recombinant antagonist of human IL-1 and approved for the treatment of Reumatoid Arthritis (RA) and certain autoinflammatory disorders with recommended doses of 1-2 mg/ $\mathrm{kg} /$ day with a maximum daily dose of $8 \mathrm{mg} / \mathrm{kg}$ [20, 21]. In terms of sepsis and MAS, a previous, highly cited phase III trial, anakinra did not improve 28-day survival rate in sepsis patients and was terminated earlier than expected [22]. Still, a new analysis of data from this trial suggested significant improvement in survival in patients with hepatobiliary dysfunction and disseminated intravascular coagulation (DIC) [14]. Anakinra was administered intravenously at $2 \mathrm{mg} / \mathrm{kg} / \mathrm{hr}$ for $72 \mathrm{~h}$ continuously in this study without safety concerns. Careful monitoring is in order, since this dose is extremely higher than those used in rheumatology routine. There are several anakinra studies registered for COVID-19, testing $100 \mathrm{mg}$ daily subcutaneous injection for 28 days to 400-600 mg/day intravenous for 5-7 days (NCT04339712, NCT04330638).

A recent study from Navarro-Millán and colleagues [23] suggested that Anakira could be benefitial in COVID-19 patients with cytokime storm syndrom when initiated early after onset of hypoxic resiratory failure. Nevertheless, due to the insufficient data on the use of interleukin (IL)-1 inhibitors, such as Anakinra, the Treatment Guidelines Panel against COVID-19 by the National Institutes of Health (NIH) from the United 
Figure 2. Drugs target against COVID-19 and immune response.

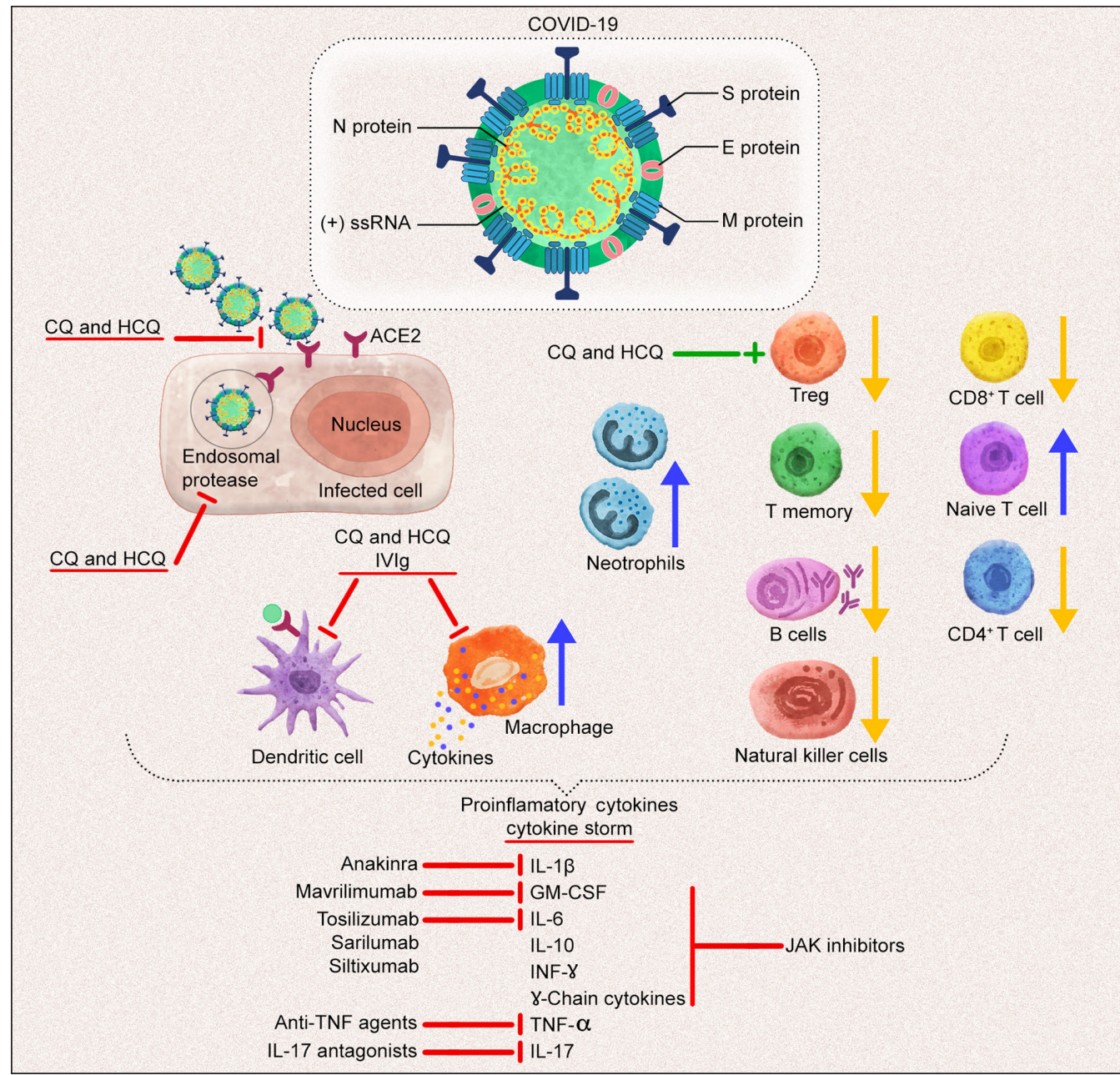

The schematic image of coronavirus $(\mathrm{CoV})$. CoVs, enveloped virus, possess nonsegmented, positive $(+)$ ssRNA genome with structural proteins: Spike (S) glycoprotein, membrane (M) protein, nucleocapsid (N) protein, and envelope (E) protein. SARS-CoV-2 S protein attaches to angiotensin-converting enzyme 2 (ACE2) receptor on the host cell to entry. After the attachment, host endosomal proteases mediate the virus membrane-endosome fusion for the release of the viral genome. Chloroquine (CQ) and hydroxycloroquine (HCQ) block the virus-receptor binding and virus-endosome fusion. Besides CQ, HCQ, and intravenous immunoglobulin (IVIg) inhibit the production of cytokines in macrophages and the antigen presentation in dendritic cells. In COVID-19, the count of neutrophils and leukosytes increase whereas the total count of lymphocytes CD4 $+\mathrm{T}$ cells, $\mathrm{CD}+8 \mathrm{~T}$ cells, regulatory $\mathrm{T}(\mathrm{T}$ reg) cells, memory $\mathrm{T}$ cells, natural killer cells, and $\mathrm{B}$ cells decrease. Another beneficial effect of CQ and HCQ is increasing the activity of Treg. The aberrant proinflammatory cytokine production is observed in COVID-19. Several immunomodulatory therapies including interleukin (IL)-6 antagonists, granulocyte colonystimulating factor (GM-CSF) inhibitor, IL-1 antagonists, IL-17 antagonists, and antitumor necrosis factor (TNF) agents might be used for this cytokine storm to resolve and limit the further inflammation and tissue damage (The yellow arrow indicates a decrease in the number of cells; the blue arrow indicates and increase in the number of cells). X (red) This agents are not recommended by FDA, CDC and WHO. Credit/Source: Tufani and colleagues [7b] This work is licensed under a Creative Commons Attribution 4.0 International License.

States does not recommend the use of interleukin (IL)-1 inhibitors against COVID-19 [15].

\section{Anti IL-17 Antagonists}

One of the cytokines found abundant in COVID-19 patients is IL-17, which is also associated with severe lung inflammation [8]. IL-17 has wide-ranging proinflammatory effects on induction of cytokines; IL-1 $\beta$, IL-6, TNF- $\alpha$; growth factors, G-CSF; chemokines; and matrix metalloproteinases. In a mouse model, it was found that H1N1 cause acute lung injury in an IL-17-dependent manner. It has been postulated 
Figure 3. Immune resoponses against COVID-19.

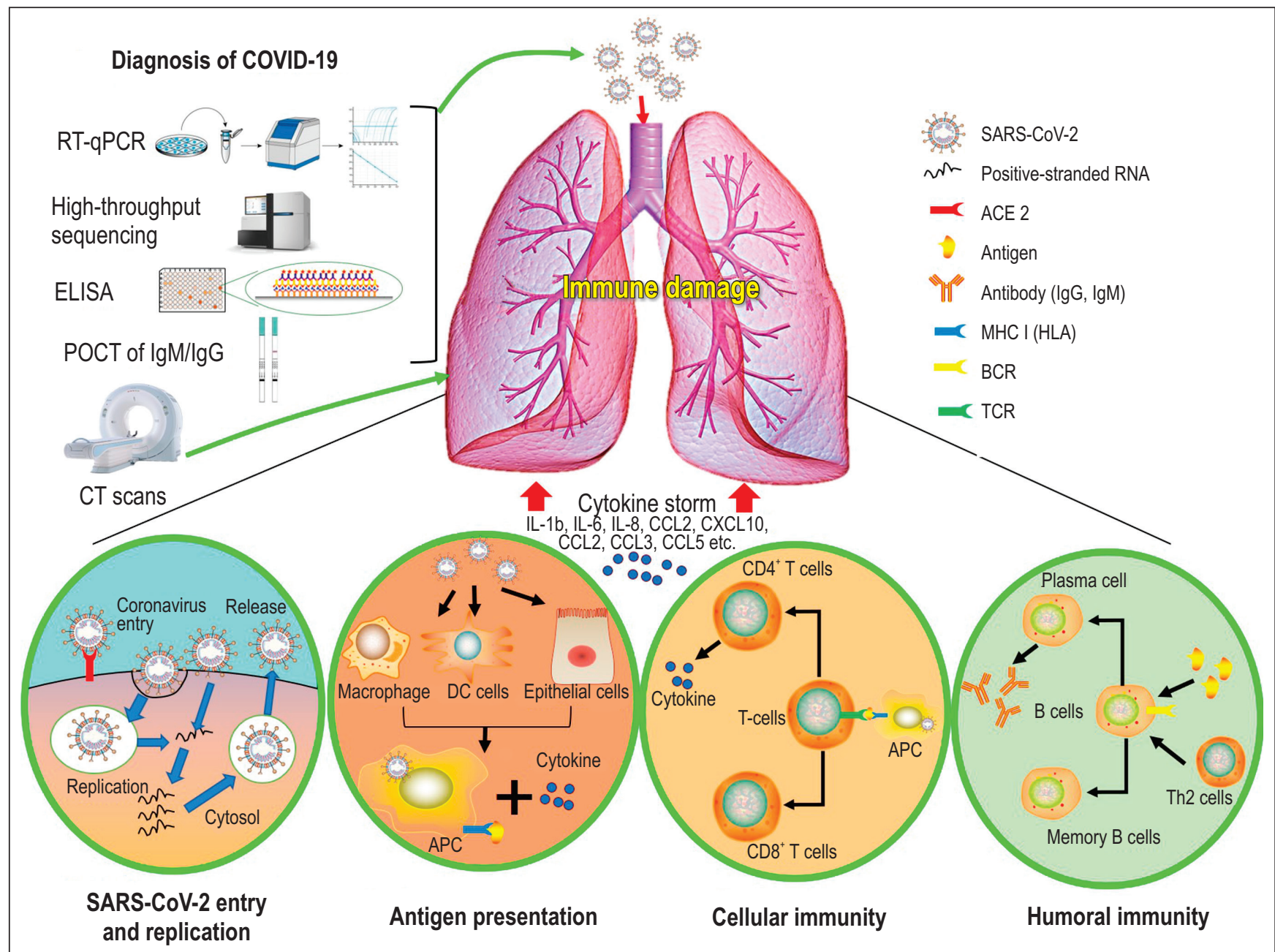

Credit/Source: Li and colleagues [7c].

that blocking this cytokine may be effective in reducing SARS-CoV-2 related organ damage [24].

The COVID-19 Treatment Guidelines Panel recommends the use of interferons in patients with severe COVID-19 only in a clinical trial. There are insufficient data to recommend either for or against the use of interferon-beta for the treatment of COVID-19 in any phase of the disease [15].

\section{$\underline{\text { IFN- } \lambda[12] ~}$}

IFN- $\lambda$ primarily activates epithelial cells and reduces the mononuclear macrophage-mediated proinflammatory activity of IFN- $\alpha \beta[13,25,26]$, and also hinders the recruitment of neutrophils to the sites of inflammation [25]. SARS-CoV and MERS-CoV mainly infect alveolar epithelial cells (AEC), and IFN- $\lambda$ is able to activate the antiviral genes in epithelial cells, thereby exerting antiviral effects without overstimulating the human immune system. For this reason, IFN- $\lambda$ may be an ideal treatment, according to Wang and colleagues' study [12]. Some studies have applied pegylated and non-pegylated interferons for the treatment of HCoVs, however, the effectiveness differed significantly due to the use of different treatment regimens. Early administration of interferons has certain benefits in diminishing viral load and enhances the clinical symptoms of patients to a certain limit. Nevertheless, it fails to decrease mortality rates $[25,26]$. 
Figure 4. Cytokine storm and immune responses by SARS-CoV-2 severe infection.

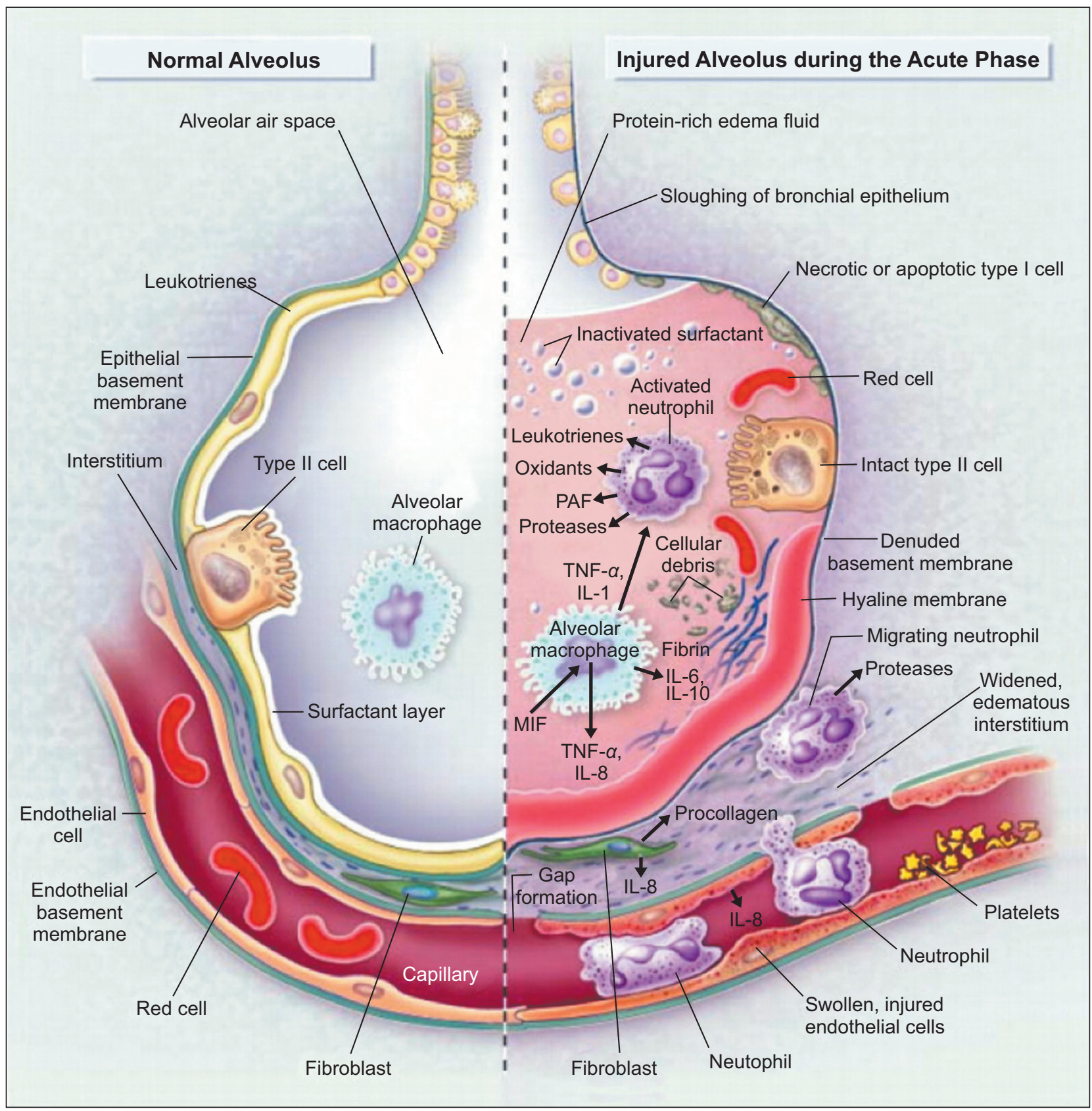

The normal alveolus (Left-Hand Side) and the injured alveolus in the acute phase of acute lung injury and the acute respiratory distress syndrome (Right-Hand Side).

Credit/Source: Bakowitz and colleagues [7c].

\section{$\underline{\text { IFN- } \alpha \beta \text { Inhibitors }}[12]$}

IFN- $\alpha \beta$ restricts viral replication by inducing the IFN-stimulated gene. Nevertheless, IFN- $\alpha \beta$ also intensifies diseases through intensifying the recruitment and function of mononuclear macrophages and other innate immune cells. Although an early interferon response has a protecting impact on mice infected with SARS$\mathrm{CoV}$, delayed IFN- $\alpha \beta$ signaling produces an imbalance of the anti-SARS-CoV immune responses in humans. This event means that the 
timing of IFN treatment is essential to the outcome of diseases. Based on these results, IFN- $\alpha \beta$ receptor blockers or antagonists should be applied in the later phases of critical disease to restrict overexpressed inflammatory responses [27].

\section{Interferon- $\alpha(I F N-\alpha)[27,28]$}

The IFN- $\alpha$, a broad-spectrum antiviral drug licensed for the treatment of viral hepatitis, is applied to treat the COVID-19 at a dose of 5 million units through vapor inhalation two times a day alone or in combination with ribavirin (500 mg 2-3 times a day) and antiviral drugs lopinavir/ritonavir (400 $\mathrm{mg} / 100 \mathrm{mg}$ ) for a period of 10 days [30]. Earlier, the combination of IFN- $\alpha 2 \mathrm{a}$, ribavirin, and lopinavir/ ritonavir was used as triple therapy for MERS-CoV in South Korea [31]. It was observed that the SARSCoV-2 is more susceptible to IFNs as compared to SARS-CoV as the inhalation of IFN- $\alpha 2 b$ decreased the infection rate significantly [28] and it can be used for prophylaxis of SARS-CoV-2 infection [33]. However, more studies should be done.

\section{Interferon- $\beta$ (IFN- $\beta)$}

The other interferon, IFN- $\beta$ was first developed for the chronic obstructive pulmonary disorder (COPD) and is recognized to enhance the lung's condition and improve its capacity to combat viral infections. Earlier, it was stated that a reduction in the production of INF- $\beta$ is straight connected to increased susceptibility of people to develop severe respiratory diseases caused by viral infections [28]. It was also observed that the SARS-CoV-2 infection represses the production of INF- $\beta$ in the body which results in protection from the immune system [32]. Recently, Synairgen, a UK biotechnology company, has been given the approval to lead a trial using IFN- $\beta$ on patients with COVID-19 [33]. The advantage with IFN- $\beta$ is that it can be inhaled alike to IFN- $\alpha$ and can be administered by patients themselves.

\section{Monoclonal Antibodies [1]}

Monoclonal antibodies affect inflammatory cytokines and other innate immune responses and represent another possible class of adjunctive therapies for COVID-19. The reason for their use is that the underlying pathophysiology of wellknown organ injury in the lungs and other organs because of the overexpressed immune response and cytokine release, or "cytokine storm" [34]. IL-6 seems to be a key role in this dysregulated inflammation based on the first case reports from China [35]. So, monoclonal antibodies against IL-6 could theoretically depress this cytokine process and improve clinical outcomes.

\section{IL-6 Antagonists}

IL-6 receptors ubiquitously expressed in almost all immune cells, and IL-6 acts as a master player inducing proliferation and differentiation of immune cells. In healthy individuals, the IL-6 levels in circulation are extremely low and are in the range of $1-5 \mathrm{pg} / \mathrm{mL}$, marked elevations reported in many inflammatory conditions including cytokine release syndrome [35]. Several therapeutic agents have been developed inhibiting the cytokine itself, the signaling via the IL-6 receptor, or its postreceptor downstream signaling pathways (JAK/STAT). Tocilizumab, sarilumab, siltuximab are IL-6 antagonists with different pharmacologic properties. Tocilizumab is approved for the treatment of Rheumatoid Arthritis (RA), juvenile idiopathic arthritis, giant cell arteritis, cytokine release syndrome, and idiopathic multicentric Castleman's disease (iMCD), whereas siltuximab received approval for iMCD and sarilumab for RA only [21].

COVID-19 patients have high plasma IL-6 levels, especially those with more severe disease presentation [36]. IL-6 production can be stimulated by SARS-CoV-2 itself or by stimulation of other immune cell [37]. Indeed, it has been shown that during COVID-19, CD4+T lymphocytes are rapidly activated to differentiate into pathogenic Th1 cells, generating GM-CSF and other proinflammatory cytokines, which further induced activation of monocytes with high expression of IL-6 [38]. In clinical view, there is striking correlation between serum IL-6 levels and SARS-CoV-2 RNAaemia, which strongly indicates worse outcome [38]. 
Besides the cytokine storm, recent studies in experimentally infected animals suggest a crucial role for virus-induced immunopathological events in causing fatal pneumonia after coronavirus infections [40]. Hence, blocking IL-6 would potentially reduce the detrimental immune response caused by SARS-CoV-2.

However, there is no robust evidence to routinely suggest IL-6 antagonists. A small clinical trial in China examined the effectiveness of tocilizumab in 21 patients who met the criteria for severe or critical COVID-19, including respiratory failure, requiring mechanical ventilation, shock, or admission to the ICU with multiple organ failures. Tocilizumab improved hypoxemia, fever, lymphopenia, CRP, and lung infiltration in most of the patients treated, without serious adverse events [41]. Recently, the favorable outcome of a patient with limited cutaneous systemic sclerosis under treatment with tocilizumab was reported [42].

Since there is an urgent need for the severe COVID-19 treatments, based on these limited data, tocilizumab is included in the treatment algorithms of many countries. The dose and timing for infusions are not determined yet. Numerous studies are ongoing to assess the efficacy of tocilizumab, sarilumab, and siltixumab in several countries. Current practice is to give tocilizumab 4-8 mg/kg (maximum $800 \mathrm{mg}$ ) as single infusion. After careful evaluation of disease severity and response to initial treatment a repeat infusion can be administered at the same dose after 12-24 h. IL-6 antagonists increase the risk of infections, therefore must be used in severe patients and at the end of the high viral load phase of COVID-19, along with antiviral treatments [43]. There are other side effects including intestinal perforation and opportunistic infections. Therefore, it is prudent to monitor patients for potential side effects.

According to the COVID-19 Treatment Guidelines Panel, there are insufficient data to recommend either for or against the use of interleukin-6 (IL-6) inhibitors (e.g., sarilumab, siltuximab, tocilizumab) for the treatment of COVID-19 [15].

\section{Tocilizumab}

Tocilizumab (branded as Actemra) is a humanized mAb developed by Roche and Chugai Pharmaceutical for treating RA and systemic juvenile idiopathic arthritis patients. At the time of publishing this article, ClinicalTrials.gov listed 20 planned studies that included tocilizumab treatment arm, all of them at the recruiting stage or earlier. A study published in April 2020 reported that 21 severe or critical COVID-19 patients in China were treated with the compound, with 20 of them recovered at the time of publication and 1 on the way to recovery (but still in ICU). Encouraged by these results, a larger multicenter clinical trial was launched (ChiCTR2000029765) and had about 500 patients treated with tocilizumab already enrolled [44].

\section{Sarilumab}

Sarilumab (branded as Kefraza), a humanized mAb, was developed by Regeneron Pharmaceuticals and Sanofi for treatment of rheumatoid arthritis (RA). A phase 2/3 randomized double-blind placebo-controlled clinical trial was planned by Regeneron Pharmaceuticals and Sanofi (and in partnership with Northwell Health's Feinstein Institutes for Medical Research) for March 2020 targeting to enroll 400 COVID- 19 patients, measuring percent change in $\mathrm{C}$-protein (Phase 2 only) and time to improvement on a 7-point scale (based on death and type of hospitalization) in patients with serum IL-6 level above a threshold as primary endpoints.As of the time of this publication, the results of this study have not been made public [45].

\section{Mavrilimumab}

As mentioned, GM-CSF is one of the key molecules involved in cytokine storm which is excessively released in COVID-19 patients [46]. Blockage of this growth factor may halt immunopathology caused by virus. Mavrilimumab is a GM-CSF inhibitor developed for the refractory RA [48] and a new trial is investigating its efficacy in COVID-19 (NCT04337216). 


\section{$\underline{\text { Colchicine }}$}

Colchicine has been approved for gout and familial Mediterranean fever. In current years, colchicine has attracted attention in the management of cardiovascular diseases by suppressing its inflammatory segment [48]. Its mechanism of activity is thought to be the restraint of tubulin polymerization and microtubule formation and, perhaps, consequences on cellular adhesion molecules, inflammatory chemokines, and the inflammasome. Colchicine may repress the activation of NLRP3 inflammasome and additionally may inhibit directly the synthesis of TNF- $\alpha$ and IL-6 [49]. Trials are investigating the effectiveness of conventional therapeutic doses of colchicine for the treatment of COVID-19 (NCT04322682, NCT04328480, NCT04326790). However, Gendelman and colleagues [51] in a study from April 2020 with an overall sample of 14,520 subjects screened for SARSCoV-2 infection and 1,317 positive, showed no significant difference in terms of rates of usage of hydroxychloroquine or colchicine between those who were found positive for SARS-CoV-2 and those who were found negative $(0.23 \%$ versus $0.25 \%$ for hydroxychloroquine, and $0.53 \%$ versus $0.48 \%$ for colchicine, respectively). These findings raise doubts regarding the protective role of these medications in the battle against SARS-CoV-2 infection.

\section{$\underline{\text { Janus Kinase (JAK) Inhibitors }}$}

JAK inhibitors are potent inhibitors of one or more of the JAK family of enzymes (JAK1, JAK2, JAK3, TYK2), thereby interfering with the JAKSTAT signaling pathway. The JAK/STAT pathway mediates the effect of many different molecules, including interleukins (IL-2, IL-3, IL-4, IL-5, IL6, IL-7, IL-9, IL-10, IL-12, IL-15, IL-21, IL-23), IFN- $(\alpha, \beta, \gamma)$ and growth factors (GM-CSF, TGF- $\beta$, erythropoietin and thrombopoietin) [24]. JAK inhibitors are currently approved for the treatment of RA and psoriatic arthritis and their use in other inflammatory disorders are continuously growing [51]. Many proinflammatory cytokines involved in cytokine storm of COVID-19 might be inhibited by JAK inhibitors.

\section{Baricitinib}

Besides above mentioned common properties of JAK inhibitors, baricitinib may block AP-2associated protein kinase 1 (AAK1) and cyclin G-associated kinase (GAK) which are host kinases that regulate viral endocytosis, according to an artificial intelligence search of viral characteristics of SARS-CoV-2. This effect is only restricted to baricitinib among other JAK inhibitors and it may block viral entry and assembly of virus particles into pneumocytes in therapeutic doses used in RA [52]. However, these hypothetical views merit further evidence for clinical use both for cytokine storm and COVID-19. Currently, baricitinib (NCT04320277, NCT04340232, NCT04321993), tofacitinib (NCT04332042) and ruxolitinib (NCT04331665) studies are ongoing.

Inhibitors of Mononuclear Macrohage Recruitment and Function [12]

An autopsy of patients with COVID-19 showed many inflammatory cell infiltration in the lungs of the deceased [53]. One potentially powerful treatment approachis to decrease therecruitment of mononuclear macrophages to the site of inflammation by small interfering RNA (siRNA)-mediated silencing of C-C chemokine receptor type 2 (CCR2) to improve the outcome of the disease, which has been demonstrated in animal experiments $[54,55]$. Toll-like receptor 7 (TLR7) agonists stimulate mononuclear macrophages to undergo a strong inflammatory response at the time of infections such as $\mathrm{HCoV}$. Hence, TLR7 antagonists may be effective to relieve the storm of inflammatory factors caused by SARS-CoV-2 infection.

\section{Intravenous Immunoglobulin (IVIg)}

IVIg is a blood product containing polyclonal immunoglobulin $\mathrm{G}$ isolated and pooled 
from healthy donors used to treat Immune Thrombocytopenic Purpura (ITP), Kawasaki disease and various inflammatory neurologic and myositis syndromes. It has immunomodulatory functions with unknown mechanism of action. One of the proposed mechanisms is the interaction of IgG-Fc with $\mathrm{Fc}$ gamma receptors located on almost all immune cells, resulting in pleiotropic functional consequences including the expansion of regulatory $\mathrm{T}$ cell population, phagocytosis, antibody-dependent cellular cytotoxicity (ADCC), immune cell differentiation and maturation, apoptosis, expression of proinflammatory cytokines, and antigen-presentation [56]. Previous studies on SARS and MERS, found that IVIg therapy was effective thus proposing high-dose IVIg as an option for severe COVID-19 patients [57]. There are a few COVID-19 cases which reported efficacy of high dose IVIg [58]. However, its high cost and limited supply restrict its general use. Inferred from rheumatic diseases, COVID-19 patients with pregnancy, secondary infections, marked thrombocytopenia, muscular, myocardial and neurologic manifestations would be better candidates for IVIg treatment. There are several studies already registered for its use in COVID-19.

\section{Inhibitors of Cell Entry of SARS-CoV-2 [58]}

\section{Inhibitors of TMPRSS2 Serine Protease}

Results from previous studies reveal that diverse viruses, including Ebola virus, SARS-coronavirus (SARS-CoV), MERS-coronavirus (MERS-CoV) and influenza virus employ host cell proteases for activation of their envelope glycoproteins [59, 60]. Cleavage and activation of the spike protein ( $\mathrm{S}$ protein) of SARS-CoV that is required for membrane fusion and host cell entry is mediated by transmembrane protease/ serine subfamily member 2 (TMPRSS2), an airway and alveolar cell serine protease [61, 62]. Hoffmann and colleagues [63] recently demonstrated that SARSCoV-2 also employs TMPRSS2 for SARS-CoV-2 $\mathrm{S}$ protein priming and $\mathrm{S}$ protein-driven cell entry.
Using camostat mesilate, a clinically proven and commercial serine protease inhibitor that partially blocks infection by SARS-CoV and HCoV-NL63 in HeLa cell expressing ACE2 and TMPRSS2 [64], it was shown that inhibition of TMPRSS2 in human lung Calu-3 cells by camostat mesilate significantly reduced infection with SARS-CoV-2. Camostat, (FOY-305), [N,N-dimethylcarbamoylmethyl 4-(4-guanidinobenzoyloxy)-phenylacetate] methanesulfate and camostat mesilate (Foipan ${ }^{\mathrm{TM}}$ ), alternatively termed camostat mesylate, (NI-03), (CAS number: 59721-28-7), constitute synthetic serine protease inhibitors that were developed decades ago for the treatment of oral squamous cell carcinoma [65], dystrophic epidermolysis [66], exocrine pancreatic enzyme inhibition [67], and chronic pancreatitis [68]. Camostat mesilate (NI-03) is manufactured as an oral drug by Nichi-Iko Pharmaceutical Co., Ltd., and Ono Pharmaceutical, Japan, with a three times daily dose recommendation of $100 \mathrm{mg}-300 \mathrm{mg}$ [69]. In a clinical trial investigating camostat mesilate against dyspepsia associated with non-alcoholic mild pancreatic disease, 95 patients received 200 $\mathrm{mg}$ camostat mesilate three times daily for 2 weeks and showed only mild, but no severe adverse effects [70], indicating that camostat mesilate is a well-tolerated drug.

\section{Nafamostat Mesilate (BUIPEL ${ }^{\mathrm{TM}}$ )}

Nafamostat mesilate (Buipel ${ }^{\mathrm{TM}}$ ), (6-amidino-2-naphthyl-4-guanidino benzoatedimethanesulfonate) (FUT-175), (CAS number: 81525-10-2), is a clinical proven and synthetic serine protease inhibitor approved in Japan for the treatment of acute pancreatitis, disseminated intravascular coagulation and for anticoagulation in extracorporeal circulation [71, 72]. In a screening approach of about 1,100 drugs approved by the FDA, nafamostat mesilate has been identified to inhibit MERS-CoV S protein-mediated viral membrane fusion with TMPRSS2- expressing lung Calu-3 host cells by inhibiting TMPRSS2 protease activity [58]. Since the S proteins of MERS-Cov 
and SARS-CoV-2 share considerable amino acid sequence homology [72, 73], nafamostat mesilate may also inhibit cell entry of SARS-CoV-2. In cell culture experiments with simian Vero E6 cells infected with SARS-CoV-2, nafamostat mesilate was shown to be inhibitive against SARS-CoV-2 infection at EC50 of $22.50 \mu \mathrm{M}$ [74], suggesting that nafamostat mesilate is able to prevent SARSCoV-2 infection. In a multicenter, randomized, open-label, phase 2 trial in 19 patients with severe acute pancreatitis, nafamostat mesilate was administered intravenously at a daily dose of 240 $\mathrm{mg}$ for 5 days without severe adverse effects.

\section{Inhibitors of Angiotensin-Converting Enzyme 2 (ACE2), Antimalarial/Parasiticide Drugs}

SARS-CoV and related coronaviruses directly interact via their $\mathrm{S}$ proteins with angiotensinconverting enzyme 2 (ACE2), a host cell exopeptidase and metallocarboxypeptidase that catalyses the conversion of angiotensin I to the nonapeptide angiotensin and the conversion of angiotensin II to angiotensin 1-7, to initiate $\mathrm{S}$ protein-mediated cell entry $[75,76]$. It was demonstrated recently that also SARS-CoV-2 uses ACE2 as a receptor for $\mathrm{S}$ protein-driven host cell entry [62, 73]. Therefore, ACE2 constitute a molecular target to inhibit cell entry of SARSCoV-2. Unfortunately, ACE inhibitors as standard drugs for the treatment of hypertension and chronic heart failure fail to inhibit ACE2 [77], but a number of other drugs and compounds have been shown to inhibit ACE2.

\section{Antimalarial Drugs (Table 1 attached)}

These drugs also fall under three categories based on their mode of action aryl amino-alcohol compound, antifolate compound and artemisinin. Most of these drugs are eliminated gradually from the body remaining for long periods of time after intake. A disadvantage of this drug is that antimalarial drug resistance develops for any drugs under this category [78].

\section{Chloroquine}

Chloroquine (CQ), a drug widely used in treating malarial and autoimmune diseases, also confers considerable broad-spectrum antiviral effects even against SARS-CoV [79-81]. A recent study demonstrated that CQ has anti-SARSCoV-2 activity in vitro [82]. A subsequent letter in Bioscience confirmed that CQ is efficacious in treating COVID-19 pneumonia in numerous related clinical trials. CQ therapy resulted in improved pulmonary lesions, shortened disease course, and good outcomes [83]. Given the apparent efficiency displayed by CQ in clinical practice, CQ has been included in the Guidelines for the Diagnosis and Treatment of COVID-19 (7th edition) issued by the National Commission of the People's Republic of China (NHPFC, 2020).

\section{Hydroxychloroquine}

Hydroxychloroquine sulfate (HCQ) shares a similar chemical structure and mechanisms of action with CQ but with lower ocular toxicity [84] and has proven efficacious in containing SARSCoV-2 in vitro [85]. CQ and HCQ exert antiviral function through various mechanisms. CQ has been shown to interfere with the glycosylation process of ACE2 in host cells, thereby inhibiting the efficiency of the binding of S protein with ACE2, in turn disrupting the virus/cell fusion process [80] CQ can increase the $\mathrm{pH}$ of acidic cellular organelles required for virus entry into host cells [86] In addition to its direct antiviral activity, CQ and HCQ can attenuate major "cytokine storms" (an overreaction of the immune system causing inflammatory "storms") by decreasing cytokine production (interleukin [IL]-1, IL-6, and tumor necrosis factor [TNF], etc.) [87].

\section{Chloroquine and Hydroxychloroquine}

Chloroquine phosphate (Resochin ${ }^{\mathrm{TM}}$ ) and its derivative hydroxychloroquine (Quensyl ${ }^{\mathrm{TM}}$, Plaquenil' ${ }^{\mathrm{TM}}$, Hydroquin ${ }^{\mathrm{TM}}$, Dolquine ${ }^{\mathrm{TM}}$, Quinoric ${ }^{\mathrm{TM}}$ ) have been used for decades for the prophylaxis and treatment of malaria and for the treatment of chronic $Q$ fever and various 
autoimmune diseases [88], and have been demonstrated as potential broad-spectrum antiviral drugs [80].

Chloroquine phosphate inhibits terminal phosphorylation of ACE2, and hydroxychloroquine elevates the $\mathrm{pH}$ in endosomes which are involved in virus cell entry [89, 90], both mechanisms constitute relevant antiviral mechanisms of chloroquine and hydroxychloroquine, respectively. In vivo, hydroxychloroquine is metabolized into chloroquine. Chloroquine phosphate has previously been shown to inhibit SARS-CoV infection and spread in vitro $[89,91]$, and results from very recent studies reveal that chloroquine phosphate [83].

However, on June 15, 2020, the FDA removed the use authorization (EUA) for hydroxychloroquine and chloroquine provided to the Strategic National Stockpile to be applied for treating hospitalized patients with COVID-19, except for licensed clinical trials [92]. So, the FDA determined that hydroxychloroquine is unpropitious to be useful in treating COVID-19 in the EUA. Also, due to ongoing severe cardiac adverse events and toxic serious adverse effects, the known and potential advantages of hydroxychloroquine no longer exceed the known and potential risks for patients with COVID-19 [93].

While further clinical trials may proceed to evaluate possible benefits, the FDA determined in the EUA that its use was no longer appropriate.

Additionally, the NIH stopped the Outcomes Related to COVID-19 treated with Hydroxychloroquine among In-patients with symptomatic Disease (ORCHID) study on June 20, 2020. After the fourth investigation that involved more than 470 participants, the NIH data and safety monitoring board concluded that while there was no harm, the study drug was very doubtful to be advantageous to hospitalized patients with COVID-19 [NIH halts clinical trial of hydroxychloroquine. HIH Media Advisory June 20, 2020]. Hydroxychloroquine and chloroquine are widely used antimalarial drugs that obtain immunomodulatory effects and are consequently also applied to treat autoimmune conditions (eg, systemic lupus erythematosus, rheumatoid arthritis). As inhibitors of heme polymerase, they are also considered to have additional antiviral activity via alkalinization of the phagolysosome, which restrains the $\mathrm{pH}$-dependent steps of viral replication. Wang and colleagues [82] reported that chloroquine efficiently inhibits SARS-CoV-2 in vitro. Thepharmacologicalaction of chloroquineand hydroxychloroquine was experimented with using SARS-CoV-2-infected Vero cells. Physiologically based pharmacokinetic models (PBPK) were conducted for each drug. Hydroxychloroquine was seen to be more potent than chloroquine in vitro. Based on PBPK models, the authors suggest a loading dose of hydroxychloroquine $400 \mathrm{mg}$ PO BID, accompanied by $200 \mathrm{mg}$ BID for 4 days [94].

Printed reports deriving from the beginning of the outbreak of COVID-19 have evaluated the potential application of these drugs in controlling cytokine storm in severe patients. Owing to widely differing dosage regimens, disease severity, evaluated outcomes, and the absence of control groups, effectiveness data have been widely inconclusive.

The UK RECOVERY Trial randomized 1,542 patients to hydroxychloroquine and 3,132 patients to usual care alone. Introductory results determined no significant difference in the primary endpoint of 28-day mortality (25.7\% hydroxychloroquine vs 23.5\% usual care; hazard ratio 1.11 [95\% CI, 0.98$1.26] ; p=0.10)$. There was also no proof of useful effects on hospital stay duration or other outcomes [95].

A multicenter, randomized, open-label trial in Brazil discovered no improvement in 504 hospitalized patients with mild-to-moderate COVID-19. Theapplicationofhydroxychloroquine, alone or with azithromycin, did not change clinical status at 15 days compared with standard care. Prolonged QTc interval and raised liver enzyme levels were more frequent in patients receiving hydroxychloroquine, alone or with azithromycin than in those who were not taking either agent [96]. 
An observational study, conducted between March 1, 2020, and April 22, 2020, with followup through May 5, 2020, with 2,512 hospitalized patients in New Jersey with confirmed COVID-19 patients presented 547 deaths $(22 \%)$ and 1,539 (61\%) discharges; and $426(17 \%)$ remained hospitalized. From them, who took at least one dose of hydroxychloroquine totaled 1,914 (76\%), and those who received hydroxychloroquine plus azithromycin totaled 1,473 (59\%). No significant differences were recognized in associated mortality among patients receiving any hydroxychloroquine during the hospitalization (HR, 0.99 [95\% CI, 0.80-1.22]), hydroxychloroquine alone (HR, 1.02 [95\% CI, 0.83-1.27]), or hydroxychloroquine with azithromycin (HR, 0.98 [95\% CI, 0.75-1.28]). The 30-day unadjusted mortality rate in patients taking hydroxychloroquine alone, azithromycin alone, and the combination of these drugs, or neither drug was $25 \%, 20 \%, 18 \%$, and $20 \%$, respectively [97].

After these studies, the WHO stopped the hydroxychloroquine arm of the Solidarity Trial and then removed its application completely as of July 4, 2020 [98]. The FDA announced a safety alert for hydroxychloroquine or chloroquine use in COVID-19 on April 24, 2020, and removed its use in EUA on June 15, 2020 [99]. "The COVID-19 Treatment Guidelines Panel (the Panel) recommends against the use of chloroquine or hydroxychloroquine for the treatment of COVID-19, except in a clinical trial (AII). The Panel recommends against the use of high-dose chloroquine (600 $\mathrm{mg}$ twice daily for 10 days) for the treatment of COVID-19 (AI). As well as, The COVID-19 Treatment Guidelines Panel recommends against using hydroxychloroquine plus azithromycin for the treatment of COVID-19, except in a clinical trial (AIII) [15]."

\section{$\underline{\text { Antiparasiticide }}$}

\section{Ivermectin [100]}

Ivermectin is a potent anthelmintic drug that was first discovered to hinder interaction between integrase (IN) molecule of human immunodeficiency virus (HIV)-1 and its nuclear transport receptor importin $\alpha / \beta$ [101]. Further studies exhibit its potential to prevent viral replication of a broad spectrum of viruses, including dengue virus, flavivirus, and influenza [102, 103]. Ivermectin, an antiparasitic drug, has exhibited restraint against SARS-CoV-2 up to 5,000 -fold at $48 \mathrm{~h}$ in vitro. Inhibition of IMP $\alpha /$ $\beta 1$-mediated nuclear import of viral proteins is proposed as the presumable cause of its antiviral action [104]. So, it presented decrease of viral RNA in Vero-hSLAM cells 2 hours postinfection with SARS-CoV-2 clinical isolate Australia/ VIC01/2020 in vitro [105]. This is an introductory study, which not translate to human use since the efficient dose is not established at this initial phase of discovery. More study is required to conclude if an antiviral effect would be obtained for humans, as the concentrations tested were much higher than what is realized from the normal oral dose [106].

Chaccour and colleagues [107] consider the recent findings regarding ivermectin permit rapid implementation of controlled clinical trials to evaluate efficacy against COVID-19. They also are worried about ivermectin-associated neurotoxicity, particularly in patients with a hyperinflammatory event possible with COVID-19. In addition, drug interactions with potent CYP3A4 inhibitors (eg, ritonavir) warrant careful consideration of coadministered drugs. Lastly, data infers that ivermectin plasma levels with significant action against COVID-19 might not be obtained without potentially toxic raises in ivermectin doses in humans. More data is needed to assess pulmonary tissue levels in humans [107, 108]. And, also, it seems that ivermectin does not interfere with the severity and mortality rate of patients.

\section{Cepharanthine/Selamectin/ \\ Mefloquine Hydrochloride}

The triple combination of cepharanthine (an antiinflammatory alkaloid from Stephania cepharantha Hayata), (CAS number: 48,104,902), selamectin (an avermectin isolated from Streptomyces avermitilis and used as an anti-helminthic 
and parasiticide drug in veterinary medicine), (CAS number. 220119-17-5), and mefloquine hydrochloride (Lariam ${ }^{\mathrm{TM}}$, used for the prophylaxis and treatment of malaria) [109, 110] has recently been shown to inhibit infection of simian Vero E6 cells with pangolin coronavirus GX_P2V/2017/ Guangxi (GX_P2V), whose S protein shares 92.2 $\%$ amino acid identity with that of SARS-CoV-2 [111]. It has also been demonstrated that GX_P2V also uses ACE2 as the receptor for viral cell entry. Two libraries of 2406 clinically approved drugs were screened for their ability to inhibit cytopathic effects on Vero E6 cells by GX_P2V, and only the combination of cepharanthine, selamectin and mefloquine hydrochloride was identified as candidate drug combination against SARS-CoV-2 infection [111].

\section{Neutralizing Antibodies Against SARS-CoV-2 [112]}

Currently, polyclonal antibodies from recovered SARS-CoV-2-infected patients have been applied to treat SARS-CoV-2 infection, but no SARS-CoV-2-specific neutralizing mAbs have been announced. Researchers are working hard to produce such $\mathrm{mAbs}$ and/or their functional fragments as putative prophylactic or therapeutic agents to prevent or treat COVID- 19. Once such antibodies are conceived, the next steps will include in vitro testing for neutralizing and/or cross-neutralizing activity, in vivo evaluation in animal models for protecting efficiency, preclinical studies, and clinical trials testing the security and efficacy before they are approved for clinical application. Hence, it may take one to many years for such SARS-CoV-2 neutralizing mAbs or their fragments to be available for human use.

However, since SARS-CoV-2 is closely related to SARS-CoV and since their $\mathrm{S}$ proteins have high sequence identity [113], researchers have attempted to discover SARS-CoV nAbs with potential cross-reactivity and/or cross-neutralizing activity against SARS-CoV-2 infection. Notably, a SARS-CoV RBD-specific human neutralizing
mAb, CR3022, could bind SARS-CoV-2 RBD with high affinity and recognize an epitope on the RBD that does not overlap with the ACE2-binding site [114]. In addition, sera from convalescent SARS patients or from animals specific for SARS-CoV S1 may cross-neutralize SARS-CoV-2 infection by reducing $\mathrm{S}$ protein-mediated SARS-CoV-2 entry [63]. Moreover, SARS-CoV RBD-specific polyclonal antibodies have cross-reacted with the SARS-CoV-2 RBD protein and cross-neutralized SARS-CoV-2 infection in HEK293T cells stably expressing the human ACE2 receptor, opening avenues for the potential development of SARSCoV RBD-based vaccines that might eventually prevent SARS-CoV-2 and SARS-CoV infection [115]. It is also possible that SARS-CoV RBDtargeting $\mathrm{nAbs}$ might be applied for prophylaxis and treatment of SARS-CoV-2 infection in the current absence of SARS-CoV-2-specific vaccines and antibodies. However, robust testing lies ahead.

\section{Convalescent Plasma [116] (Table 1 attached)}

In this procedure, plasma or purified monoclonal antibodies generated against COVID-19 are collected from recovered patients and delivered to new patients as treatment. From 20 January to 25 March 2020, convalescent plasma treatments were administered to five critically sick COVID-19 patients in Shenzhen, China [117]. In this study, patients took convalescent plasma with a SARS-CoV-2-specific antibody between 10 and 22 days after admission. Among the five patients, four of them presented a reduced score in sequential organ failure assessments and viral loads. Their viral test also became negative within 12 days after the transfusion. These four patients were also removed from mechanical ventilation within 2 weeks of treatment. Lastly, three patients were discharged from the hospital in approximately 50 days. Although this trial has a small sample size, the results of convalescent plasma treatment are still hopeful. This method has been suggested as a treatment option in the US [118]. 
A Cochrane review of convalescent plasma use in patients with COVID-19 is perpetually being updated as data emerge. As of July 10, 2020, the review included 20 studies with 5,443 participants, of whom 5,211 received convalescent plasma. Among these studies was one randomized controlled trial with 103 participants (52 received convalescent plasma). The authors of this review expressed doubt as to the advantages of convalescent plasma in terms of influencing mortality at hospital discharge, prolonging time to death, or enhancing clinical symptoms at 7 or 28 days [119].

Ameta-analysis of 15 controlled studies revealed a significantly lower mortality rate in patients with COVID-19 who received convalescent plasma compared with control groups. Nevertheless, the authors point out that the studies were of very low quality and a moderate or high risk of bias [120].

An open-label study $(\mathrm{n}=103)$ with COVID-19 patients in Wuhan, China, who received convalescent plasma did not result in a statistically significant change in time to clinical improvement within 28 days compared with standard of care [121].

A nonrandomized study transfused patients with convalescent plasma based on supplemental oxygen needs. Supplemental oxygen requirements and survival were compared between plasma recipients and controls. Outcomes determined that convalescent plasma transfusion enhanced survival in non-intubated patients $(\mathrm{p}=0.015)$, but not in intubated patients $(\mathrm{p}=0.752)$ [122].

\section{Hyperimmune Globulin Therapy [123]}

Extending experimental findings of $\mathrm{CoV}$ in animal models [124] to infer the risk of antibodyenhanced immunopathology in humans is more nuanced. There are likely major differences between vaccine induced $v s$ infection-induced antibodies. It is well known that innate immune response drives adaptive immune responses [125-127]. As SARS$\mathrm{CoV}-2$ infection is known to induce cytokine and chemokine expression, convalescent COVID-19 patients would likely produce antibodies that are qualitatively and quantitatively different to those elicited by vaccination alone. Although vaccines could also elicit innate immune responses, the magnitude would likely be significantly lower than those found in acutely ill COVID-19 patients since the disease is probably mediated by a proinflammatory cytokine response [50]. Moreover, the antigenic burden of wild-type SARS-CoV-2 infection can be expected to be significantly greater than those derived from vaccination. The level of such antigenic burden is known to drive adaptive immune responses, including neutralizing antibody titers [128, 129]. Consequently, extending findings from vaccine studies to infer the risk from hyperimmune globulin ignore the possibility of differences between the quality and titer of antibodies produced from infection and vaccination. This same explanation was also found to underpin how inactivated measles vaccination increases the risk of atypical pneumonia [130].

Early anecdotal reports that infusion of convalescent plasma to acutely ill COVID-19 patients suggest the potential of hyperimmune globulin as a treatment to halt the progression of infection to severe pulmonary disease. Hyperimmune globulin treatment, besides inhibiting viral infection, could also downregulate pro-inflammatory responses and reduce disease severity in COVID-19 patients. Intravenous immunoglobulin (IVIG) infusion is associated with anti-inflammatory responses [131], including those from viral infection [132]. Mechanistically, how this anti-inflammatory effect is mediated remains to be fully defined. High dose antibodies could bind a number of different inhibitory receptors, including the inhibitory Fc gamma receptor IIB (FcgRIIB) [129, 130], FcgRIIC $[135,137]$ or other receptors $[141]$ to induce the anti-inflammatory response. Regardless of the mechanism, the presence of neutralizing SARSCoV-2 antibodies as well as high concentration of total antibodies could produce anti-inflammatory rather than the postulated immunopathology enhancement effects in COVID-19 patients to improve prognosis. 


\section{Antiinflammatory Therapy [7]}

\section{$\underline{\text { Corticosteroids }}$}

Systemic corticosteroids have broad-spectrum actions on the immune system that may suppress the exuberant systemic inflammatory response that occurs in ARDS. Severe multi-source systemic inflammation is associated with adverse outcomes, so one may think that corticosteroids may of benefit with their broad spectrum immunosuppressive effects. However, evidence has shown that use of corticosteroids delayed viral clearance in SARS and MERS infections, similarly they increased secondary infection rates, mortality and complications of steroid therapy in survivors of influenza pneumonitis [142]. In a randomized controlled trial that included 16 non-ICU SARS patients, "early" ( $<7$ days of illness) hydrocortisone therapy was associated with a higher subsequent plasma viral load. Therefore, corticosteroids should not be used early phases of disease unless there is a clear indication for their use [139]. In SARS infection, some patients showed severe inflammatory features despite reductions in viral load with subsequent seroconversion, suggestive of exuberant immune response independent of viral load [140]. In two small observational study, use of corticosteroids did not show a survival benefit in COVID-19 patients even increased mortality rates when used in high doses [141, 142]. Moreover, corticosteroid use was prolonged SARS-CoV-2 RNA shedding as observed in SARS and MERS infections [143]. In the light of preliminary data, corticosteroids are more likely to function on inflammationmediated lung injury and interstitial fibrosis at latestage of ARDS [144]. However, the dose, duration, and timing of corticosteroids must be individualized considering risk-benefit ratio, until results of ongoing well-designed prospective cohort studies obtained. At present, several studies are registered to assess the efficacy of corticosteroids in COVID-19 [145].

\section{Methylprednisolone}

As a potent anti-inflammatory and anti-fibrotic drug, low doses of methylprednisolone (DEPO-
Medrol or SOLUMedrol) have the potential to prevent an extended cytokine response and may accelerate resolution of pulmonary and systemic inflammation in pneumonia [138, 145]. Recently, many medical researchers believe that corticosteroids, especially methylprednisolone, may improve dysregulated immune response caused by sepsis (possible complication of infection with COVID-19) and increase blood pressure when it is low [146]. Specifically, in a retrospective cohort study, 201 patients with confirmed COVID-19 who developed ARDS were treated with methylprednisolone $(1-2 \mathrm{mg} / \mathrm{kg}$ daily IVfor 5-7days) and the results showed that treatment with methylprednisolone may be beneficial for patients who develop ARDS in the reduction of the risk of death. Briefly, of those patients with ARDS who received methylprednisolone treatment, 23 of $50(46 \%)$ patients died, while those who did not receive methylprednisolone, 21 of 34 (61.8\%) died [147]. In another study, 46 patients with severe COVID-19 that progressed to acute respiratory failure, use of methylprednisolone was associated with improvement in clinical symptoms (i.e., fever, hypoxia) and a shortened disease course in patients who received the drug compared with those who did not [148]. Moreover, according to expert consensus statement from Chinese Thoracic Society, dosage regimen of methylprednisolone should be low to moderate (i.e., $\leq 0.5$ to $1 \mathrm{mg} / \mathrm{kg}$ daily or equivalent) [149] and the most common regimens of methylprednisolone applied in China were typically 40-80 mg IV daily for a course of 3-6 days [150]. The appropriate dosage (low dose versus high dose), place in therapy (early versus late), and role for corticosteroids (cytokine storm or comorbidity management) require additional clarity. There is concern that the use of corticosteroids may have deleterious effects (i.e., inhibition of immune response and pathogen clearance) in patients with COVID-19 [138]. One study reported no effect on mortality and decreased viral clearance with the use of corticosteroids [2]. Furthermore, the Infectious Diseases Society of American recommends against the routine use 
of corticosteroids in COVID-19. However, they do recommend the use of corticosteroids in the setting of ARDS in the context of a clinical trial [151]. Similarly, the Surviving Sepsis Campaign recommendsagainstcorticosteroids inmechanically ventilated patients with acute lung injury in the absence of ARDS [152]. However, they provide a recommendation for the use of corticosteroids in patients with ARDS acknowledging the weak level of evidence.

\section{Dexamethasone (Table 1 attached)}

Dexamethasone has demonstrated utility on ARDS by decreasing ventilator days and mortality on severe ARDS in patients without COVID-19 [153]. RECOVERY, a multicenter, randomized, open-label trial in hospitalized patients with COVID-19, revealed that the mortality rate was lower among patients who were randomized to take dexamethasone than with those who took the standard of care (SOC). This benefit was noted in patients who needed supplemental oxygen at enrollment. No advantage of dexamethasone was seen in patients who did not need supplemental oxygen at enrollment [154]. According to the COVID-19 Treatment Guidelines Panel [15]:

" On the basis of the preliminary report from the Randomised Evaluation of COVID-19 Therapy (RECOVERY) trial (discussed below), the COVID-19 Treatment Guidelines Panel (the Panel) recommends using dexamethasone $6 \mathrm{mg}$ per day for up to 10 days for the treatment of COVID-19 in patients who are mechanically ventilated (AI) and in patients who require supplemental oxygen but who are not mechanically ventilated (BI).

- The Panel recommends against using dexamethasone for the treatment of COVID-19 in patients who do not require supplemental oxygen (AI).

- If dexamethasone is not available, the Panel recommends using alternative glucocorticoids such as prednisone, methylprednisolone, or hydrocortisone (see Additional Considerations below for dosing recommendations) (AIII)."
Nonsteroidal Antiinflammatory Drugs (NSAIDs) [7]

An association between ibuprofen and more serious outcome in COVID-19 patients was hypothesized, however, with very low evidence [155]. In an in vitro study, another NSAID, indomethacin, was announced to have a direct antiviral impact on SARS-CoV by interfering with viral RNA synthesis, independent of cyclooxygenase inhibition. A trial is currently selecting patients to define the efficacy of naproxen for its potential synergy with viral nucleoproteins (NCT04325633). Hence, although evidence is insufficient, indomethacin or naproxen could be favored over other NSAIDs when indicated [156].

\section{Antithrombotic Therapy [144]}

Due to plaque rupture (i.e., type $1 \mathrm{MI}$ ) [158], dual antiplatelet therapy, and full-dose anticoagulation should be administered, unless there are contraindications according to the American College of Cardiology (ACC)/American Heart Association (AHA) and ESC guidelines $[159,160]$. In patients with high bleeding risk, regimens with short potent antiplatelet agents, such as with clopidogrel, should be considered, since hemorrhagic complications are not rare. Special attention should be also given to drugdrug interactions between antiplatelet agents or anticoagulants and COVID-19 investigational therapies. Major interactions with parenteral antithrombotic agents and COVID-19 investigational therapies are not clearly delimited

\section{Antibiotics}

For patients with COVID-19, some physicians manage broad-spectrum antibiotics to all patients with moderate or severe hypoxemia. Other experts administer antibiotics only for specific cases, such as the presence of a lobar infiltrate on a chest x-ray, leukocytosis, high serum lactate level, microbiologic data, or shock. Gram stain 
and cultures or testing of respiratory specimens are frequently not available due to concerns about aerosolization of the virus during diagnostic procedures or when processing specimens. There are no clinical trials that have estimated the use of empiric antimicrobial agents in patients with COVID-19 or other severe coronavirus infections. With influenza, empiric antibacterial treatment is strongly prescribed for patients with initial severe disease (i.e., those with extensive pneumonia, respiratory failure, hypotension, and fever) and those who worsen after initial improvement [161]. These recommendations are based on considerations that bacterial superinfections, especially those due to Staphylococcus aureus and Streptococcus pneumonia, are not unusual and have terrible consequences if not treated immediately. Whether moderate or severe COVID-19 disease should be approached like severe influenza will continue uncertain until more microbiologic and clinical data become available.

\section{Azithromycin (Table 2 attached)}

Azithromycin is an antibiotic that can be used to fight many different types of infections caused by susceptible bacteria, such as respiratory infections, skin infections, and sexually transmitted diseases [149, 150]. Moreover, it has been proven to be active in vitro against Zika and Ebola viruses and to prevent severe respiratory tract infections when treated to patients suffering viral infection [164, 165]. For the mechanism of action, azithromycin prevents bacteria from growing by interfering with their protein synthesis. It binds to the $50 \mathrm{~S}$ subunit of the bacterial ribosome, thus inhibiting translation of mRNA. Previously, azithromycin has been used as adjunctive therapy to provide antibacterial coverage and potential immunomodulatory and anti-inflammatory effects in the treatment of some viral respiratory tract infections (e.g., influenza) [166, 167]. Currently, many trials are testing the effect of azithromycin conjunction with hydroxychloroquine on the course of disease in people with SARS-CoV-2. For example,
Pfizer has announced positive data for the use of its azithromycin (Zithromax) drug, along with hydroxychloroquine, in a COVID-19 clinical trial that was performed in France. In brief, the clinical trial was conducted to assess hydroxychloroquine in 20 patients, 6 of which were co-administered with azithromycin. Compared with 16 controls and 14 hydroxychloroquine alone group, the 6 patients treated with hydroxychloroquine + azithromycin presented with highest virologic cure rate following 6-day treatment [166]. Three other clinical studies used azithromycin (500 mg on day 1, then $250 \mathrm{mg}$ daily on days 2-5) co-treated with 10 - day regimen of hydroxychloroquine (600 mg daily) in an openlabel non-randomized study in France (6 pts) [166], open-label uncontrolled study in France (11 pts) [168], and uncontrolled observational study in France (80 pts) [168]. Specifically, Gautret and colleagues reported a $100 \%$ viral clearance in nasopharyngeal swabs in their 6 patients after cotreated of hydroxychloroquine and azithromycin [166]. But the findings reported by Molina and colleagues stand in contrast with those reported by Gautret. Molina and colleagues repeated the experiments, thought the rapid and full viral clearance was quite unexpected and found 8 of 11 patients had significant comorbidities [168]. Based on those results, data presented to date are insufficient to evaluate possible clinical benefits of azithromycin in patients with COVID-19 [168]. Furthermore, one must consider the additive cardiac toxicity of hydroxychloroquine and azithromycin. Both agents are known to prolong the QT interval and may potentiate the risk for cardiac events in a population known to have cardiac-related comorbidities.

\section{Antiviral Drugs (Table 2 attached)}

Drugs under this category usually follow either of the following three mechanisms in the virus-viral replication inhibition, ion channel inhibition and serine protease inhibition. Commercially available antiviral drugs mostly target the four major groups of viruses: human immunodeficiency virus (HIV), 
herpes, hepatitis and influenza [169]. Earlier outbreak episodes of viral infections like SARS$\mathrm{CoV}$ and MERS-CoV as well as hemorrhagic fever viruses like Ebola were treated with this category of drugs [170].

\section{$\underline{\text { Ribavirin }}$}

Ribavirin is a broad-spectrum drug whose therapeutic potential was uncovered during 1972. This antiviral drug is used in the treatment of hepatitis C. It is usually used in combination with interferon $\alpha$ (IFN). This drug, approved by the FDA, competes for the active site of RdRp. Ribavirin scored $109.5 \mu \mathrm{M}$ of half maximal concentration against SARS-CoV-2 [171].

\section{$\underline{\text { Sofosbuvir }}$}

This drug is also an FDA approved drug against NS5B and acts as a nucleotide polymerase inhibitor used for the treatment of hepatitis C. It was used in combinationwith interferon or RBV. This drug was previously used for the treatment of Zika virus [172].

\section{$\underline{\text { Remdesivir }}$}

Remdesivir is an intravenous (IV) investigational nucleotide prodrug of an adenosine analog. Remdesivir attaches to the viral RNA-dependent RNA polymerase, restraining viral replication by RNA transcription. Its activity has been presented in an in vitro study against severe acute respiratory syndrome coronavirus 2 (SARS-CoV-2) [82]. In a rhesus macaque model of SARS-CoV-2 infection, remdesivir treatment was initiated soon after inoculation; and the results showed that remdesivirtreated animals had lower virus levels in the lungs and less lung injury than the control animals [173]. According to The COVID-19 Treatment Guidelines Panel [15], remdesivir stocks are insufficient, so the Panel recommends that it be prioritized for use in hospitalized patients with COVID-19 who need supplemental oxygen but who are not on high- flow oxygen, noninvasive ventilation, mechanical ventilation, or extracorporeal membrane oxygenation (ECMO).

On May 1, 2020, The FDA approved the use of remdesivir for severe COVID-19 (confirmed or suspected) in hospitalized adults and children $[174,175]$. A phase $1 \mathrm{~b}$ trial of an inhaled nebulized version was beginning in late June 2020 to decide if remdesivir can be utilized on an outpatient basis and at earlier phases of COVID-19 [176].

Remdesivir was studied in clinical trials for Ebola virus infections but presented a limited benefit [177]. Remdesivir has been revealed to restrain the replication of other human coronaviruses associated with high morbidity in tissue cultures, including severe acute respiratory syndrome coronavirus (SARS-CoV) in 2003 and Middle East respiratory syndrome coronavirus (MERS-CoV) in 2012. Effectiveness has been shown for SARS-CoV and MERS-CoV in animal models [178].

A phase 3 clinical trials are testing remdesivir for the treatment ofCOVID-19 in the United States, South Korea, and China, and positive results were presented. The drug was prescribed under an openlabel use protocol, but the FDA has since changed and permit enlarged access to remdesivir, allowing established places to prescribe the product for multiple patients under protocol without inquiring permission for each. An adaptive randomized trial of remdesivir directed by the National Institute of Health (NCT04280705) was begun first against placebo, but additional therapies can be combined with the protocol as data emerges. The first experience with this study included travelers of the Diamond Princess cruise ship in quarantine at the University of Nebraska Medical Center in February 2020 after turning back to the United States from Japan following an onboard outbreak of COVID-19. Trials of remdesivir for moderate and severe COVID-19 correlated with standard of care and differing treatment durations are continuing.

The preliminary data analysis of these studies of the Adaptive COVID-19 Treatment Trial (ACTT) was declared on April 29, 2020. 
The analysis included 1,063 hospitalized patients with advanced COVID-19 and lung involvement, pointing that patients who received remdesivir improved faster than related patients who received a placebo. Introductory results show that patients who received remdesivir had a $31 \%$ faster time to recovery than those who took placebo $(\mathrm{p}<0.001)$. Especially, the median time to improvement was 11 days in patients treated with remdesivir compared with 15 days in those who took the placebo. Results also proposed a survival benefit by day 14, with a mortality rate of $7.1 \%$ in the remdesivir group, associated with $11.9 \%$ in the placebo group, but this was not statistically significant [179].

The ACTT results are different from another randomized trial conducted in China. Results from this randomized, double-blind, placebocontrolled, multicenter trial study $(\mathrm{n}=237 ; 158$ to remdesivir and 79 to placebo; 1 patient withdrew) observed that remdesivir was not correlated with statistically significant clinical benefits in adults hospitalized with severe COVID-19. Although not statistically meaningful, patients taking remdesivir had a numerically time faster improvement than those receiving placebo among patients with symptoms of the first 10 days or less. The authors concluded that the reduction in time to clinical improvement in those treated first needs confirmation in larger studies [180]. A phase 3, randomized, open-label trial revealed that remdesivir was associated with the higher recovery and reduced odds of death when compared with the standard of care in patients with critical COVID-19.

The recovery rate at day 14 was higher in patients who took remdesivir $(\mathrm{n}=312)$ compared with those who received standard of care $(n=818)$ (74.4\% vs 59\%; $\mathrm{p}<0.001)$. The mortality rate at day 14 was also lower in the remdesivir group (7.6\% vs 12.5\%; $\mathrm{p}=0.001)$ [181].

The open-label phase 3 SIMPLE trial $(n=397)$ in hospitalized patients with severe COVID-19 disease not needing mechanical ventilation exhibited related improvement in the clinical state with the 5-day remdesivir regimen compared with the 10-day regimen on day 14 (OR: 0.75 [95\% CI $0.51-1.12]$ ). In this study, $65 \%$ of patients who underwent a 5-day course of remdesivir presented a clinical improvement of at least 2 points on the 7-point ordinal scale on day 14, compared with $54 \%$ of patients who took a 10 -day course. After correcting for inequalities in baseline clinical status, patients taking a 10-day course of remdesivir had a distribution in clinical status at day 14 that was alike to that of patients taking a 5 -day course $(p=0.14)$. The study illustrates the potential for some patients to be treated with a 5-day regimen, which could significantly enlarge the number of patients who could be treated with the current stock of remdesivir. The trial is continuing with an enrollment purpose of 6,000 patients [182].

Data presented at the virtual COVID-19 Conferencein July 2020 incorporated a comparative analysis of clinical recovery and mortality outcomes from the phase 3 SIMPLE trials versus a realworld cohort of patients with severe COVID-19 taking the standard of care. The analysis revealed remdesivir was related to a $62 \%$ decrease in the risk of mortality compared with standard of care. Subgroup analyses obtained from these results were alike to different racial and ethnic groups. While these data are important, they need confirmation in prospective clinical trials [183.

Similarly, the phase 3 SIMPLE II trial in patients with moderate COVID-19 disease revealed that 5 days of remdesivir treatment was $65 \%$ more likely to yield clinical improvement at day 11 than the standard of care $(p=0.18)$. These data demonstrate that immediate intervention with a 5-day treatment course can significantly better outcomes [183, 184].

\section{$\underline{\text { Favipiravir }}$}

Favipiravir (Avigan) also identified as T-705 was original approved for the treatment of influenza virus this February, and it has the capacity of inhibiting RNA-dependent RNA polymerase in RNA viruses such as SARS-CoV-2 [185]. In 
February, a preliminary clinical trial on favipiravir was handled in China on 80 patients and showed better effects compared to lopinavir/ritonavir with minor adverse effects [186]. Another clinical trial with 340 patients in China resulted in highly promising results as the patients taking favipiravir compared to standard care presented released viral load in four days as compared to eleven days in patients taking standard care [187]. Another multicenter, open-labeled, randomized trial in China has compared the efficacy of favipiravir $(1,600 \mathrm{mg} \times 2$ on the first day followed by 600 $\mathrm{mg} \times 2$ for 9 days $)$ and umifenovir $(200 \mathrm{mg} \times 3$ per day for 10 days) and the outcomes showed a higher recovery rate and better clinical results in the patients treated with favipiravir at day 7 [188]. A phase III trial is ongoing in Japan including 100 patients and is presumed to be completed in June.

Nevertheless, Avigan was not that much helpful in critically ill patients and did not reveal encouraging results. It seems that it has to be taken before the viral load peaks in the body. Favipiravir would need government approval for usage against COVID-19.

\section{$\underline{\text { MK-4482 }}$}

Another antiviral originally designed to fight the flu, MK-4482 (previously known as EIDD2801) has had promising results against the new coronavirus in studies in cells and on animals. Sheahan and colleagues [189] presented that the analog ribonucleoside ( $\beta$-D-N4-hydroxycytidine NHC; EIDD-1931) has broad-spectrum antiviral activity against the coronaviruses (SARS-CoV-2, MERS-CoV, SARS-CoV), and also a better possible mutations beard of CoVs when compared to the nucleoside analog inhibitor remdesivir. The in vivo study with mice infected with $\mathrm{SARS}-\mathrm{CoV}$ or MERS-CoV, both prophylactic and therapeutic administration ofEIDD-2801 improved pulmonary function and reduced virus titer and body weight loss. Merck, which has been running the clinical trials on the drug has announced the beginning of the Phase III trial in the next September.

\section{$\underline{\text { Umifenovir (Arbidol) }}$}

Umifenovir (arbidol) showed efficacy in the treatment of influenza virus infection. It is a viral entrance inhibitor to the target cells, without significant side effects. It has revealed highly promising action against SARS-CoV-2 in vitro [190]. A randomized, open-labeled, multi-centered clinical trial conducted in China compared the effectiveness and security of favipiravir and arbidol on COVID-19 patients on 7 day's clinical recovery rate. 120 patients were allocated to each group taking favipiravir and arbidol along with standard therapy. The results showed that the 7-day recovery rate for the arbidol group was $55.86 \%$ in comparison to $71.43 \%$ for the favipiravir group $(\mathrm{p}=0.0199)$. Patients with hypertension or diabetes also showed better recovery in the favipiravir group [189]. Currently, three more phase IV clinical trials are designed for arbidol in the treatment of COVID-19. One clinical trial will compare the efficacy of arbidol on 380 patients at Jieming QU, Ruijin Hospital, China in comparison to the standard treatment [191], whereas, the other two would compare the efficacy of arbidol with oseltamivir [192] on 400 patients at Tongji Hospital, China, and carrimycin on 520 patients at Beijing Youan Hospital, China [193, 194].

\section{$\underline{\text { Oseltamivir and Baloxavir }}$}

Oseltamivir and Baloxavir have antiviral activity against influenza. So, they were considered as possible treatment possibilities for COVID-19. This was used in excess in the initial report of the cases in Wuhan, where patients were managed with COVID-19 receiving oseltamivir in addition to broad-spectrum antimicrobials [2]. It is important to note that the application of oseltamivir was not as targeted therapy of SARS-CoV-2 but an option by the lack of knowledge of the causative pathogen at the time of treatment and the hope to empirically treat influenza. The authors do not recommend the use of oseltamivir for COVID-19 in this study, and there are no data suggesting in vitro activity of oseltamivir against SARS-CoV-2. The only data evaluating 
oseltamivir activity against coronaviruses showed to be ineffective at inhibiting SARS-CoV-1 [195, 196]. Coronaviruses do not utilize neuraminidase, and thus there is no enzyme to be inhibited by oseltamivir.

\section{$\underline{\text { Nitazonide }}$}

Nitazoxanide has shown potent in vitro action against SARS-CoV-2, with an EC50 at 48 hours of $2.12 \mu \mathrm{M}$ in Vero E6 cells [80]. This powerful activity is compatible with EC50 values for nitazoxanide and its active metabolite, tizoxanide, against MERS$\mathrm{CoV}$ in LLC-MK2 cells [197]. Nitazoxanide exhibits broad-spectrum in vitro antiviral action against influenza, respiratory syncytial virus, parainfluenza, rotavirus, and norovirus among others in addition to coronaviruses [196, 197]. This broad-spectrum antiviral activity is thought to be due to the mechanism of action, which is based on interference with host-regulated pathways involved in viral replication rather than virusspecific pathways [197]. Due to its broad-spectrum antiviral action, nitazoxanide is being studied for the management of influenza and other acute respiratory infections. Positive data were described in a phase $2 b / 3$ study for the outpatient management of influenza [198]. Three-phase randomized controlled trials in uncomplicated influenza have since been completed (ClinicalTrials.gov Identifier NCT01610245 [March 2018], NCT02612922 [April 2018], and NCT03336619 [September 2019]), although results are still unavailable. Nitazoxanide declined to decrease the duration of hospitalization or the time to symptom alleviation in phase 2 randomized controlled trial in patients with severe acute respiratory illnesses needing hospitalization [199]. Although the in vitro activity of nitazoxanide against SARS-CoV-2 is promising, more data are clearly required to define its role in the management of COVID-19.

\section{Anti-HIV Drugs}

Thesedrugs are classified into differentcategories based on their targets reverse transcription, retro- transcription, proteolytic processing, viral-cell fusion, co-receptors interactions and incorporation of proviral DNA into the host genome. Drugs that fall in these categories have been approved by the FDA (Food and Drug Administration) and are now officially used for the treatment of $\operatorname{HIV}[181,184]$.

\section{Lopinavir/Ritonavir}

Lopinavir/ritonavir (LPV-r) is a co-formulated human immunodeficiency virus (HIV)-specific protease inhibitor that serves as first-line therapy for HIV [200]. Concomitant use of ritonavir could increase the plasma half-life of lopinavir through cytochrome P450 inhibition in the liver. During the 2003 SARS outbreak, LPV-r was reported to have in vitro inhibitory activity against SARSCoV [201], and combination therapy of LPV-r and ribavirin provided favorable results in treating patients with SARS [202]. Triple combination therapy with LPV-r, ribavirin, and IFN- $\alpha$ has shown clinical effectiveness for MERS [203]. Notwithstanding, a recent open-label randomized study with 199 patients in Wuhan showed that LPV-r monotherapy did not produce any therapeutic benefits for COVID-19 patients compared with standard supportive care, which might be caused by the higher throat viral loads in the LPV-r group, concurrent pharmacologic interventions, and late treatment initiation [204]. The enrolled COVID-19 patients were critically ill, and LPV-r treatment might have been started relatively late. However, in another retrospective cohort study, combination therapy of LPV-r and arbidol was associated with improved pulmonary computed tomography images [205].

\section{Darunavir}

Darunavir (Prezista) is another antiviral drug utilized as an HIV-1 protease inhibitor that demonstrated to be hopeful anti-SARS-CoV-2 activity in vitro earlier in February in a test that occurred in China. Nevertheless, Johnson and Johnson stated on March 18, 2020, that there is no indication of sustaining the activity of darunavir against SARS-CoV-2. 
Darunavir was approved with a boosting agent such as ritonavir or cobicistat [206]. A singlecenter open-labeled randomized and controlled phase III trial, conducted at Shanghai Public Health Clinical Center (SPHCC) for the efficacy of darunavir/cobicistat association on the 30th day of COVID-19 patients, revealed that the combination was not efficient in decreasing the symptoms or the duration of treatment [207].

\section{Nelfinavir}

Nelfinavir, an HIV-1 protease inhibitor, might be effective against SARS-CoV-2 based on a preprint publication that used homology modeling [208], but no clinical data exist.

\section{Stem Cell Therapy (Table 1 attached)}

The mesenchymal stem cells (MSC), a relevant portion of the stem cell family, have the potential of self-renewal and multidirectional differentiation, and also have powerful anti-inflammatory and immune regulatory functions. MSC can restrain the irregular activation of $\mathrm{T}$ lymphocytes and macrophages, and provoke their differentiation into regulatory $\mathrm{T}$ cell (Treg) subsets and antiinflammatory macrophages, respectively. Also, it can inhibit the secretion of proinflammatory cytokines, such as IL-1, TNF- $\alpha$, IL-6, IL-12, and IFN- $\gamma$, thereby decreasing the event of cytokine storms [209-211]. MSC can secrete IL-10, hepatocyte growth factor, keratinocyte growth factor, and VEGF to relieve ARDS, restore and repair injured lung tissues, and combat fibrosis [211]. Hence, many uses of MSC are presumed to make it a useful method for the treatment of COVID-19.

\section{Other Therapies}

\section{Thalidomide}

Thalidomide is an anti-inflammatory and an immunomodulatory agent. It was designed to expand $\mathrm{T}$ cells, treat inflammation, restrain cell proliferation, and decrease lung injury and pulmonary fibrosis $[116,213]$. The main role of thalidomide in COVID-19 is to preserve the lungs from injury induced by immunological reactions. Nevertheless, thalidomide requires to be used with another antiviral agent, since it does not eliminate or suppress viral load. Wenzhou Medical University reported a case that has demonstrated that thalidomide has adjuvant effects in COVID-19 treatment.

\section{Leflunomide [213]}

Leflunomide is efficient in improving SARSCoV-2 clearance and hospital releasing in refractory COVID-19 patients. The addition of leflunomide to SOC (standard of care) did not develop adverse events versus SOC. These introductory considerations emphasize a demand for a randomized clinical study of leflunomide against SARS-CoV-2 infection.

\section{Dipeptidyl Peptidase 4 (DPP4; CD26)}

Dipeptidyl peptidase 4 (DPP4) is a functional receptor for the emerging human coronavirus via S-protein, as well as ACE2 [215]. The interaction between the virus and the host cell membrane permits for viral S-protein-directed cell-cell fusion and the resultant spread of viral infections [216]. The specific role of DPP4 on COVID-19 persists to be examined. Further research is needed to use DPP-4 as a therapeutic target for COVID-19.

\section{Aminopeptidase N (APN; CD13)}

The aminopeptidase N (APN) is associated with broad receptor engagement, which promotes the cross-species transmission of COVID-19 [217]. Earlier studies recognized APN as a surface tag for cancer stem cells in the human liver [218].

Other studies also enabled the development of a poly(ethylene glycol)-poly(lysine) block copolymer-conjugate (Ubenimex) that targets APN especially [219]. So, low doses of APN inhibitors, 
including Ubenimex or its derivatives, may be useful for restraining the spread of the virus.

\section{Ulinastatin [12]}

Ulinastatin is a natural anti-inflammatory element in the body. It protects the vascular endothelium by restraining the generation and discharge of inflammatory mediators. Ulinastatin is popularly used in clinical practice to treat pancreatitis and acute circulatory failure. Ulinastatin decreases the levels of proinflammatory factors such as TNF- $\alpha$, IL- 6 , and IFN- $\gamma$, and raises the level of anti-inflammatory factor IL-10 [220]. These actions of ulinastatin promote the balance between proinflammatory and anti-inflammatory responses in humans, thus disrupting the cytokine storm. Animal studies reveal that the antiinflammatory effect of high-dose ulinastatin is similar to that of hormones [221]. Nevertheless, unlike glucocorticoids, ulinastatin does not restrain immune functions. Consequently, ulinastatin could have a great application in the treatment of COVID-19.

\section{$\underline{\text { Sirolimus }}$}

Sirolimus (rapamycin) is an immunosuppressant that is used to prevent organ transplant rejection and to treat lymphangioleiomyomatosis (LAM) by repressing the mammalian target of rapamycin (mTOR) kinase. It was originally isolated from the bacterium Streptomyces hygroscopicus located on Easter Island (Rapa Nui) [222] and is commercially available as Rapamune (Pfizer). But there is no data against COVID-19. mTOR, and more specifically a protein complex mTORC1 formed by mTOR, plays a key role in viral replication. In an in vitro experiment, sirolimus has been shown to affect PI3K/AKT/mTOR pathway which inhibited MERS-CoV activity [223]. A new randomized double-blind placebo-controlled clinical trial (SCOPE) by University of Cincinnati is planned to be conducted between April and September 2020 to test the effect of sirolimus on progression of patients hospitalized with COVID-19 to advanced respiratory support [224]. Studies of patients hospitalized with influenza can further shed light on the antiviral effect of sirolimus. In a randomized clinical trial conducted on 38 patients with confirmed H1N1 pneumonia and on mechanical ventilator support, a group treated with corticosteroids and 2 $\mathrm{mg}$ /day of sirolimus for 14 days $(\mathrm{N}=19)$ showed significantly better clinical outcomes compared with the group treated with corticosteroids only, including shorter median duration of ventilator used [225]. Delayed oseltamivir plus sirolimus treatment in $\mathrm{pH} 1 \mathrm{~N} 1$-infected mouse model further suggested a significant association between the sirolimus treatment and improved outcomes [226]. Additionally, a new trial by the Chinese University of Hong Kong is planned to begin in August 2020 to investigate the effect of sirolimus and oseltamivir on normalization of respiratory status and changes in biomarkers (viral RNA concentration, 10 cytokines/ chemokines and pro-inflammatory mediators) and several other clinical endpoints in influenza patients [227]. At least one in silico study identified sirolimus as one of the 16 potential candidates for treating COVID-19 patients based on data from other human coronavirus infections using network-based drug repurposing model [228].

Sphingosine-1-phosphate Receptor 1 Agonist Therapy

Sphingosine-1-phosphate (S1P) is a signal lysophospholipid that promotes cytokine synthesis and secretion [229]. The S1P receptor signaling pathwayssignificantlyinhibitthepathologicalinjury caused by the host's innate and adaptive immune responses. So, this fact reduces the cytokine storm provoked by influenza virus infection [230, 231]. In mouse models of IAV infection, sphingosine-1phosphate receptor 1 (S1P1) signal transduction in respiratory endothelial cells modulates pathogenic inflammatory responses [231]. Agonists targeting S1P1 restrain extreme recruitment of inflammatory cells, inhibit proinflammatory cytokines and chemokines, and decrease the morbidity and 
mortality of IAV [232]. SARS-CoV-2 also principally affects human lung epithelial cells and endothelial cells. Consequently, S1P1 agonists may be possible therapeutic drugs for decreasing cytokine and chemokine responses in those $\mathrm{HCoV}$ patients whose cells produced excessive immune responses. An S1 preceptor modulating drug, siponimod, was approved in 2019 to treat multiple sclerosis. However, clinical trials are required to further confirm whether siponimod is an alternative for the treatment of cytokine storm.

The Inhibitory Effect of Oxidized Phospholipids (OxPL)

OxPL improved the production of cytokines/ chemokines in lung macrophages through the Tolllike receptor 4 (TLR4)-TIR-domain- containing adapter-inducing interferon- $\beta$ signaling pathway in a mouse model of influenza A virus (IAV) infection, promoting the occurrence of ALI [234]. Eritoran is a TLR4 antagonist and has antiviral activity and strong immunomodulatory functions. Eritoran dramatically reduces the production of OxPL, inflammatory cytokines, and chemokines in IAV-infected mice, lowering death [234]. Pathogenic human coronaviruses also cause a high accumulation of OxPL in patients' lung tissues, resulting in ALI [233] Thus, it seems that eritoran and other OxPL inhibitors may also be able to alleviate $\mathrm{HCoV}$-induced inflammatory responses.

\section{$\underline{\text { Mycophenolate Mofetil (MMF) }}$}

MMF is widely used for the treatment of severe manifestations of connective tissue disorders and vasculitis syndromes. Mycophenolate exhibited strong antiviral effects on SARS-CoV and MERS-CoV as demonstrated in vitro studies, with its interaction with viral proteases [235]. A small clinical study reported efficacy of MMF in combination with IFN- $\beta$ on MERS patients [236]. However, considering strong immunosuppressant effects of MMF, it is likely to cause more harm than benefit in COVID-19 patients.

\section{$\underline{\text { Statins }}$}

Statins reduce the inflammatory processes of atherosclerosis [237]. Because of this, issues have risen whether statins may be helpful to reducing inflammation related to COVID-19.

This issue has been presented before the studies of patients who took statins to have acute viral infections by COVID-19. Virani [238] presents a brief review of data concerning observational and randomized controlled trials (RCTs) of statins and viral infections. Some observational studies insinuate that cardiovascular outcomes were decreased in patients taking statins hospitalized with influenza and/or pneumonia. RCTs of statins as anti-inflammatory agents for viral infections are poor, and outcomes have been confused. An important point that Virani reported is that no harm was associated with patients who took statins and had COVID-19 in previous trials of statins and viral infections, indicating that patients should adhere to their statin regimen.

\section{Current Clinical Treatment Experience and Recommendations by World Health Organization (WHO), Center for Disease Control and Prevention (CDC), and National Institutes of Health (NIH) (Tables 1 and 2 attached)}

The COVID-19 Treatment Guidelines Panel [15] had been developed to informing physicians on how to caring for patients with COVID-19. The references in these Guidelines are based on scientific data and expert evaluation. Each recommendation involves two ratings: a letter $(\mathrm{A}, \mathrm{B}$, or $\mathrm{C})$ that designates the strength of the recommendation and a Roman numeral (I, II, or III) that designates the quality of the evidence that confirms the recommendation (Table 3).

Because clinical information about the optimal management of COVID-19 is developing quickly, these Guidelines will be updated periodically as announced data and other authoritative knowledge 
become available. Panel members incorporate representatives from federal agencies, health care and academic institutions, and professional societies. Federal agencies and professional societies reproduced on the Panel include:

- American College of Chest Physicians

- American College of Emergency Physicians

- American Society of Hematology

- American Thoracic Society

- Biomedical Advanced Research and Development Authority

- Centers for Disease Control and Prevention

- Department of Defense

- Department of Veterans Affairs

- Food and Drug Administration

- Infectious Diseases Society of America

- National Institutes of Health

- Pediatric Infectious Diseases Society

- Society of Critical Care Medicine

- Society of Infectious Diseases Pharmacists

\section{Alternative Therapies}

We would like to mention that all about surrounding this topic need further studies and evidence. We bring them in order to include all therapeutic purposes to COVID-19 infection.

\section{$\underline{\text { Vitamin C }}$}

Vitamin C is a vital nutrient and plays important role in the human body. It can neutralize free radicals and help to prevent or reverse cellular injury as a powerful antioxidant agent. It is also associated with some biological processes, many of which are correlated with the immune system [239]. Furthermore, vitamin C seems to be useful as an antiviral agent, especially against influenza viruses [240]. Many studies revealed that vitamin $\mathrm{C}$ positively influences the development and maturation of $\mathrm{T}$ lymphocytes and NK (natural killer) cells implicated in the immune response to viral agents. It also contributes to the restraint of reactive oxygen species (ROS) production and to the modulation of the cytokines typically involved in the systemic inflammatory syndrome [241]. Given this background, a phase II clinical trial (NCT04264533) is initiated in China to evaluate high-dose IV vitamin C in ICU patients with severe COVID-19-associated pneumonia [242]. Some hospitals have reported giving infected patients $1500 \mathrm{mg}$ of vitamin $\mathrm{C}$ as supportive treatment. High-dose IV vitamin $\mathrm{C}$ has been given in the treatment of 50 moderate to severe COVID-19 patients in China [243]. The doses varied between 2 and $10 \mathrm{~g}$ per day, given over a period of 8--10-h IV infusion. The oxygenation index was improved in real time and all the patients eventually recovered and were discharged [243]. Moreover, high-dose $(1.5 \mathrm{mg} / \mathrm{kg}$ bodyweight) vitamin $\mathrm{C}$ has been used for several decades clinically and an NIH panel also documented clearly that this dose regimen is safe and has no major side effects [244].

\section{Nitric Oxid and Epoprostenol}

Since patients with pre-existing pulmonary conditions are at higher risk of COVID-19 and should be closely monitored and cared, pulmonary vasodilator agents have been used in some patients for hypoxemia refractory to conventional treatments, but no study has been performed specifically on COVID-19 patients. The Surviving Sepsis Campaign suggested a trial of inhaled pulmonary vasodilator method as rescue therapy in mechanically ventilated adults with COVID-19, severe ARDS, and hypoxemia despite optimized ventilation and other rescue strategies. Inhaled nitric oxide (iNO) and inhaled epoprostenol (iEPO, a naturally occurring prostaglandin) are two common pulmonary vasodilators that have been widely studied [245, 246]. Experience in patients with ARDS indicates that iNO can substantially reduce mean pulmonary artery pressure and improve oxygenation in such patients. Furthermore, in vitro evidence of direct antiviral activity against SARS-CoV was studied and the genetic similarity between SARS-CoV and SARS-CoV-2 suggests their potential effectiveness 
against SARS-CoV-2 [249]. For iEPO, dosages up to $50 \mathrm{ng} / \mathrm{kg}$ per minute have been used [245, 248]250]. Previous studies reported that to provide a clinically important increase in $\mathrm{PaO} 2$ and reduction in pulmonary artery pressure, the most effective and safe dosage appears to be $20-30 \mathrm{ng} /$ $\mathrm{kg}$ per minute in adults and $30 \mathrm{ng} / \mathrm{kg}$ per minute in pediatric patients [251]. For iNO, therapy was given for $\geq 3$ days (30 ppm on day 1 , followed by 20 and 10 ppm on days 2 and 3, respectively, thenweaned on day 4) in a pilot study on SARS$\mathrm{CoV}$ [251]. Additionally, clinical trials evaluating iNO for treatment or prevention of COVID-19 are planned or underway (NCT04305457, NCT04306393, NCT04312243) [252]. And on March 20, 2020, FDA admitted emergency extended entrance allowing its iNO delivery system (INOpulse ${ }^{\circledR}$ ) to be quickly applied for the treatment of COVID-19. Lastly, further studies are needed to appraise the potential role of iEPO and iNO in the treatment of COVID-19 patients.

\section{$\underline{\text { Natural PAK1-Blockers }}$}

A specific vaccine is an effective cure for each viral infection. Nevertheless, it demands at least 1218 months to be prepared according to the WHO. Until then we have to combat the coronavirus with the guidance of the major research Centers and $\mathrm{WHO}$ as well as supportive treatments. Also, "alternative" or "unconventional" therapeutics for coronaviral infection, many natural or synthetic PAK1-blockers readily accessible in the market are introduced.

\section{The Bee Product "Propolis"}

Propolis is one of the most popular and ancient substances used for medical supportive treatments. It has been adopted as traditional medicine since the ancient Egyptian era. Its properties are both anti-bacterial and anti-viral. In the modern era, propolis was identified as an anti-cancer medicine in the late 1980 s by a group at Columbia University in NYC [253]. The major anti-cancer component in propolis turned out to be CAPE, an ester of caffeic acid [253] which downregulates RAC, thereby inactivating PAK1 [254]. Nevertheless, the anti-cancer properties of propolis vary from one product to another, depending on where bees store the extract. The principal anti-cancer ingredient in Brazilian green propolis is artepillin C (ARC), whereas those in subtropical propolis from Okinawa or Taiwan are polyphenols (Nymphaeols), which directly restrain PAK1 [255]. However, all propolis have PAK1-blockers. Since PAK1 is responsible not only for cancers but also for infection with a wide diversity of viruses such as influenza, HIV, papillomavirus, and coronavirus in generally, as well as immunesuppression [256, 257], propolis would be helpful for blocking coronavirus-induced fibrosis in lungs and stimulating the immune system as well. Nevertheless, the power of propolis alters from one product to another, depending on both the chemical nature of components and their content [256-259]. It's suggested daily dose is $1 \mathrm{~mL}$ ( 250 mg) /10 kg (body weight).

\section{Pineal Hormone "Melatonine"}

In 1953, Aaron Lerner at Yale University recognized the serotonin melatonin as an antimelanogenic hormone that originated from pineal glands [260]. Around the last decade, it was found that melanogenesis depends on PAK1 [261]. Melatonin shares a broad diversity of other anti-PAK1 actions such as anti-infectious, antiinflammatory, anti-cancer, immune stimulative, analgesic, sleepy, among others. Thus, melatonin, a current sleeping pill, could be useful for the therapeutic of coronaviral infection. Russel Reiter, recently highlighted that melatonin is an alternative or adjuvant COVID-19 therapeutic [262].

\section{Glucocorticoid Hormone "Ciclesonide"}

Ciclesonide is used to treat inflammatory diseases such as asthma and allergic rhinitis. Concerning the molecular mechanism of its antiinflammatory effect, it seems that this hormone bars PAK1, mainly for the following purposes: (i) 
Table 3. Recommendation rating scheme.

\begin{tabular}{|l|l|}
\hline Strength of Recommendation & Quality of Evidence for Recommendation \\
\hline $\begin{array}{l}\text { A: Strong recommendation for the statement } \\
\text { outcomes and/or validated laboratory endpoints }\end{array}$ & I: One or more randomized trials with clinical \\
$\begin{array}{l}\text { B: Moderate recommendation for the statement } \\
\text { trials or observational cohort studies }\end{array}$ & II: One or more well-designed, nonrandomized \\
C: Optional recommendation for the statement & III: Expert opinion \\
\hline
\end{tabular}

Credit/Source: NIAID-RML [15].

An example how the recommendation scheme works, there are for blood-derived products under evaluation for the treatment of COVID-19. According to the Papel, there is a summary recomendations: (Last Updated: July 30, 2020) [15].

\section{Summary Recommendations}

There are insufficient data for the COVID-19 Treatment Guidelines Panel (the Panel) to recommend either for or against the use of the following blood-derived products for the treatment of COVID-19:

- COVID-19 convalescent plasma

- Severe acute respiratory syndrome coronavirus 2 (SARS-CoV-2) immunoglobulins

The Panel recommends against the use of the following blood-derived products for the treatment of COVID-19, except in a clinical trial:

- Mesenchymal stem cells (AII)

- Non-SARS-CoV-2-specific intravenous immunoglobulins (IVIG) (AIII). This recommendation should not preclude the use of IVIG when it is otherwise indicated for the treatment of complications that arise during the course of COVID-19.

inflammation requires PAK1 [263], and in PAK1null mutant of mice no inflammation occurs [264], (ii) ciclesonide $(10 \mathrm{mg} / \mathrm{kg} /$ day) almost completely suppresses the PAK1-dependent growth of lung cancer (A541 cell line) in immunedeficient mice [265], and (iii) this hormone was recently presented to blocking PAK1-dependent replication and pathogenesis of COVID-19 infection [266].

\section{Triptolide from Thunder God Vine and Its Water- Soluble Derivative}

The herbal called "Triptolide from thunder god vine" was observed to inactivate RAC, thereby barring PAK1 [267, 259]. In 2010, triptolide was found to defeat virus production during dengue virus infection of the human lungs by obstructing the PAK1 signaling pathway [268]. But, its water-solubility is very poor. Thus, a group at the University of Minnesota headed by Gunda George boosted its water-solubility [269].
The resultant phosphatase-sensitive prodrug of triptolide called "Minnelide" is in clinical trials for cancers. Thus, both Triptolide and Minnelide could be possibly valuable for the treatment of coronavirus infection.

\section{Ivermectin from Soil Bacterium (Streptomyces avermitilis)}

In the 1975s, a precursor of Ivermectin (Avermectin) was identified from a soil bacterium by a group headed by Satoshi Omura, but it provokes side effects. To reducing its side effect, a Merck group directed by William Campbell, decreased it to create "Ivermectin" (dihydroAvermectin), sharing the Nobel prize in 2015. It turned a medicine by Merck in 1981. It has been used to treat many types of parasite infestations including head lice, scabies, river blindness (onchocerciasis), among others. Three decades after this discovery, it was demonstrated by a Russian group to suppress the increase of cancers 
as well, and ultimately, we discovered that its anti-cancer action is due to the inactivation of PAK1 [270]. So, it could possibly work as an alternative (and inexpensive) therapeutic to abolish the PAK1-dependent coronaviral infection as well. In fact, very recent studies proved that Ivermectin blocks the COVID-19 infection in animal experiments [271]. A curiosity is that the IC50 against COVID-19 is essentially the same as IC50 against the PAK1dependent growth of cancer cells [272], which strongly suggests the PAK1-dependency of COVID-19 replication.

\section{Artemisinin: Anti-Malaria from an Old Chinese Medical Herb}

In 2015, Youyou Tu and colleagues discovered an anti-malaria compound called "Artemisinin" (AM). This substance was originally isolated from the plant Artemisia annua, a herb used in Chinese traditional medicine around the 1970s. Although the exact molecular mechanism about its anti-malaria and anti-viral action still persists unclear, the purpose is not the pathogens (Plasmodium falciparum or virus) themselves, but the host cells, most probably PAK1 or a component essential for both malaria and viral infection [273, 274], based on the next considerations: (i) the AM defeats both RAS (upstream of PAK1) and RAF (downstream of both RAS and PAK1) in T-cells [263, 276], and (ii) the dihydro derivative of AM suppresses the increase pancreatic cancer cells by upregulation of p21 (a CDK inhibitor) whose expression is suppressed by PAK1 [263, 273].

\section{Extract of Chinese (Sichuan) Pepper (HuaJiao)}

Chinese red peppercorns from Sichuan Province called "Hua Jiao" are among traditional spices adopted for the preparation of an old spicy Chinese cuisine called "Marbo-beancurd". In 2006, it was demonstrated that $70 \%$ ethanol or hot (above $45^{\circ} \mathrm{C}$ ) water extract of Hua Jiao inhibits PAK1 with IC50 around $10 \mu \mathrm{g} / \mathrm{mL}$, and thereby defeating cyclin D1 expression in both NF1-deficient triple-negative breast cancer (MDA-MB-231) and MPNST cell lines in which PAK1-is abnormally activated [277]. Thus, the drinking of "Hua Jiao" tea (extract) could be helpful in COVID-19 infection. However, its major PAK1-blocking component has not been chemically known as yet. So, further studies are necessary to investigate the positive evidence of "Hua Jiao" in COVID-19 treatment.

\section{FK 228 (Istodax): Blocking HDAC-PAK1 Pathway}

Fujisawa Pharm Group isolated FK228 from a soil bacterium in 1995. It well restrains the increase of RAS cancers such as pancreatic and colon cancers, which carry oncogenic mutant of Ki-RAS. A few years later it was discovered that it inhibits directly HDAC (histone deacetylase) with IC50 around $1 \mathrm{nM}$. In 2005, it was found that FK228 inactivates PAK1 in several cancer cells, including Tamoxiphen-resistant breast cancers and NF1-deficient MPNST (malignant peripheral nerve sheath tumor) [277]. In 2009, it was approved by FDA for the treatment of Cutaneous T-cell Lymphoma (CTCL). Thus, due to its property of inhibits HDAC and suppresses the increase of RAS, it could be useful for the therapy of COVID-19 infection as well.

\section{$\underline{\text { Synthetic PAK1-Blockers }}$}

\section{Ketorolac}

"Toradol" is a racemic ( $1: 1)$ mix of S-and R-forms of ketorolac. Since S-form directly inhibits COX2 , it has been used against pain. Nevertheless, a few years ago, R-form was observed to downregulate RAC, thereby inactivating PAK1 [278, 279]. Thus, "Toradol" could be applied for the treatment of PAK1-dependent coronaviral infection. The resultant potent PAK1-blocker, called 1,2,3-triazolyl 295 ester of Ketorolac $(15 \mathrm{~K})$, suppresses both increase and metastasis of chemo-resistant human pancreatic cancer xenografts in mice with IC50 $<0.1 \mathrm{mg} / \mathrm{kg} / \mathrm{day}$, and causes no side effect even at $5 \mathrm{mg} / \mathrm{kg} /$ day 
298 [280]. Thus, $15 \mathrm{~K}$ could be applied not only for pancreatic cancer therapy but also for therapy of infectious diseases caused by a coronavirus (COVID300 19) and many other dangerous viruses in the future.

\section{Vitamin D3 and Its Derivative (MART-10)}

The most generally known pharmacological action of Vitamin D3 is calcemic, i.e., stimulating the absorption of calcium into bone tissues. Nevertheless, researchers of Melbourne in the late 1980s, discovered that Vitamin D3 can suppress the increase of tumors in mice fed with a calcium-less diet [281]. However, the therapy with Vitamin D3 against cancers has never been successful. This clinical failure is due to the inactivation of Vitamin D3 by CYP24 in the human body.

Thus, a Japanese group in 2010 developed a derivative of Vitamin D3, called "MART10 ", which is very resistant to CYP24 and definitely less calcemic [283]. The "MART-10" is 1000 times more powerful than Vitamin D3 against breast and pancreatic cancers [282]. A few years ago, a German group at Tuebingen University discovered that Vitamin D3 downregulates RAC, inactivating PAK1 and leading to depolymerization of actin filaments [283]. Independently, MART-10 also induced the depolymerization of actin in cancer cells [284]. Moreover, CYP24 expression turned out to depend on the oncogenic RAS-PAK1-NF $\kappa \mathrm{B} /$ Ets signaling pathway [285]. Thus, probably, either "MART-10" alone or in combination with Vitamin D3 and a CYP24-resistant PAK1blocker such as propolis could be possibly helpful for the treatment of coronaviral infection.

Pythochemicals and Natural Products Targeting Coronaviruses

Natural productscaninhibitvariousstepsinviral infection and replication, and many of them have broad-spectrum antiviral effects, the mechanisms of which have not been fully characterized. They also can function as immunomodulators, suppressing inflammatory reaction responsible for the major morbidity and mortality of SARSCoV-2 infection. Phytochemicals, especially flavonoids, which are widely distributed in food plants and botanicals, have been shown to interfere with NLRP3 inflammasome signaling [286]. The respiratory distress syndrome associated with SARS coronaviruses develops in part due to viral activation of the NLRP3 inflammasome within activated macrophages and $\mathrm{T}$ helper-1 lymphocytes, which causes increased production of inflammatory cytokines [287]. Several flavonoids that interfere with activation of the NLRP3 inflammasome may modulate inflammatory response to SARS beta coronaviruses: luteolin [288], myricetin [289], apigenin [290], quercetin [291] kaempferol [292], baicalin [293], and wogonoside [294].

These flavonoids have been shown to be active against a wide variety of viruses, via multiple mechanisms [295, 296], and are available as nutraceutical supplements at a daily dose ranging from $100 \mathrm{mg}$ to $500 \mathrm{mg}$. Emodin (6-methyl1,3,8-trihydroxyanthraquinone) (CAS number: 518-82-1) is an anthraquinone compound found in various Chinese herbs and is also produced by many species of fungi, including members of the genera Aspergillus, Pyrenochaeta, and Pestalotiopsis. Emodin has been shown to inhibit the interaction of SARS-CoV S protein with its receptor ACE2 in a dose-dependent manner [297]. Resveratrol (trans-3,5,4'-trihydroxystilbene) (CAS number: 501-36-0) is a stilbenoid and a natural polyphenol that is found in high concentrations in the skins of red wine grapes (Vitis vinifera), in red wine and in sprouted peanuts (Arachis hypogaea). Resveratrol has been demonstrated in vitro to inhibit MERS-CoV infection and to prolong cellular survival after virus infection. Further, expression of MERS$\mathrm{CoV}$ nucleocapsid protein essential for virus replication as well as MERS-CoV- induced host 
cell apoptosis are inhibited by resveratrol [298], suggesting that resveratrol may also be effective against SARS-CoV-2 infection.

\section{Blood Purification Treatments}

Blood purification treatments currently utilized in clinical practice are capable to eliminate some inflammatory factors. The purification system, which involves plasma replacement, adsorption, perfusion, blood/plasma filtration, and other procedures, can exclude some quantity of inflammatory factors, barring "cytokine storms", and decrease the damage from the body's inflammatory response. This treatment can be applied for critical patients in the early and middle phases of the disease. This artificial technology, which was led by Academician Li Lan-Juan, can reduce inflammatory factors on a huge scale. This technology has also been adopted to resist the cytokine storm of H7N9. The application of this treatment on COVID-19 has obtained certain efficiency [299]. Early renal replacement therapy appears to be an efficient method to control cytokine storm.

\section{Inhibitors of Mononuclear Macrophage}

\section{Recruitment and Function.}

The autopsy of patients with COVID-19 revealed many inflammatory cell infiltration in the lungs of the deceased [300]. One treatment method that can be possibly efficient is to reduce the recruitment of mononuclear macrophages to the site of inflammation by small interfering RNA (siRNA)-mediated silencing of C-C chemokine receptor type 2 (CCR2) to increase the outcome of the disease [301, 302]. Toll-like receptor 7 (TLR7) agonists excite mononuclear macrophages to undergo a strong inflammatory response at the time of infection with singlestranded RNA (ssRNA) viruses such as $\mathrm{HCoV}$. Hence, TLR7 antagonists may be able to mitigate the storm of inflammatory factors induced by SARS-CoV-2 infection.

\section{References}

1. CDC. 2019 Novel coronavirus, Hubei, China. https://www. cdc.gov/coronavirus/2019

2. Sanders JM, Marguerite LM, Pharm D. Pharmacologic Treatments for Coronavirus Disease 2019 (COVID-19): A Review. JAMA 2020;323(18):1824-1836. Doi:10.1001/ jama.2020.6019.

3. Zhu N, Zhang D, Wang W, et al. China Novel Coronavirus Investigating and Research Team. A novel coronavirus from patients with pneumonia in China, 2019. N Engl J Med 2020;382(8):727-733. doi:10.1056/NEJMoa2001017.

4. Chinese Clinical Trials. http://www/chictr.org/enindex.aspx.

5. Chen Y, Liu Q, Guo D. Emerging coronaviruses: genome structure, replication, and pathogenesis. J Med Virol 2020;92(4):418-423. doi:10.1002/jmv.25681.

6. Fehr AR, Perlman S. Coronaviruses: an overview of their replication and pathogenesis. Methods Mol Biol 2015;1282:123. doi:10.1007/978-1-4939-2438-7 1.

7. Fung TS, Liu DX. Coronavirus infection, ER stress, apoptosis and innate immunity. Front Microbiol. 2014;5:296. doi:10.3389/fmicb.2014.00296.

7a. Fragkou PC, Belhadi D, Peiffer-Smadja N, Moschopoulos $\mathrm{CD}$, et al. Review of trials currently testing treatment and prevention of COVID-19. Clinical Microbiology and Infection 2020;26:988e998.

7b. Tufani A, Avanoglu A, Cerini MM. COVID-19, immune system response, hyperinflammation and repurposing antirheumatic drugs. Turk J Med Sci 2020;50:620-632. Doi:10.3906/sag-2004-168.

7c. 18. Li X, Geng M, Peng Y, et al. Molecular immune pathogenesis and diagnosis of COVID-19. Journal of Pharmaceutical Analysis 10 (2020) 102e108. (C2020 Xi'an Jiaotong University. Production and hosting by Elsevier B.V. This is an open access articleunder the CC BY-NCND license. Journal of Pharmaceutical Analysis 10 (2020) 102e108. https://doi.org/10.1016/j.jpha.2020.03.001.

7d. Belouzard S, Chu VC, Whittaker GR Activation of the SARS coronavirus spike protein via sequential proteolytic cleavage at two distinct sites. Proc Natl Acad Sci USA 2009;106:5871e5876, https://doi.org/10.1073/ pnas.0809524106.

8. Tufani A, Güller AA, Cerinic MM. COVID-19, immune system response, hyperinflammation and repurposing antirheumatic drugs. Turk J Med Sci 2020;50:620-632. Doi:10.3906/sag-2004-168.

9. Huang C, Wang Y, Li X, et al. Clinical features of patients infected with 2019 novel coronavirus in Wuhan, China [published correction appears in Lancet. 2020 Jan 30;:]. Lancet. 2020;395(10223):497-506. doi:10.1016/S01406736(20)30183-5.

10. Haga S, Yamamoto N, Nakai-Murakami C, et al. Modulation of TNF-alpha-converting enzyme by the spike protein of SARS-CoV and ACE2 induces TNF-alpha production and facilitates viral entry. Proc Natl Acad Sci U S A. 2008;105(22):7809-7814. doi:10.1073/pnas.0711241105.

11. Feldmann M, Maini RN, Woody JN, et al. Trials of antitumour necrosis factor therapy for COVID-19 are urgently needed. Lancet. 2020;395(10234):1407-1409. doi:10.1016/ S0140-6736(20)30858-8. 


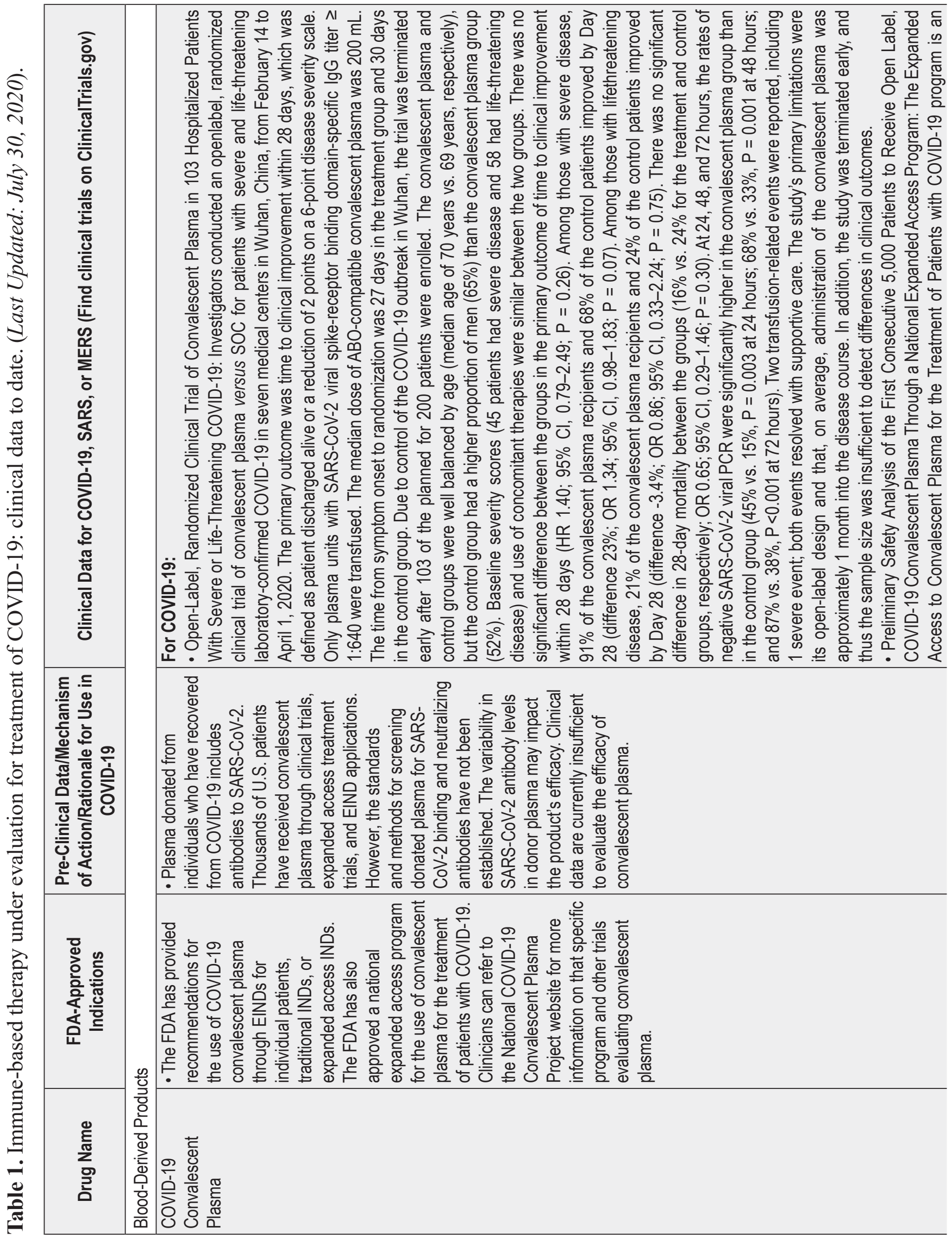




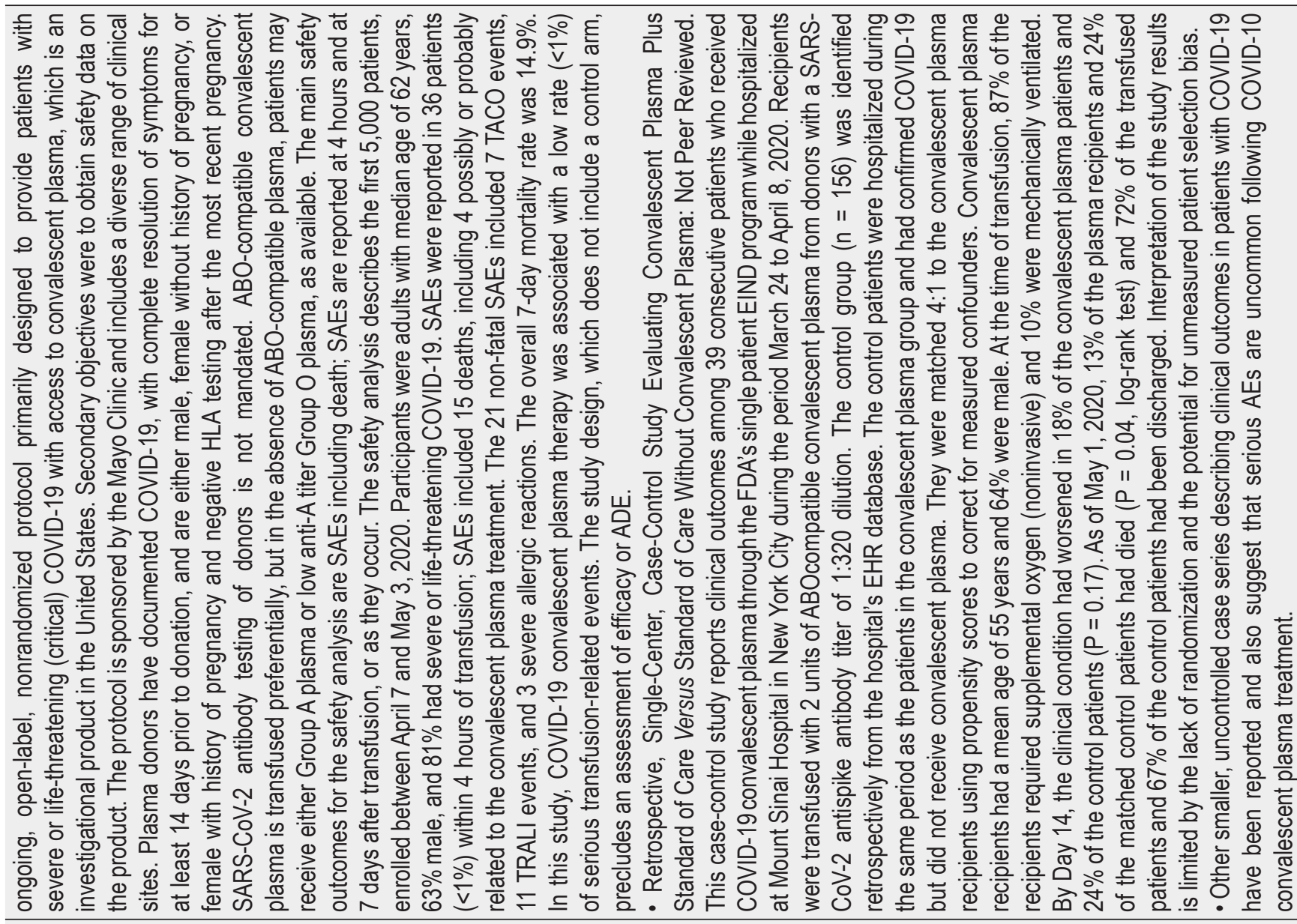




\begin{tabular}{|c|c|c|}
\hline 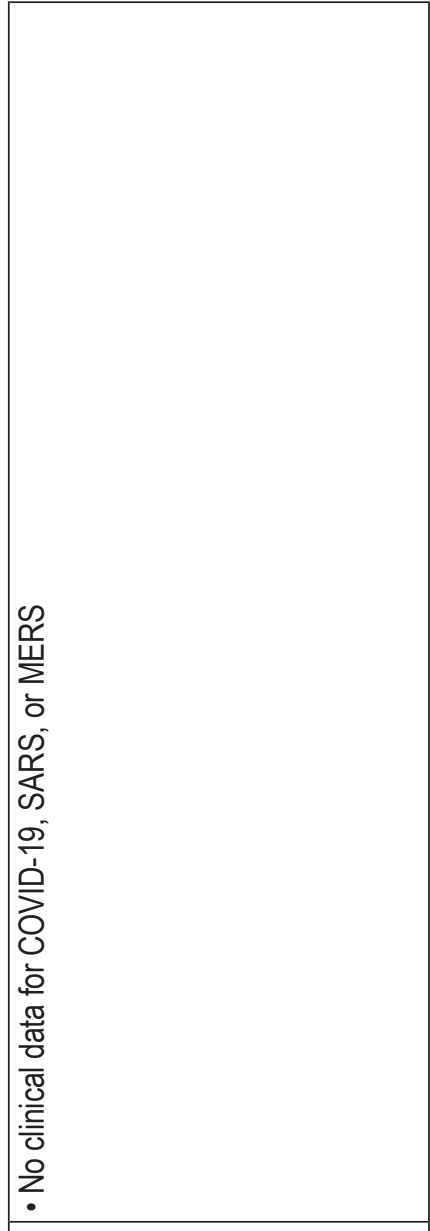 & 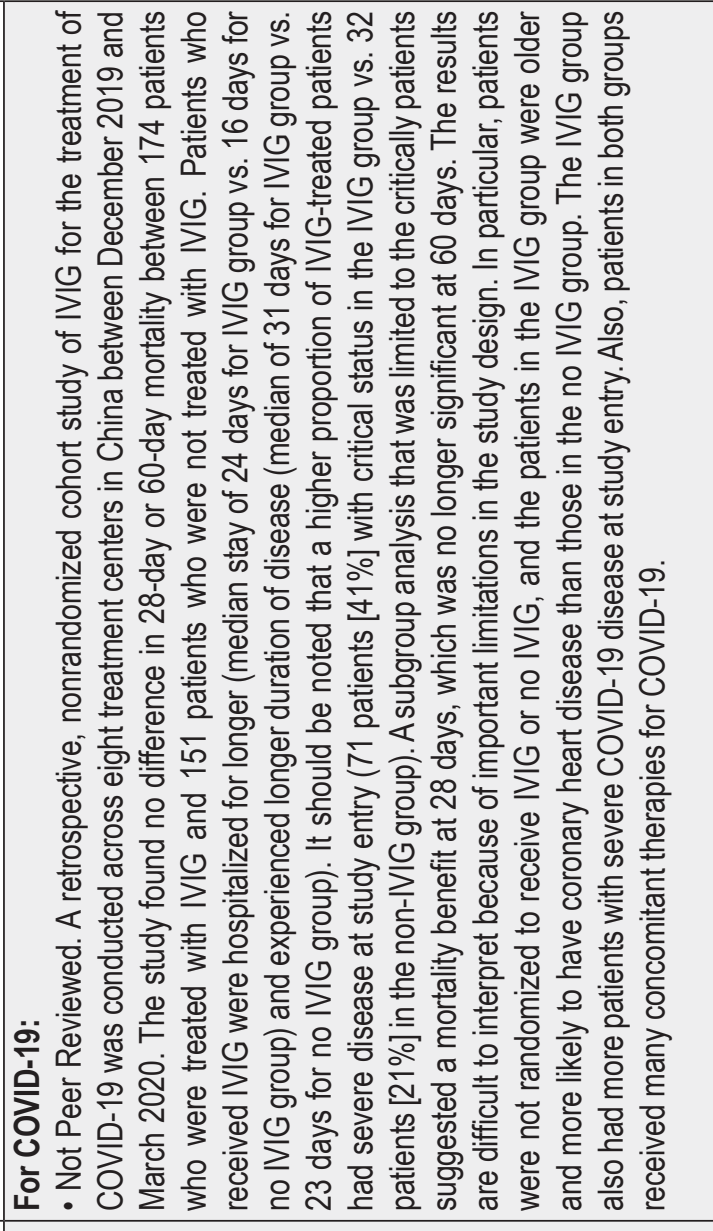 & 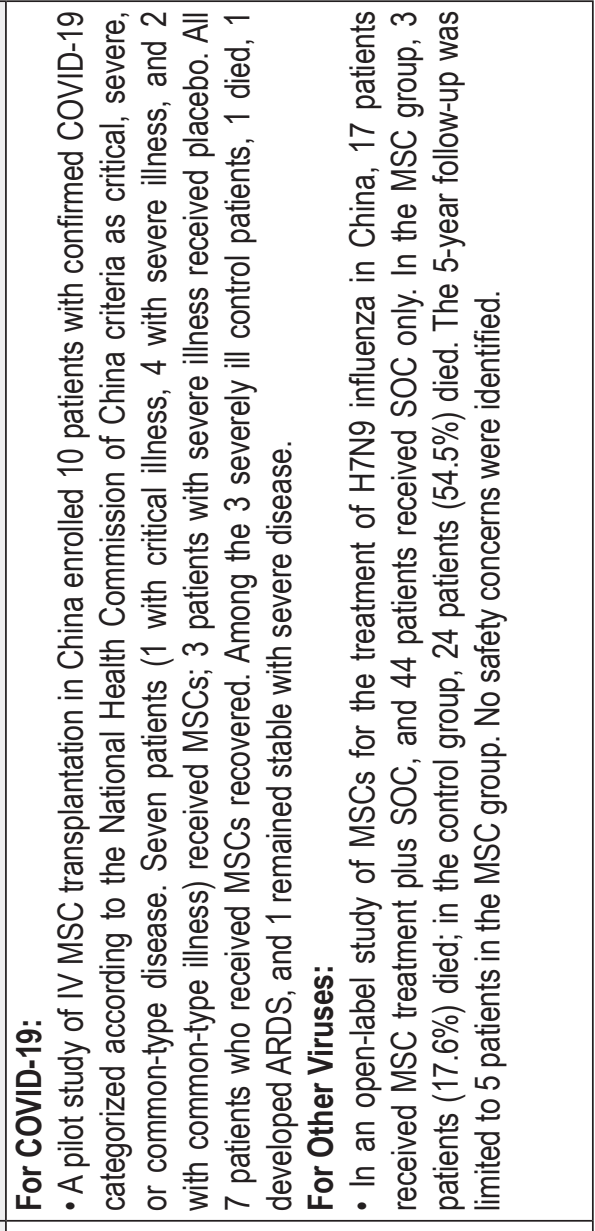 \\
\hline 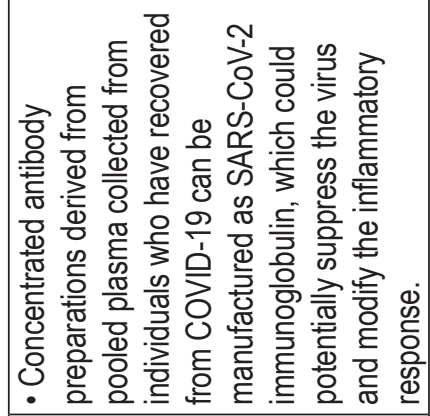 & 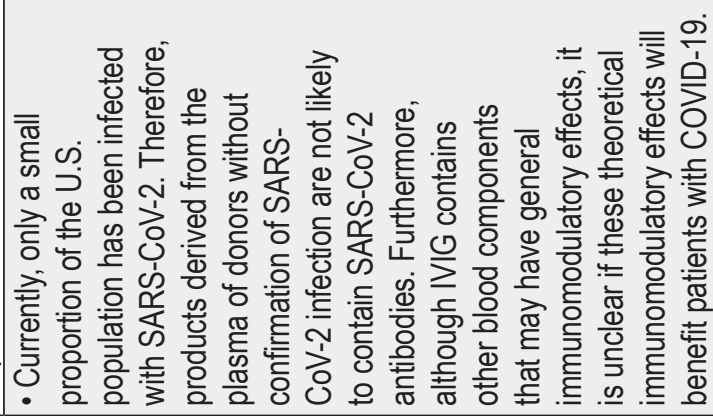 & 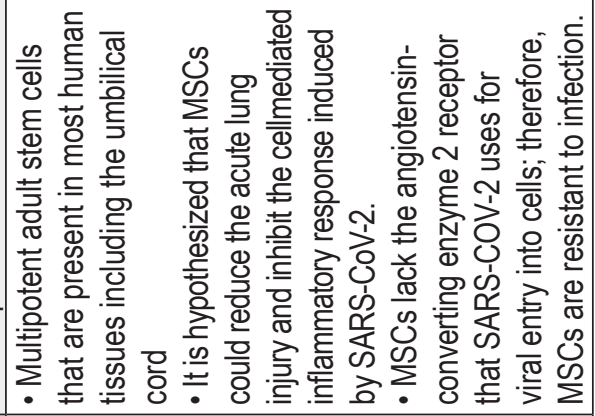 \\
\hline 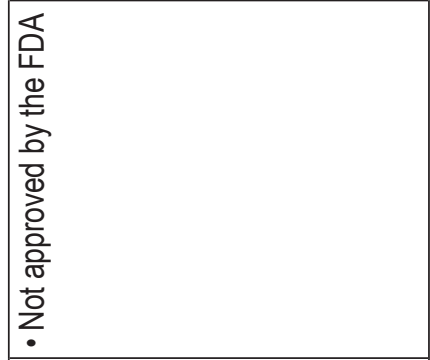 & 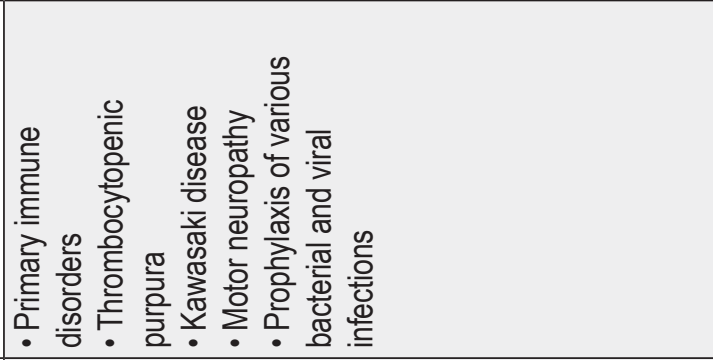 & 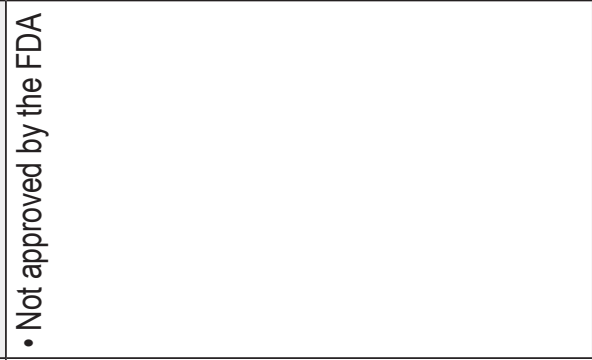 \\
\hline 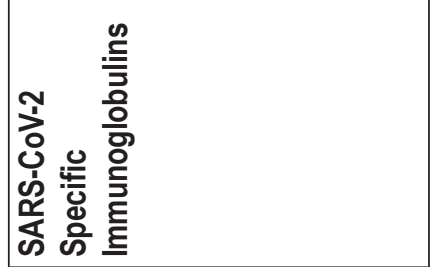 & 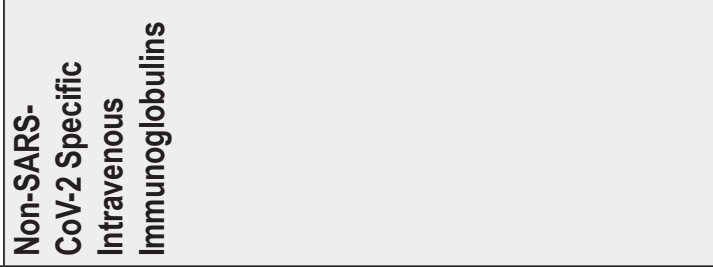 & 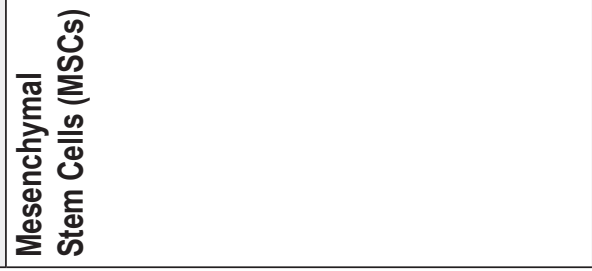 \\
\hline
\end{tabular}




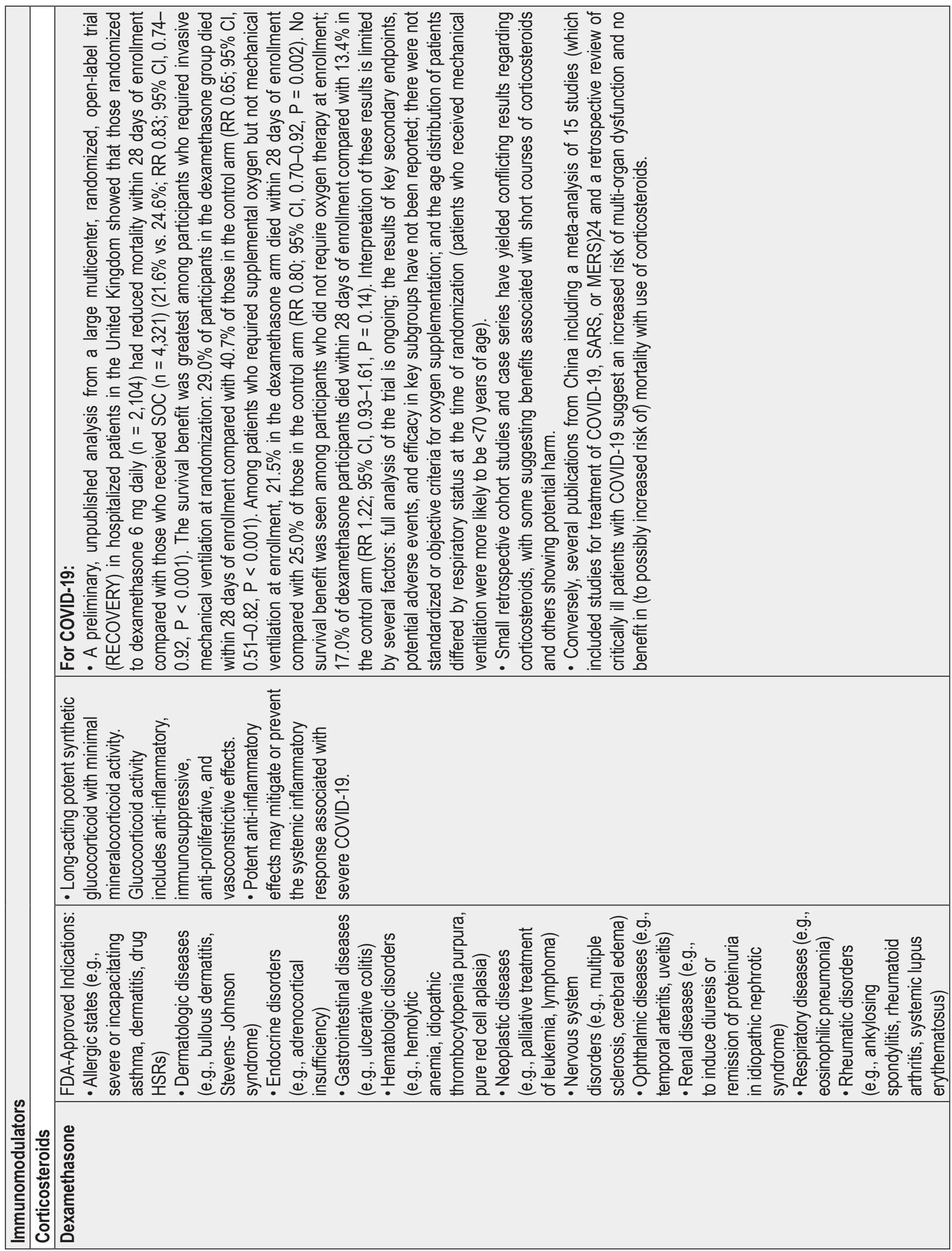




\begin{tabular}{|c|c|c|}
\hline & 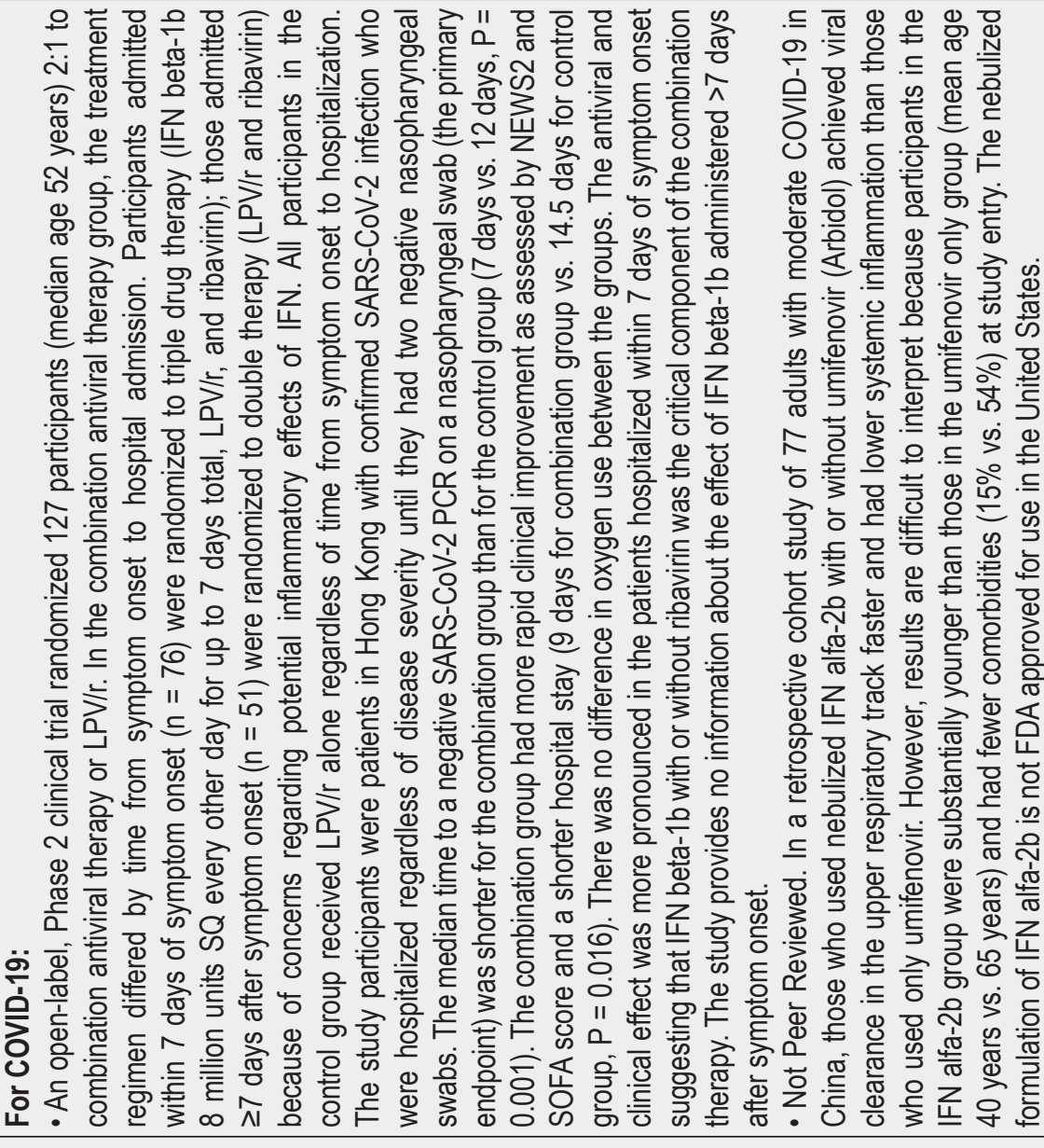 & \\
\hline & 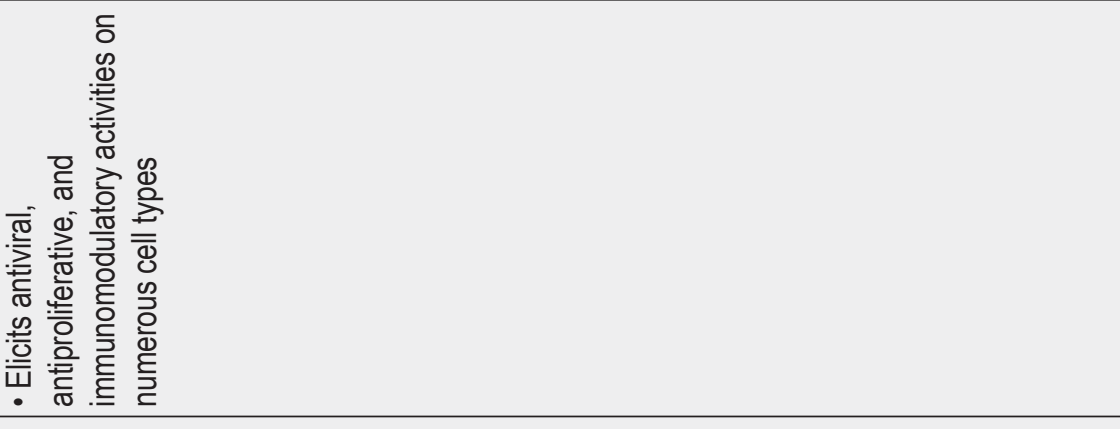 & 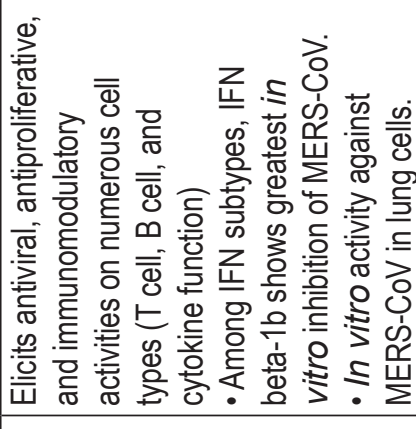 \\
\hline & 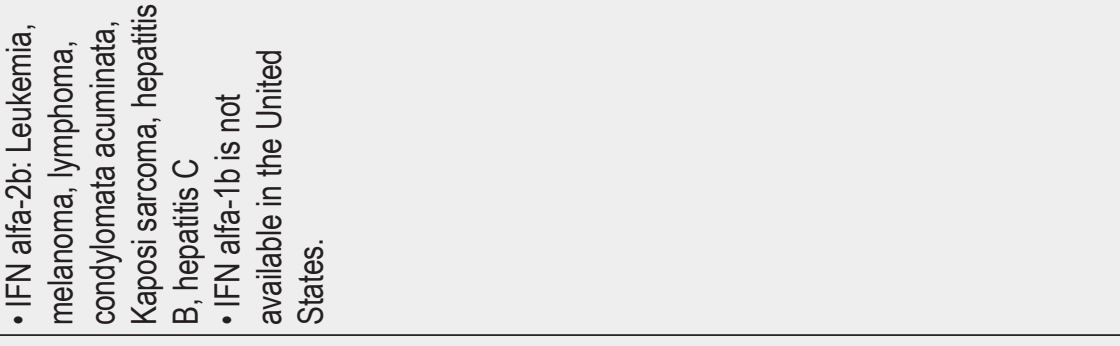 & 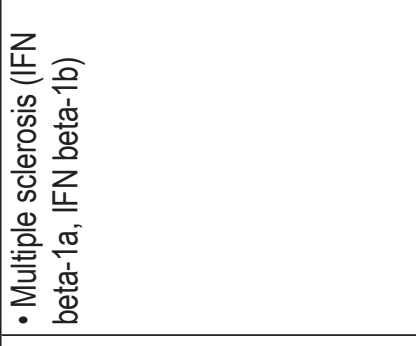 \\
\hline 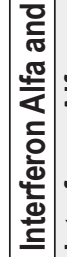 & 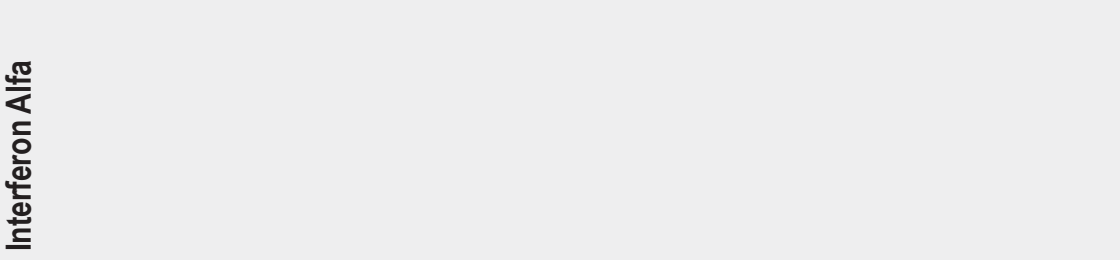 & 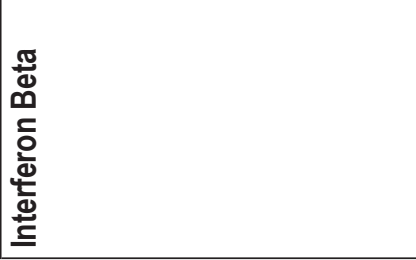 \\
\hline
\end{tabular}




\begin{tabular}{|c|c|}
\hline \multicolumn{2}{|r|}{ 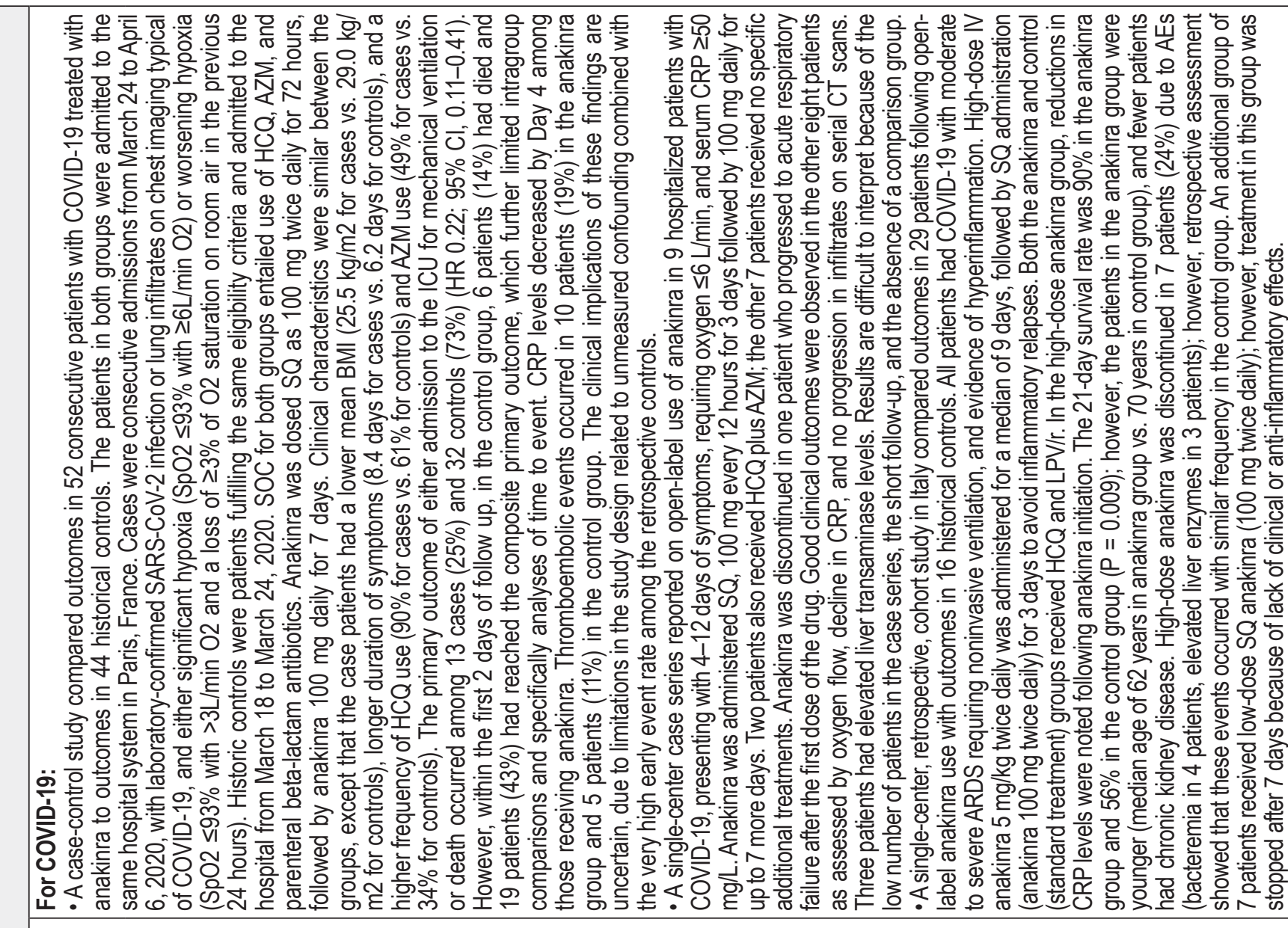 } \\
\hline & 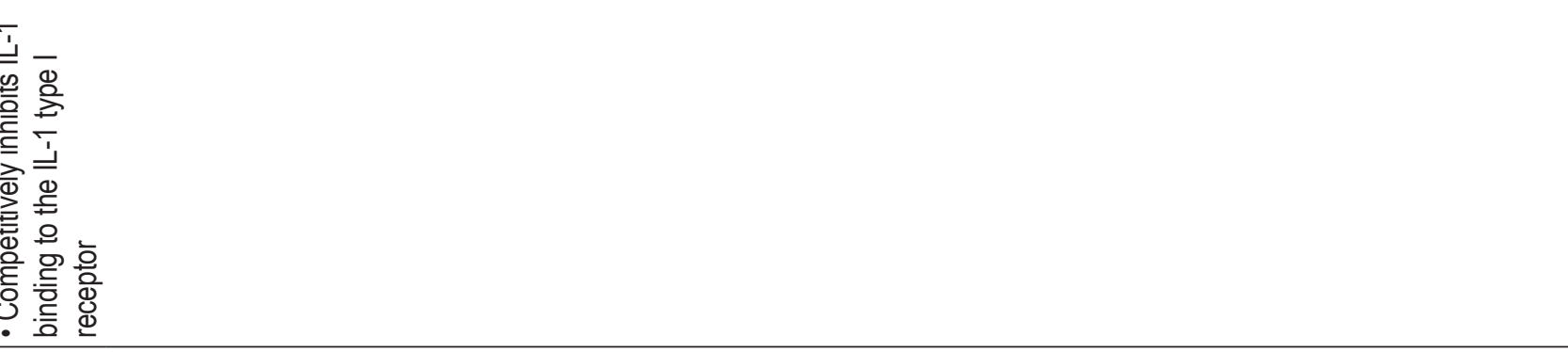 \\
\hline & 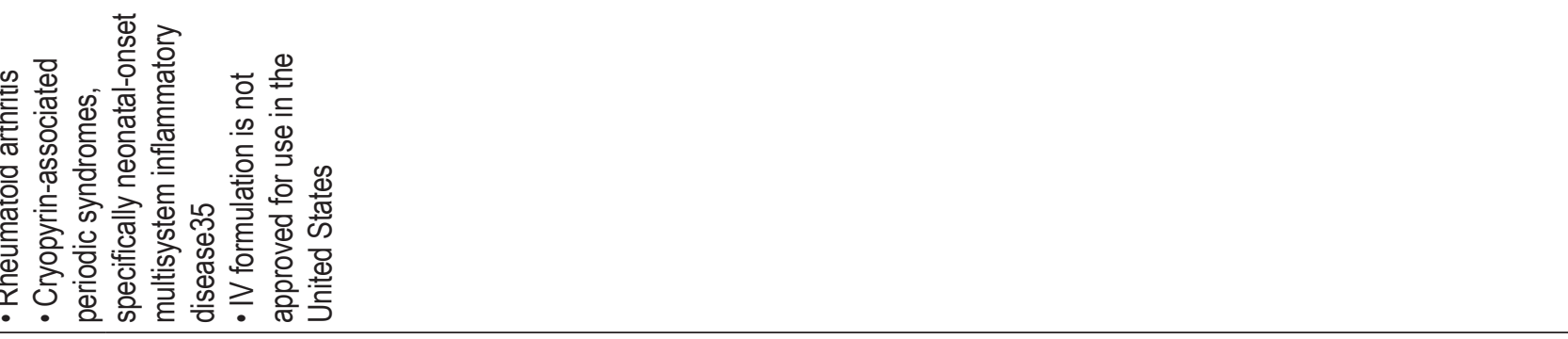 \\
\hline & \\
\hline
\end{tabular}




\begin{tabular}{|c|c|c|c|}
\hline 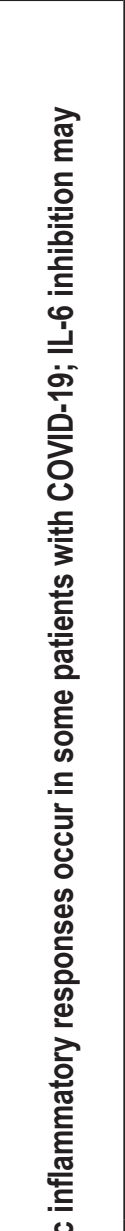 & 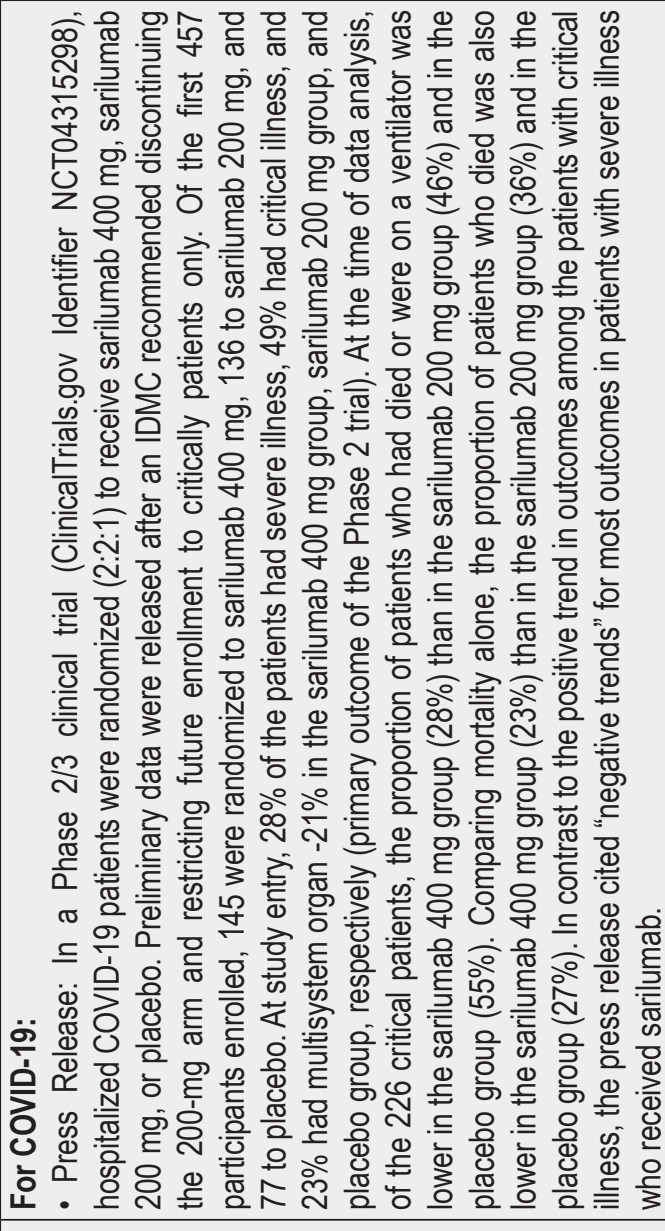 & 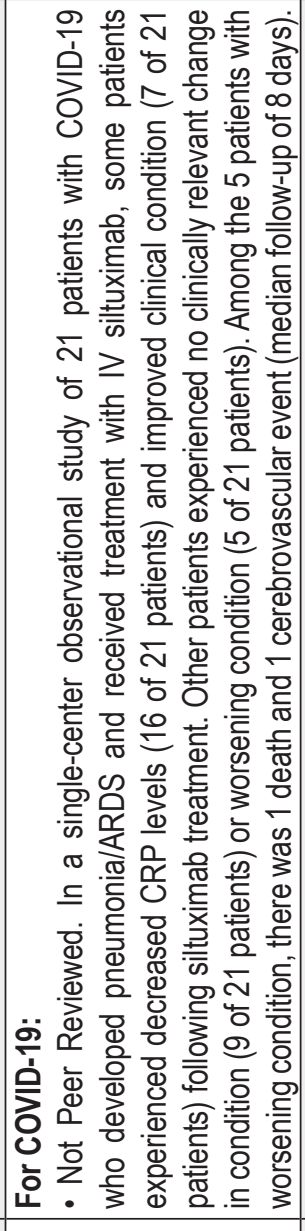 & 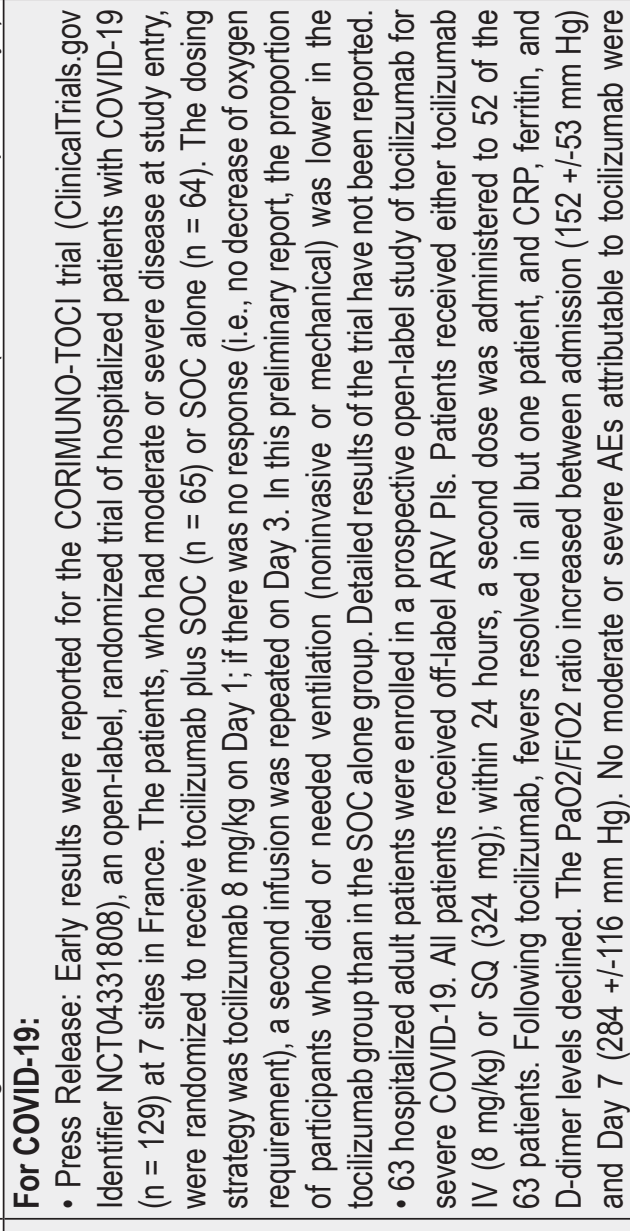 \\
\hline 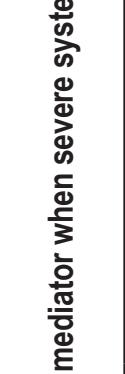 & 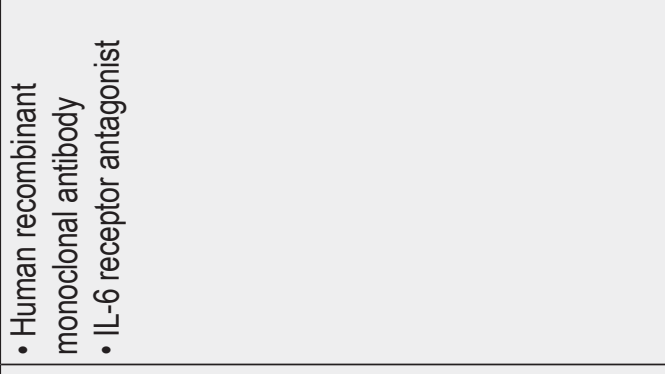 & 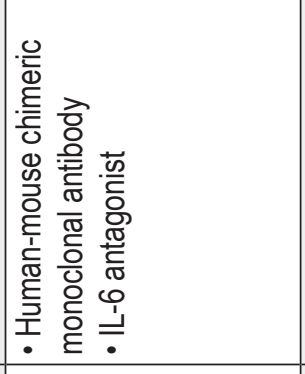 & 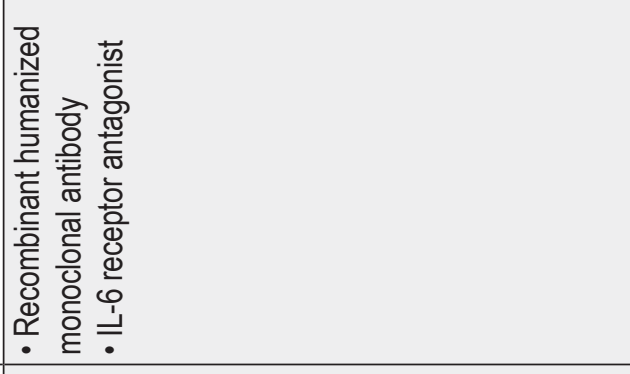 \\
\hline 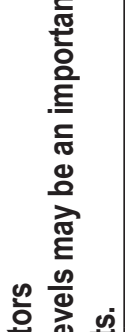 & 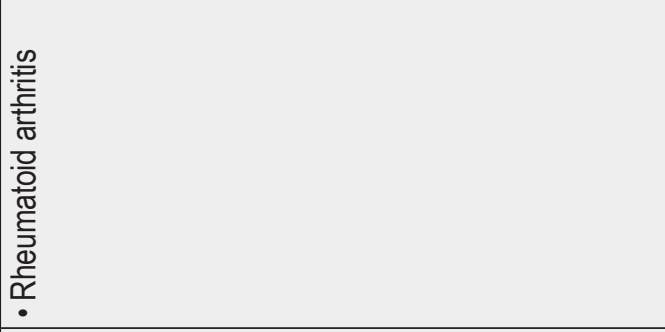 & 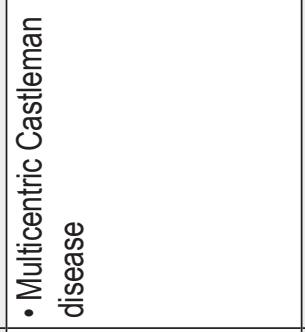 & 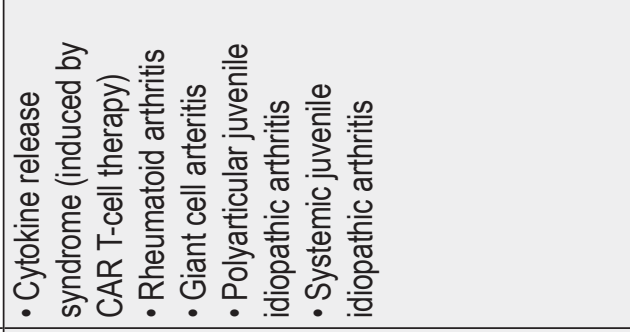 \\
\hline 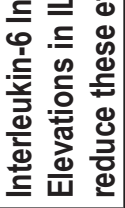 & & 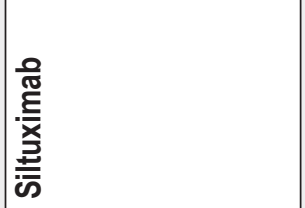 & 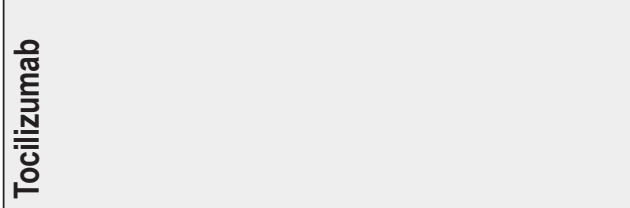 \\
\hline
\end{tabular}




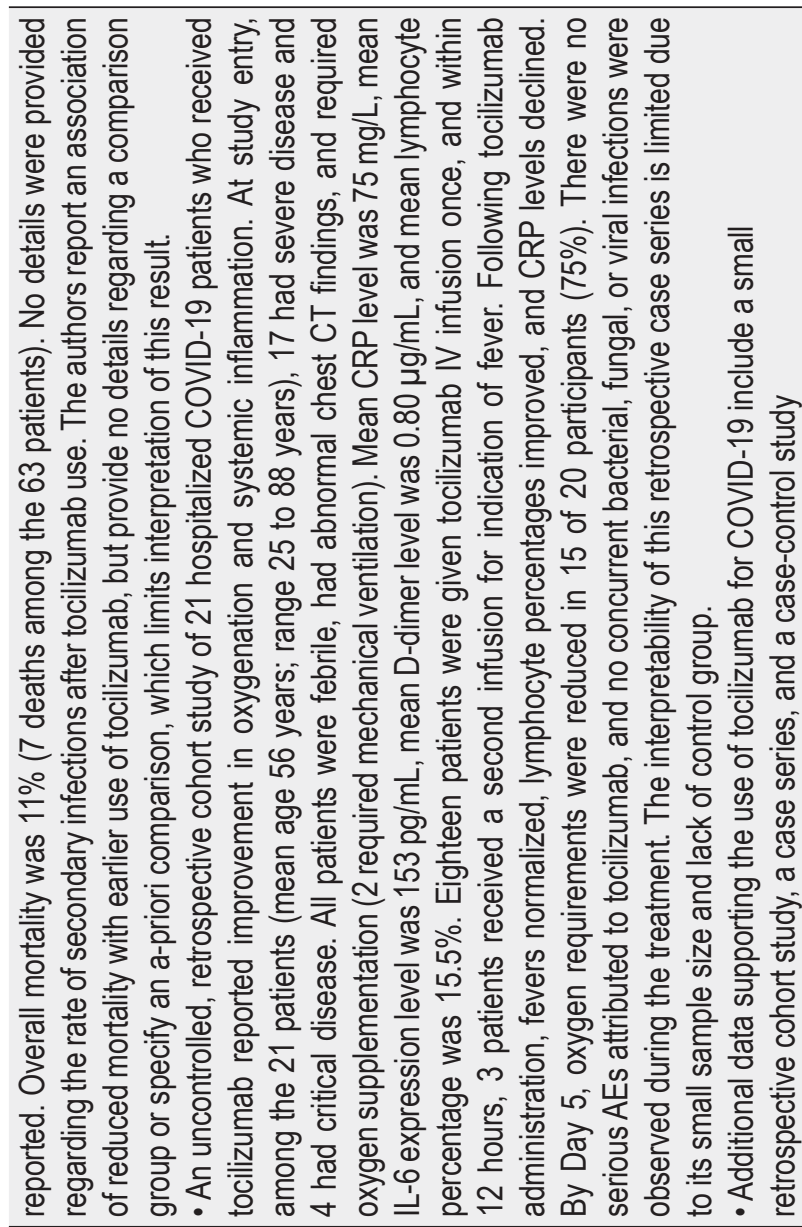

\begin{tabular}{|c|c|c|}
\hline \multicolumn{2}{|r|}{ 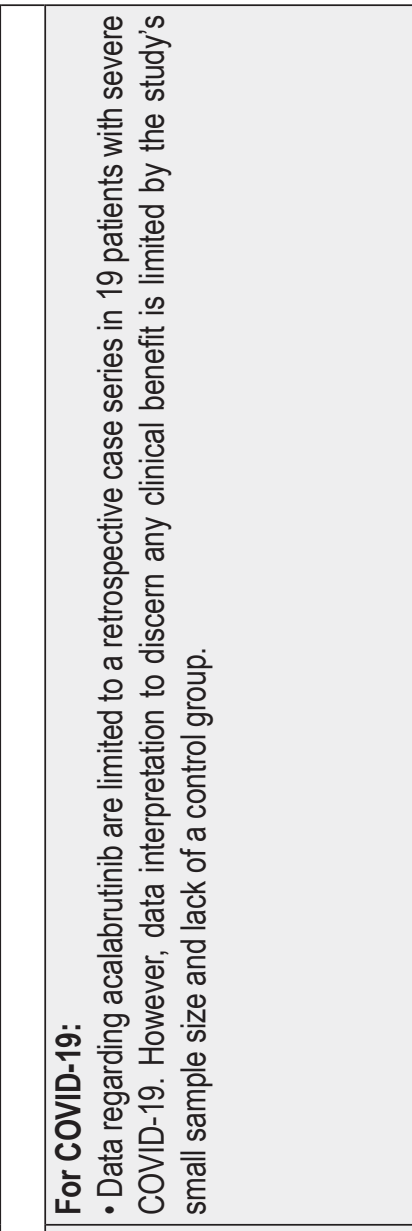 } & 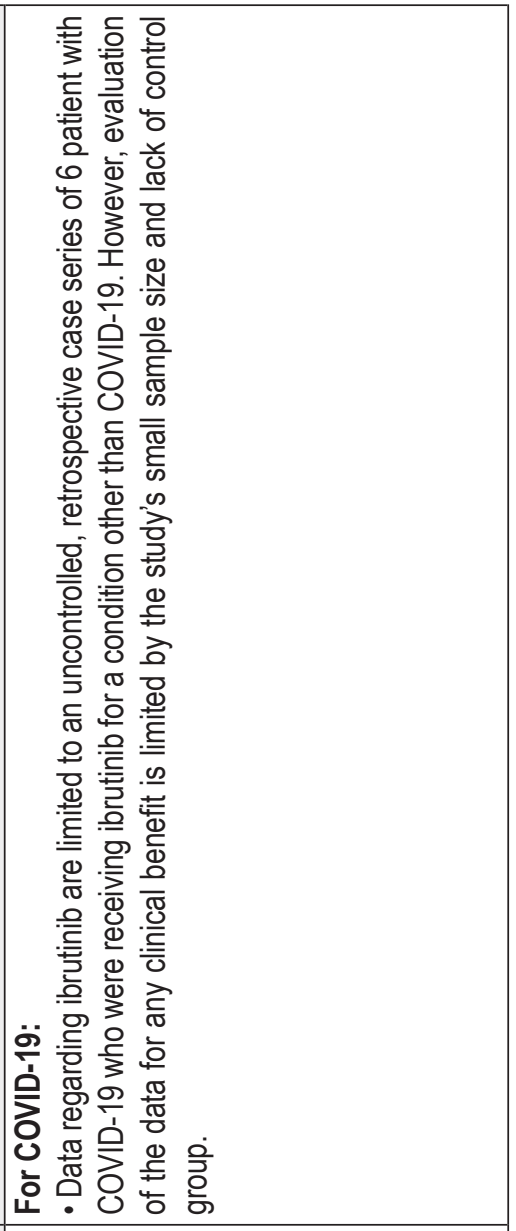 \\
\hline & 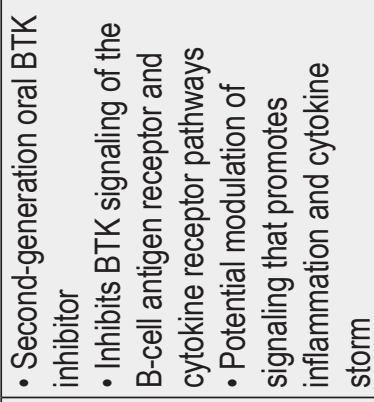 & 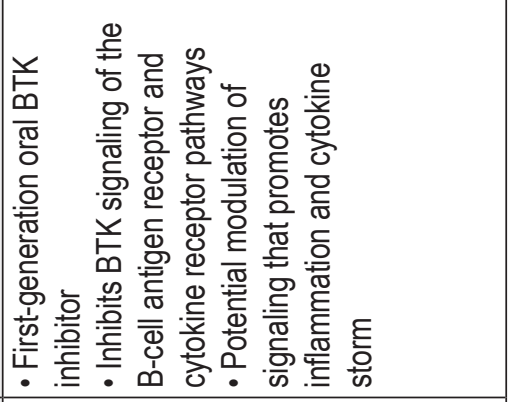 \\
\hline & 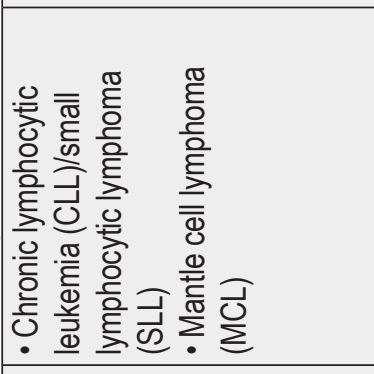 & 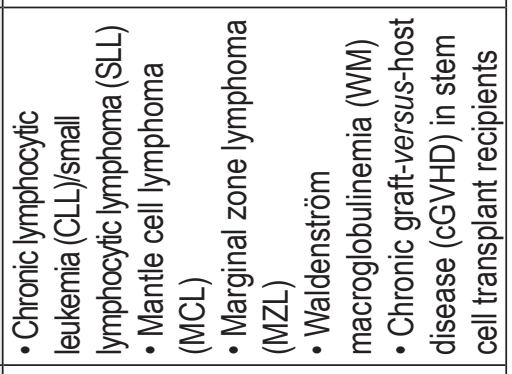 \\
\hline & & \\
\hline
\end{tabular}




\begin{tabular}{|c|c|c|}
\hline 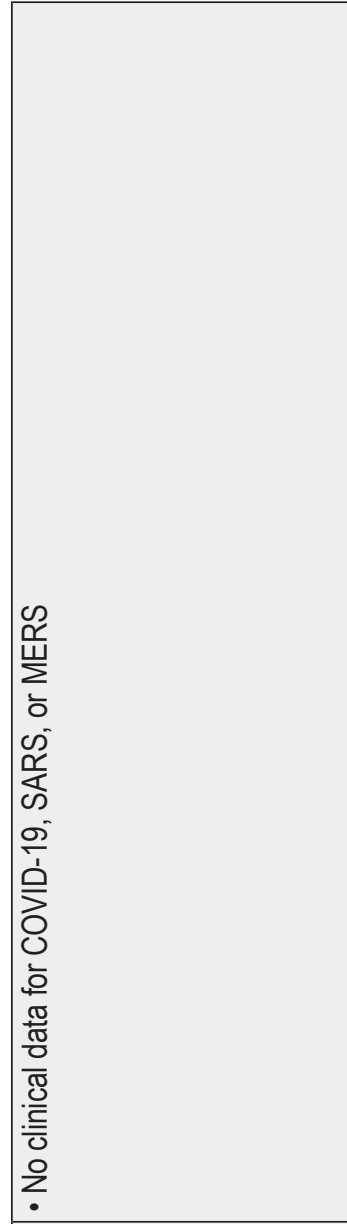 & 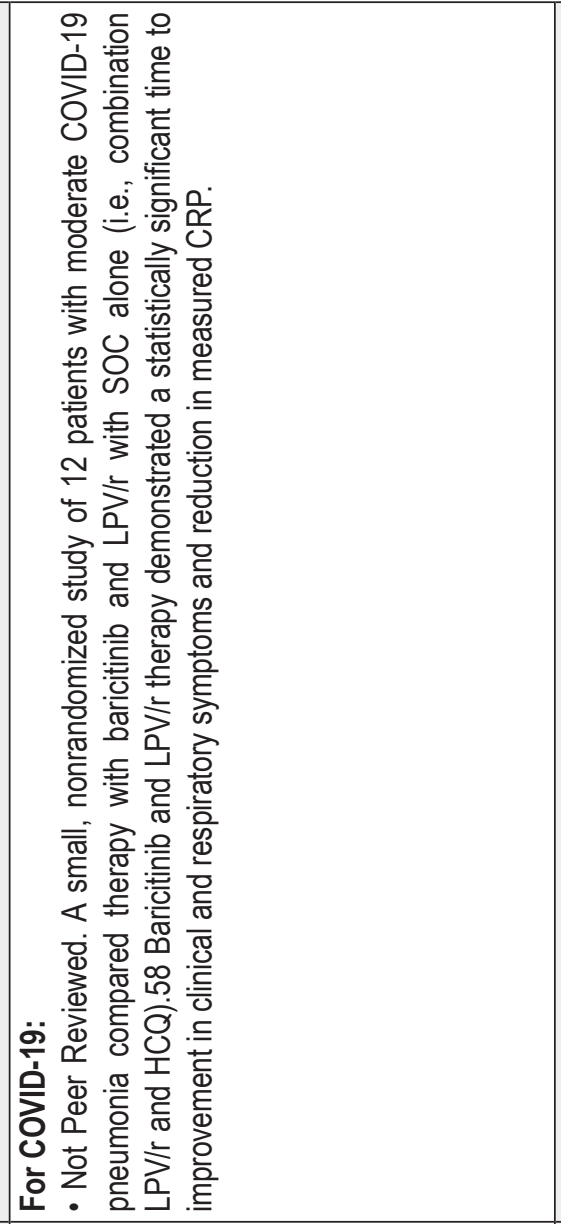 & 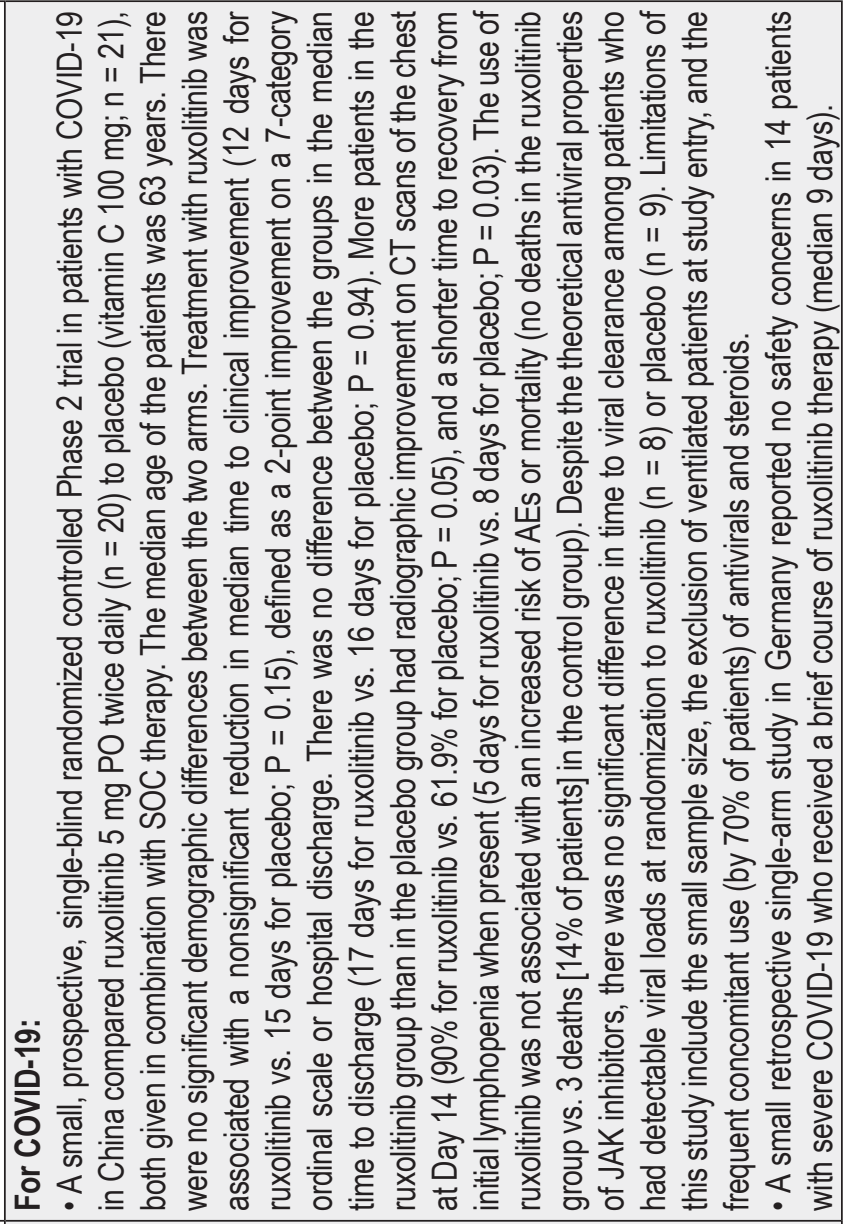 \\
\hline 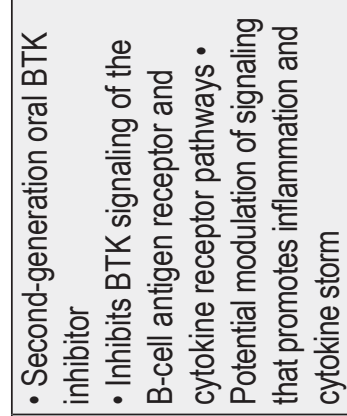 & 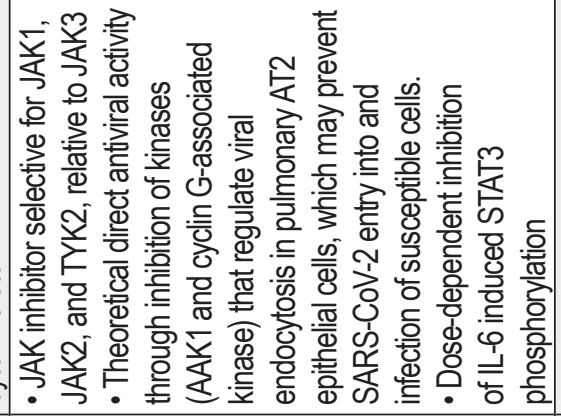 & 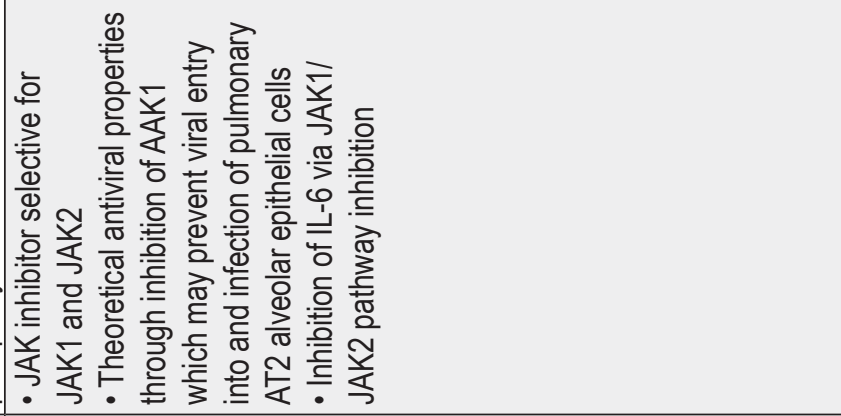 \\
\hline 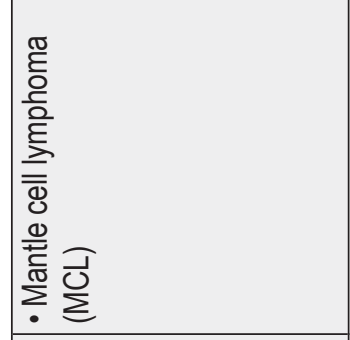 & 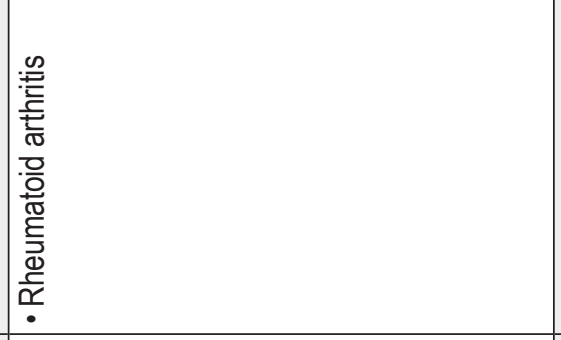 & 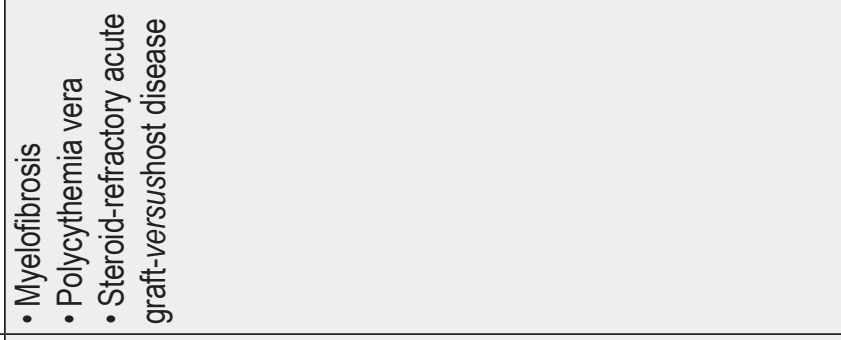 \\
\hline & 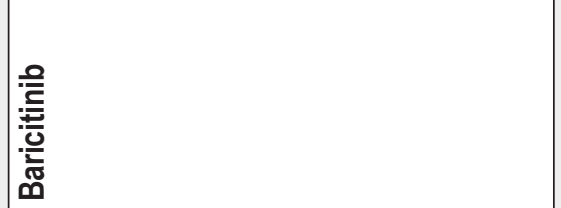 & 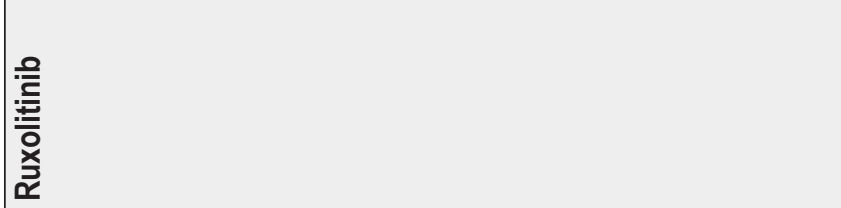 \\
\hline
\end{tabular}




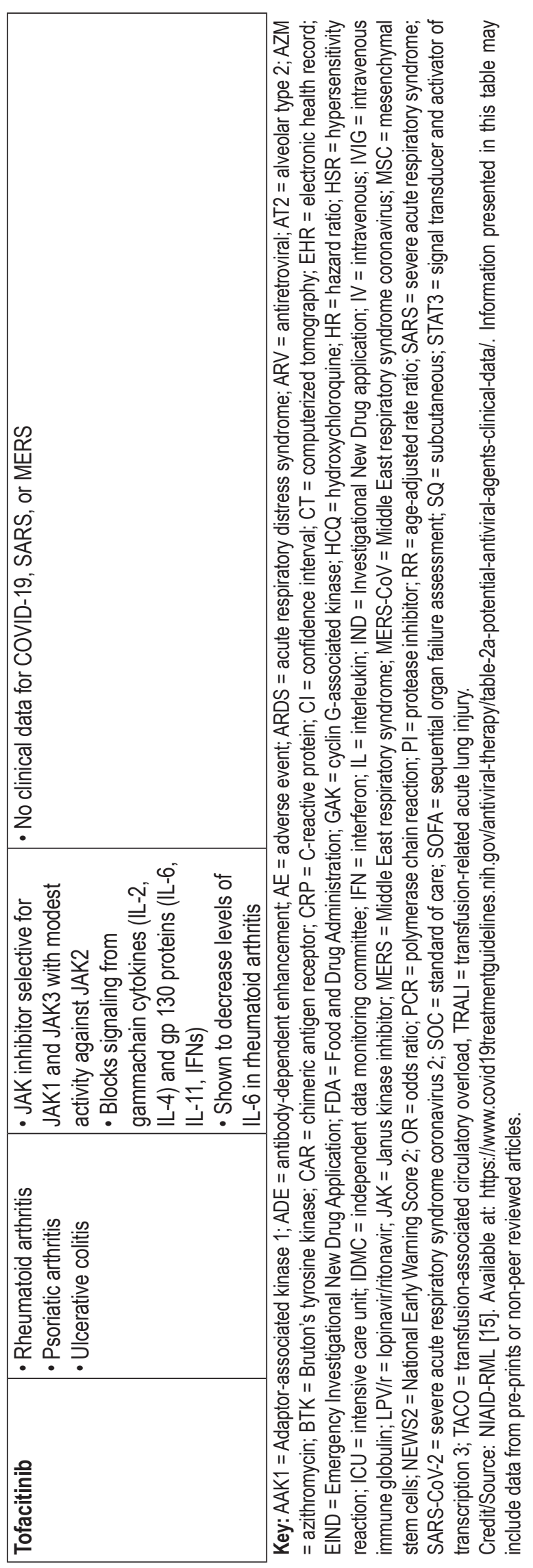




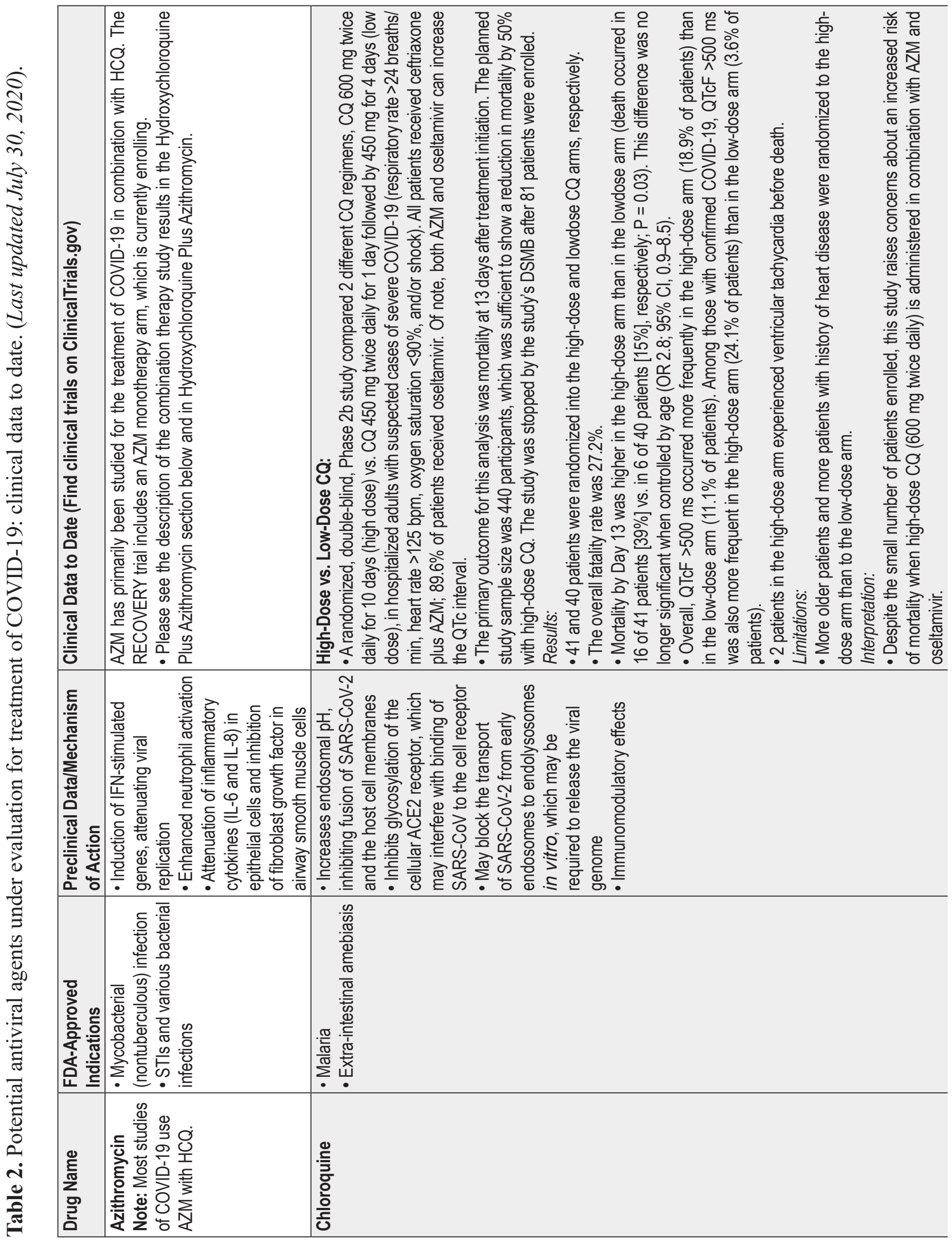




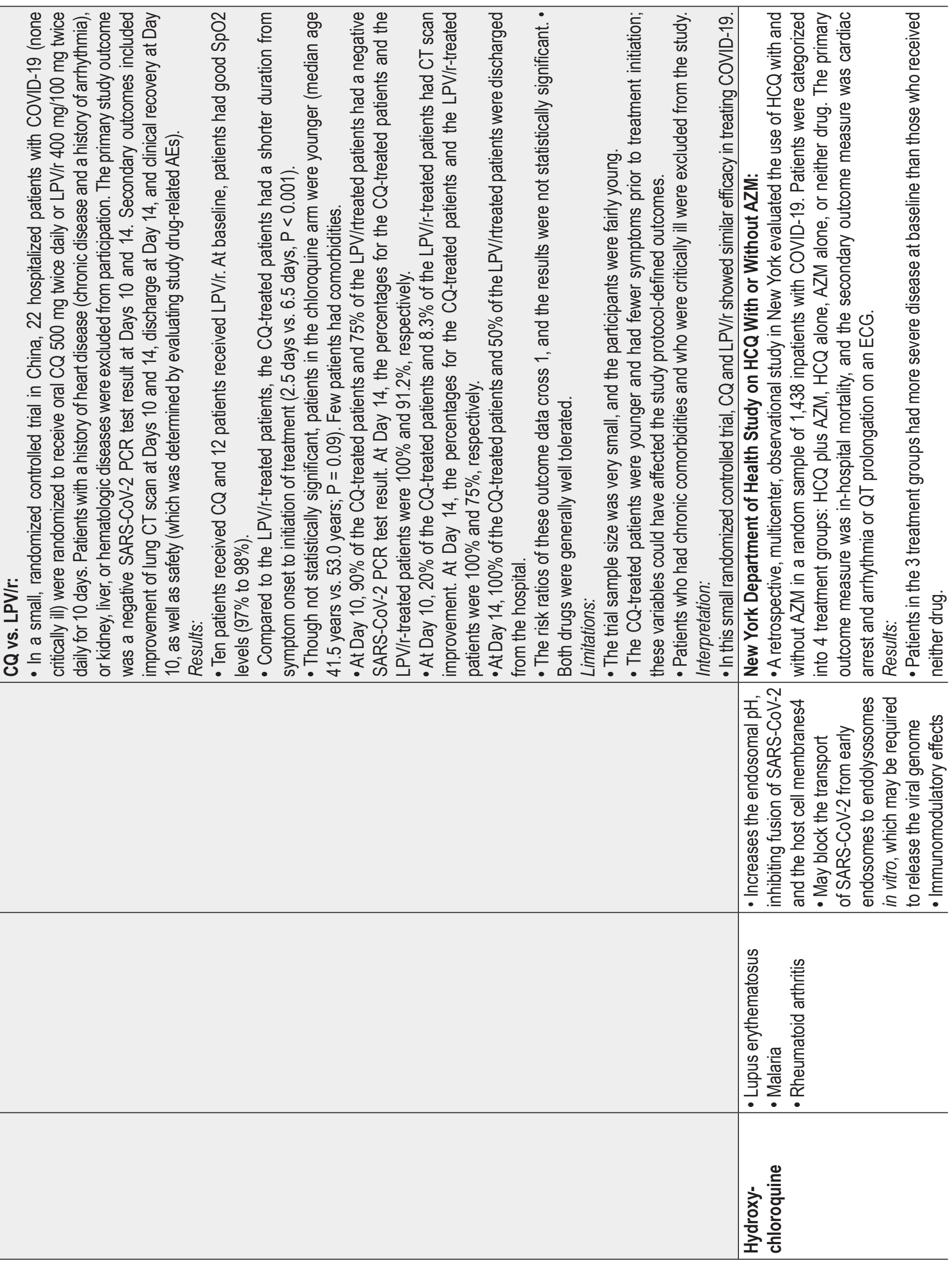




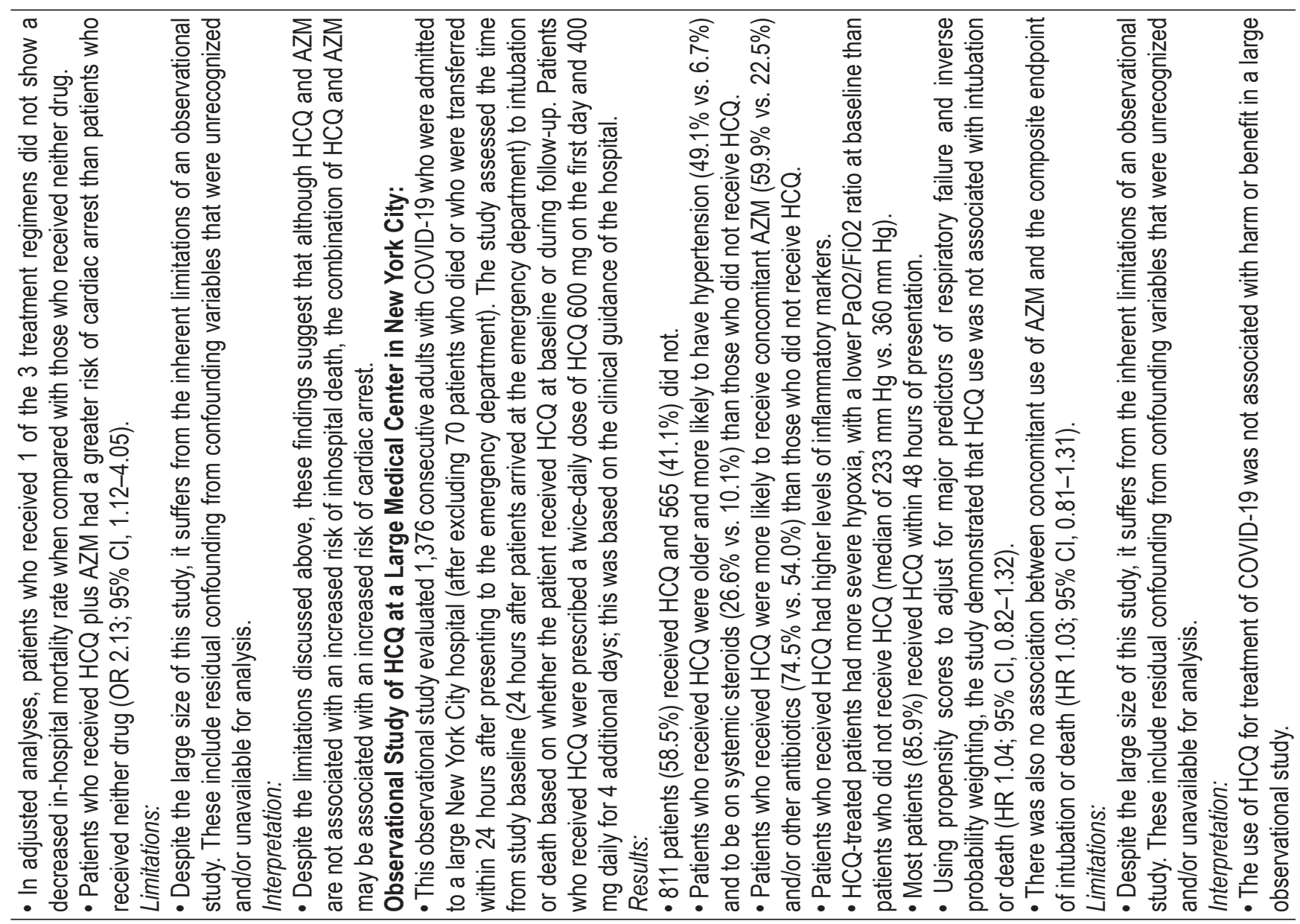




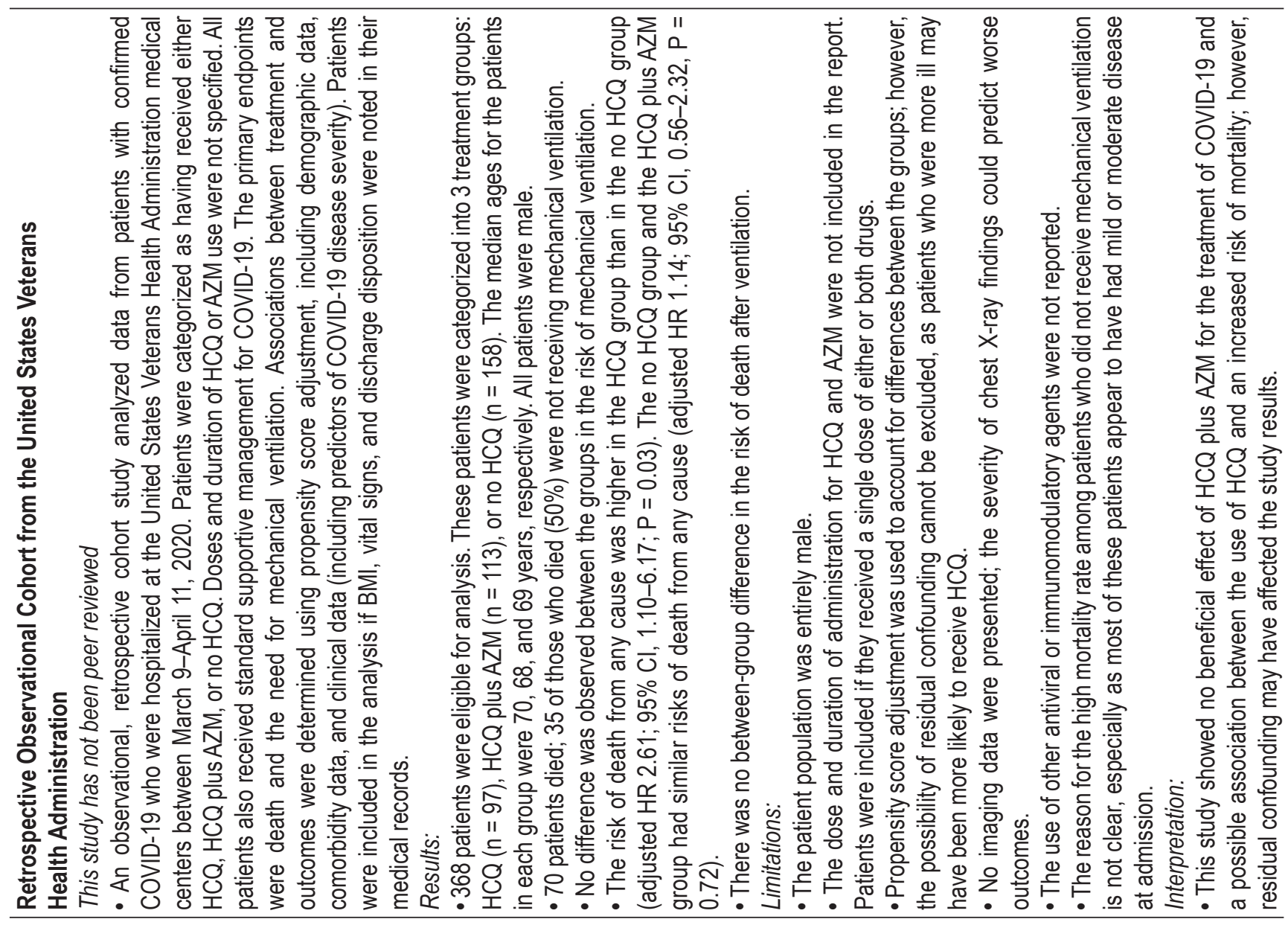




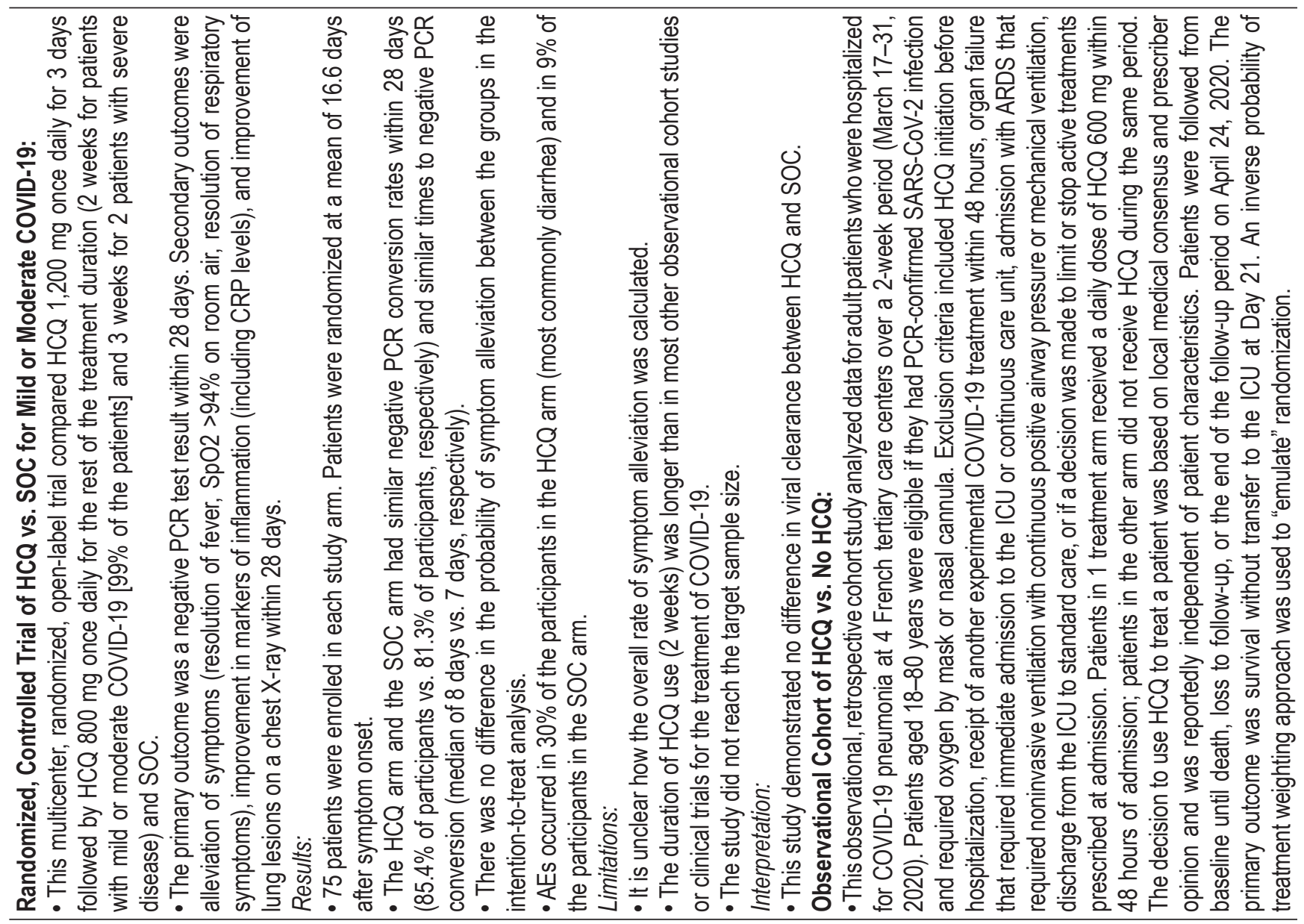




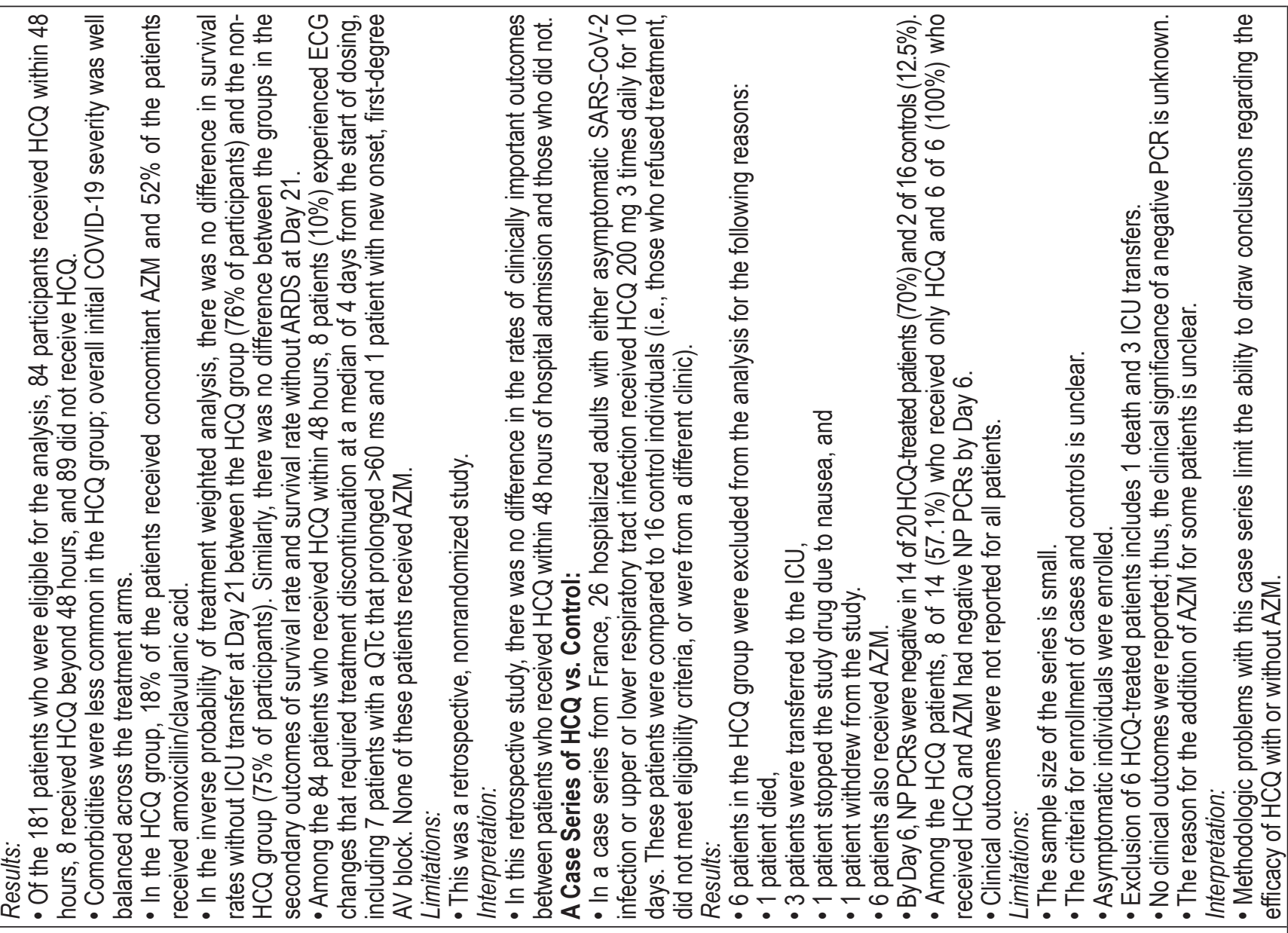




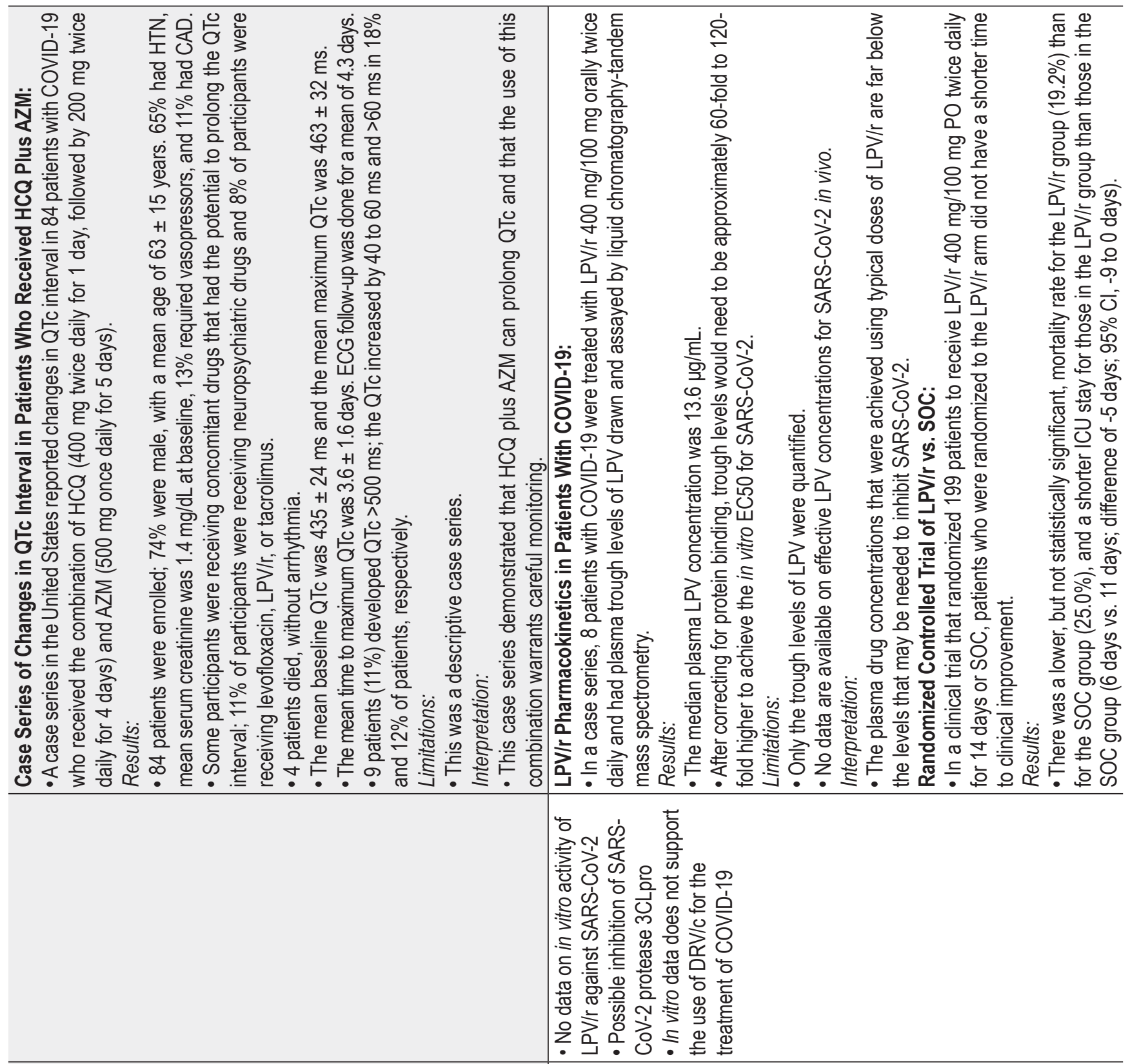

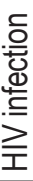

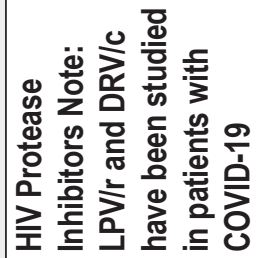




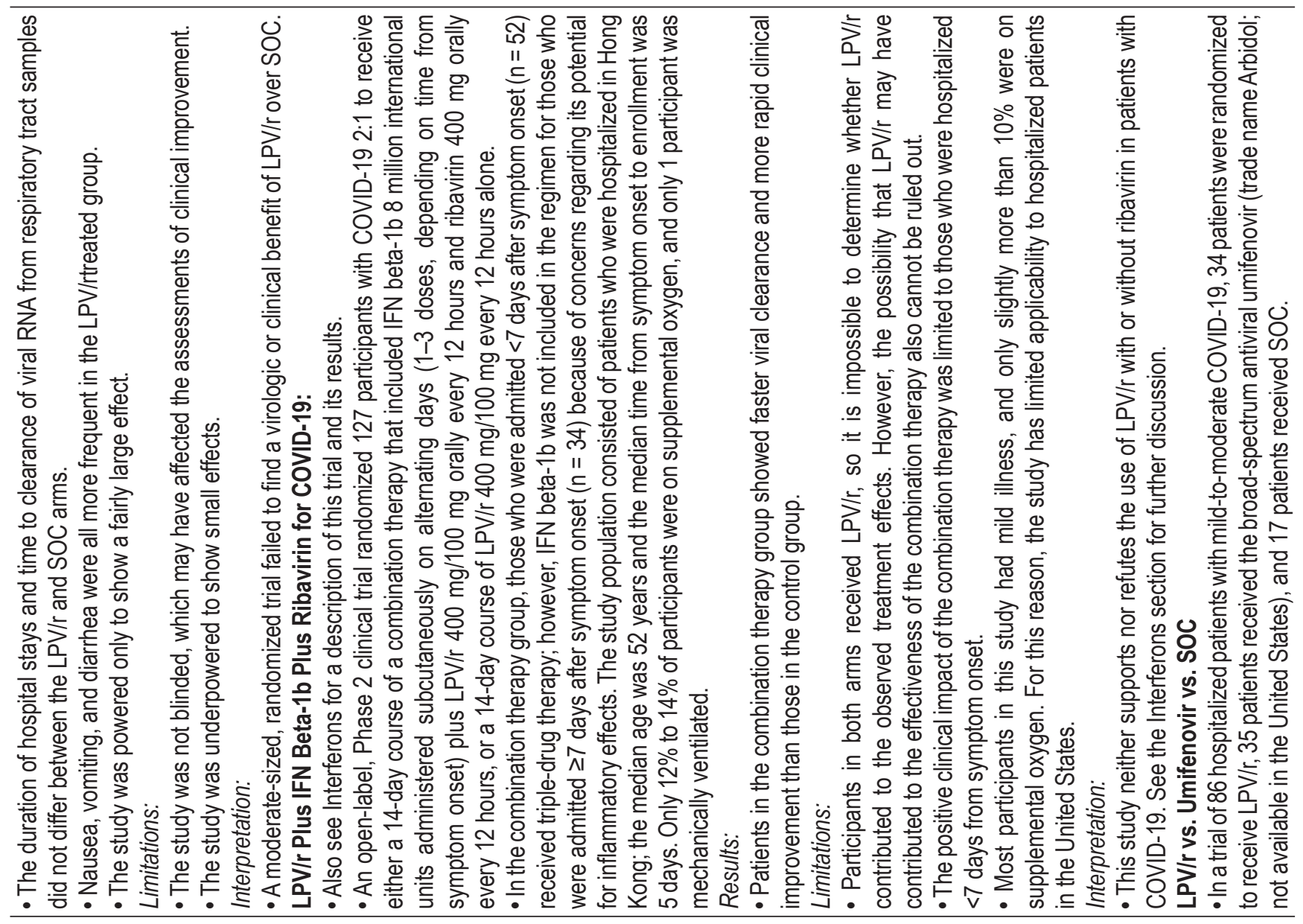




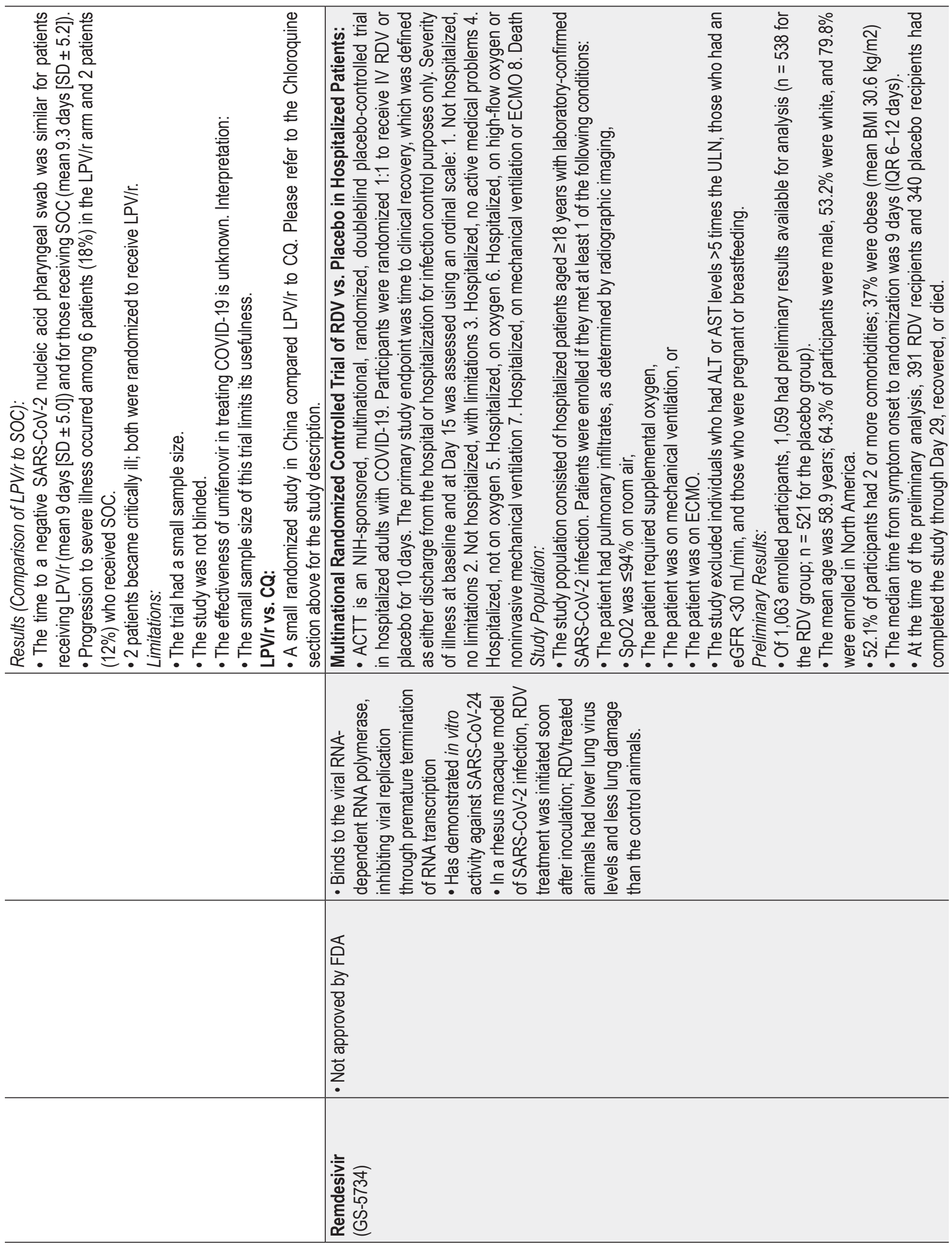




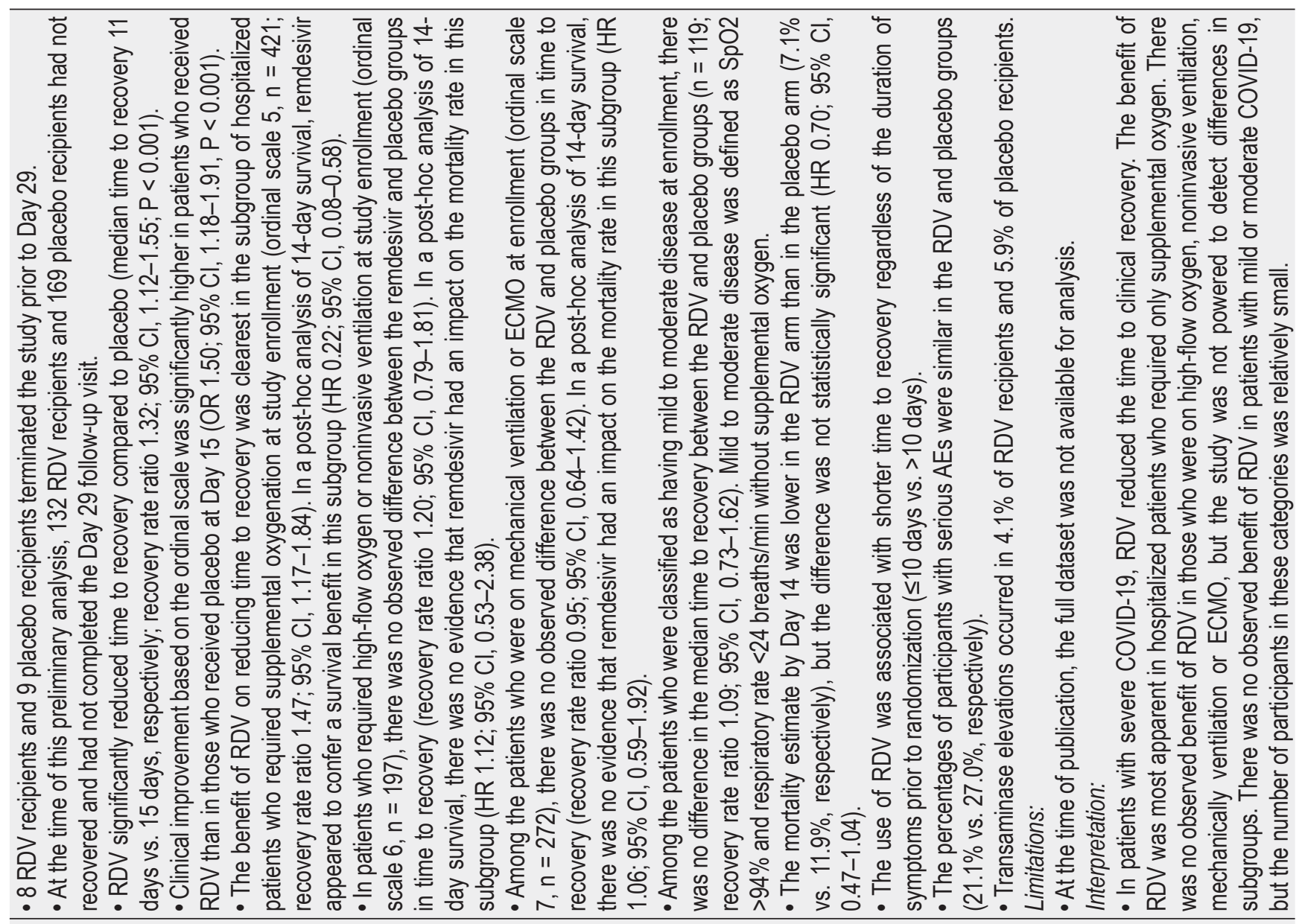




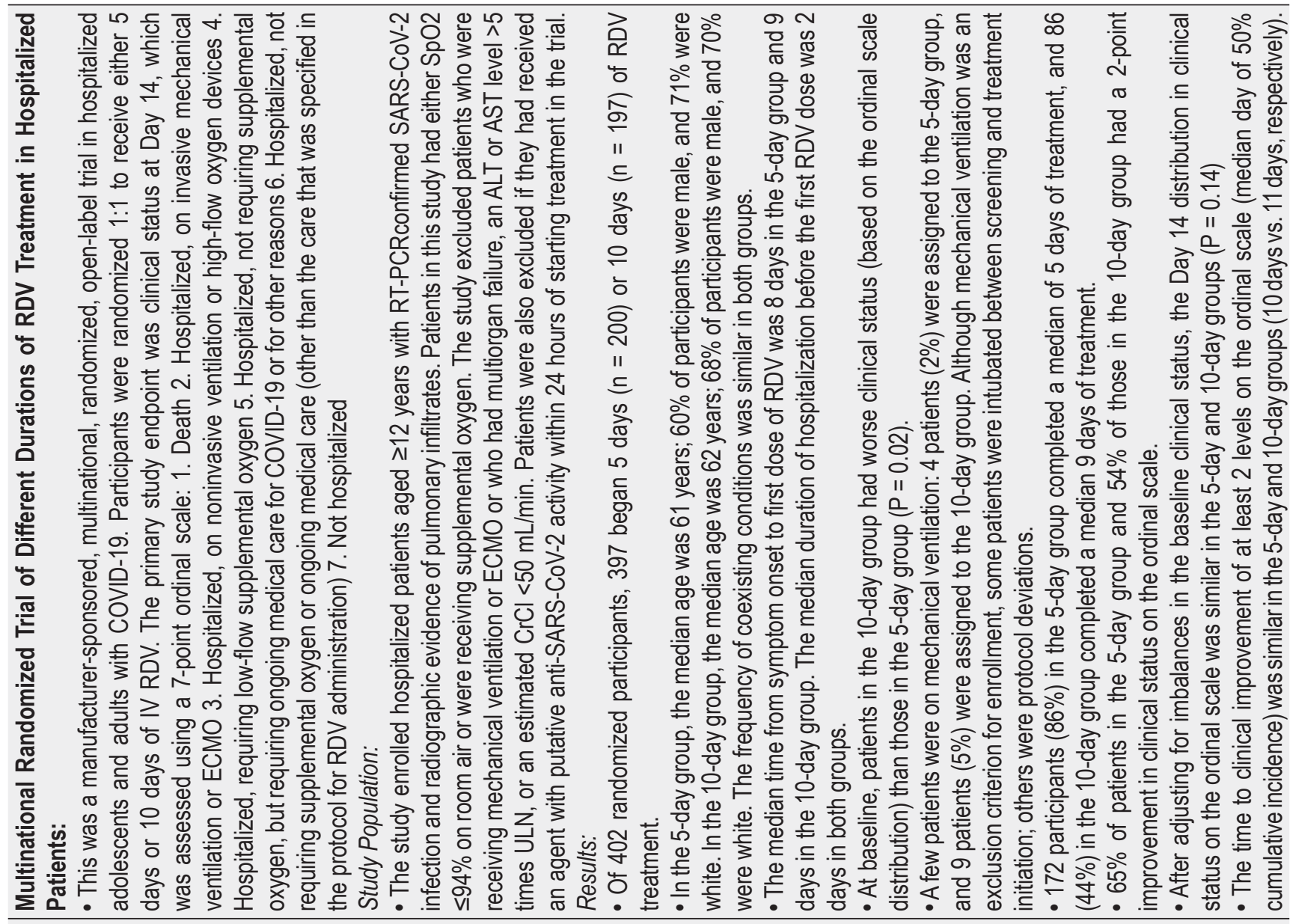




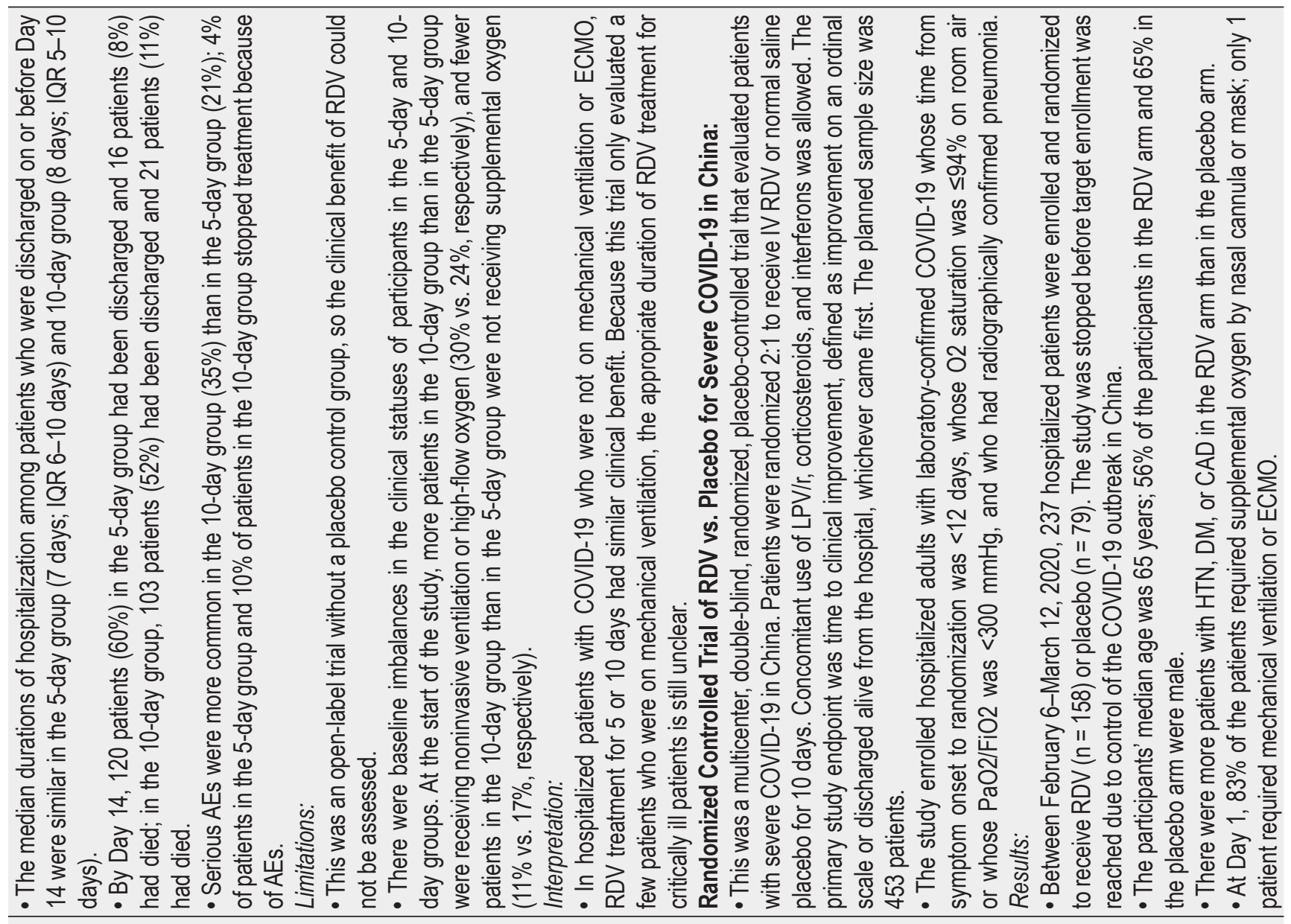




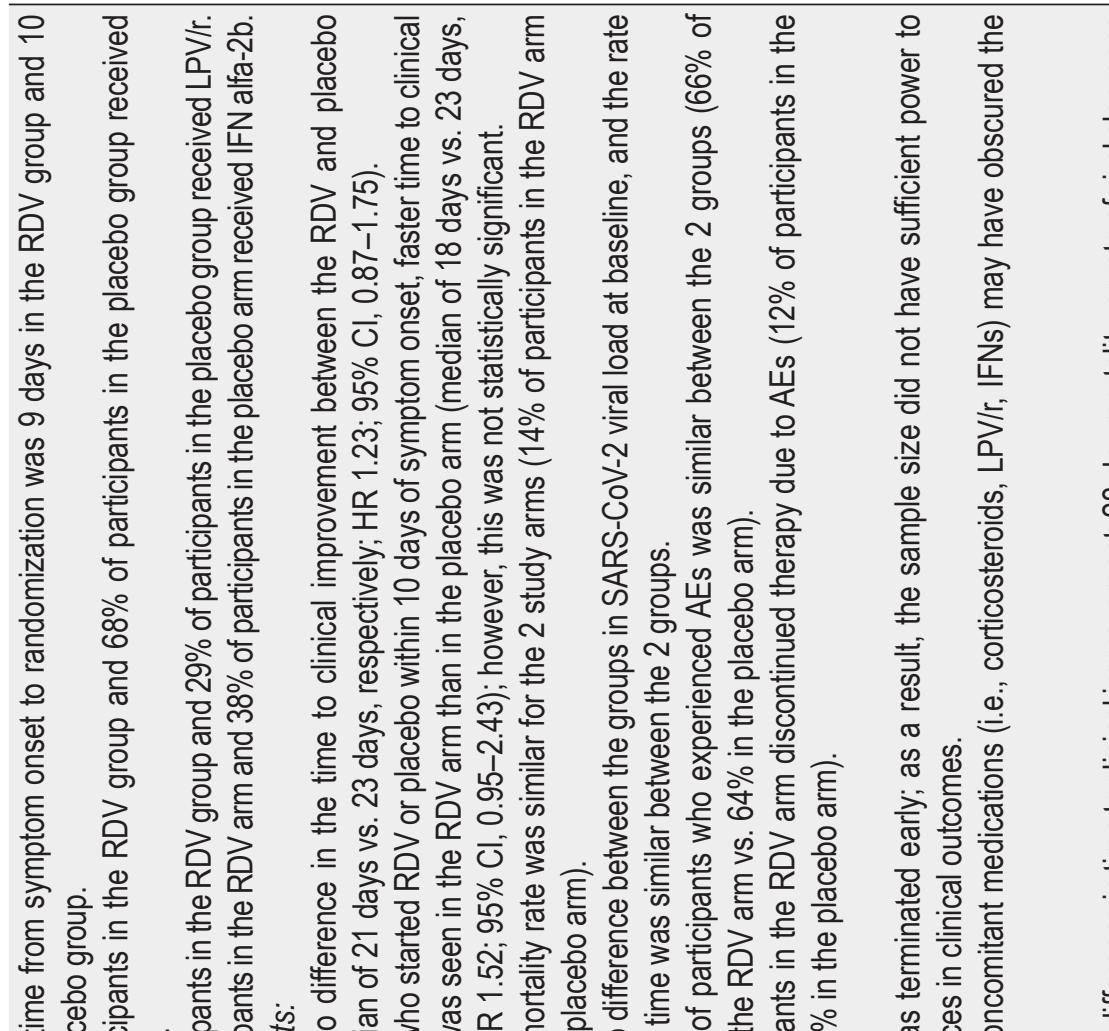

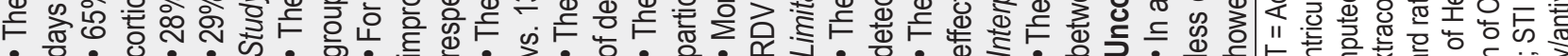

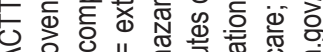

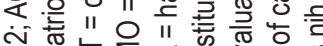

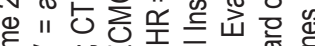

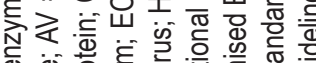
बक

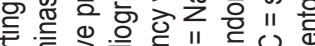

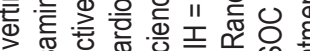

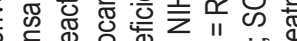

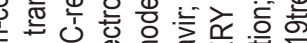
ब 离焉员 "

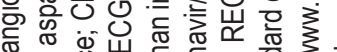
స 눙 覀

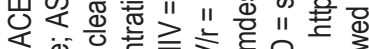
غิ

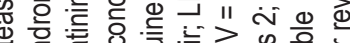

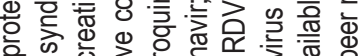

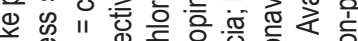
产

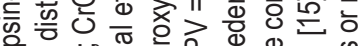

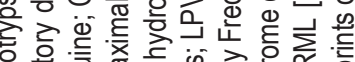

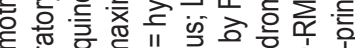

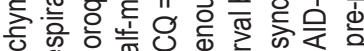

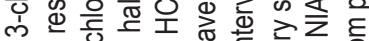
"I

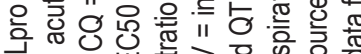
") "

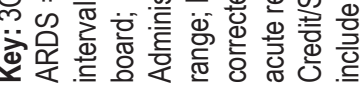


12. Wang QYB, Mao J. The pathogenesis and treatment of the 'Cytokine Storm' in COVID-19. Journal of Infection 2020. https://doi.org/10.1016/j.jinf.2020.03.037.

13. Shimabukuro-Vornhagen A, Gödel P, Subklewe M, Stemmler HJ, Schlößer HA, Schlaak M. Cytokine release syndrome. J ImmunoTherapy Cancer 2018;6(1):56.

14. Shakoory B, Carcillo JA, Chatham WW, Amdur RL, Zhao H, Dinarello CA. Interleukin-1 receptor blockade is associated with reduced mortality in sepsis patients with features of macrophage activation syndrome: reanalysis of a prior phase III trial. Critical Care Med 2016;44(2):275-281.

15. NIAID-RML. COVID-19 Treatment Guidelines Panel. Coronavirus Disease 2019 (COVID-19) Treatment Guidelines. National Institutes of Health. Available at https://www. covid19treatmentguidelines.nih.gov/. Updated July 31, 2020.

16. Chen IY, Moriyama M, Chang MF, Ichinohe T. Severe Acute Respiratory Syndrome Coronavirus Viroporin 3a Activates the NLRP3 Inflammasome. Front Microbiol. 2019;10:50. Published 2019 Jan 29. doi:10.3389/fmicb.2019.00050

17. Nieto-Torres JL, Verdia-Baguena C, Jimenez-Guardeno JM, Regla-Nava J, Castano-Rodriguez C. Severe acute respiratory syndrome coronavirus $\mathrm{E}$ protein transports calcium ions and activates the NLRP3 inflammasome. Virology 2015;485:330 339.

18. P.C. Fragkou, D. Belhadi, N. Peiffer-Smadja, C.D. Moschopoulos, et al. Review of trials currently testing treatment and prevention of COVID-19. Clinical Microbiology and Infection 26 (2020) 988e998.

19. Conti P, Gallenga CE, Tete G, Caraffa A, Ronconi G. How to reduce the likelihood of coronavirus-19 (CoV-19 or SARSCoV-2) infection and lung inflammation mediated by IL-1. Journal of Biological Regulators and Homeostatic Agents 2020;34

20. Wan S, Yi Q, Fan S, Lv J, Zhang X. Characteristics of lymphocyte subsets and cytokines in peripheral blood of 123 hospitalized patients with 2019 novel coronavirus pneumonia (NCP) MedRxiv. 2020;

21. FDA. Kineret ${ }^{\circledR}$ (anakinra) for injection, for subcutaneous use: highlights of prescribing information [online] Website https://www.accessdata.fda.gov/drugsatfda_ docs/ label/2012/103950s5136lbl.pdf. 2001.

22. Haffizulla J, Hartman A, Hoppers M, et al. Effect of nitazoxanide in adults and adolescents with acute uncomplicated influenza: a double-blind, randomised, placebo-controlled, phase $2 \mathrm{~b} / 3$ trial. Lancet Infect Dis 2014; 14:609-18.

23. Navarro-Millán I, et al. Use of Anakinra to Prevent Mechanical Ventilation in Severe COVID-19: A Case Series. Arthritis and Reumatology June 30, 2020. https://doi.org/10.1002/ art.41422.

24. Wu D, Yang XO. TH17 responses in cytokine storm of COVID-19: An emerging target of JAK2 inhibitor Fedratinib. Journal of Microbiology, Immunology, and Infection 2020;10.

25. Blazek K, Eames HL, Weiss M, Byrne AJ, Perocheau D, Pease JE. IFN- $\lambda$ resolves inflammation via suppression of neutrophil infiltration and IL-1 $\beta$ production. J Exper Med 2015;212(6):845-853.

26. Davidson S, McCabe TM, Crotta S, Gad HH, Hessel EM, Beinke S. IFN $\lambda$ is a potent anti-influenza therapeutic without the inflammatory side effects of IFN $\alpha$ treatment. EMBO Molecul Med 2016;8(9):1099-1112.
27. Davidson S, Maini MK, Wack A. Disease-promoting effects of type I interferons in viral, bacterial, and coinfections. J Int Soc Interf Cytokine Res 2015;35(4):252-264.

28. Sallard E, Lescure FX, Yazdanpanah Y, Mentre F, Smadja NP. Type 1 interferons as a potential treatment against COVID-19. Antivir Res 2020;178:104791.

29. Ahsan W, Javed S, Al Bratty M. Treatment of SARS-CoV2:How far have we reached? Drug Discoveries \& Therapeurics 2020; 14 (2):67-72. Doi:10.5582/DDT.2020.03008.

30. Lu H. Drug treatment options for the 2019-new coronavirus (2019-nCoV). Biosci Trends 2020;14:69-71

31. Sheahan TP, Sims AC, Leist SR, et al. Comparative therapeutic efficacy of remdesivir and combination lopinavir, ritonavir, and interferon beta against MERS-CoV. Nat Commun 2020; 11:222.

32. Global Data Healthcare. Inhaled interferon-beta launches into the fight against the COVID-19 pandemic. https:// www.pharmaceutical-technology.com/comment/synairgensng001-COVID-19-trials

33. Mehta P, McAuley DF, Brown M, Sanchez E, Tattersall RS, Manson JJ. HLH Across Speciality Collaboration, UK. COVID-19: consider cytokine storm syndromes and immunosuppression. Lancet 2020;395(10229):1033-1034. Doi:10.1016/S0140-6736(20)30628-0.

34. Zhou F, Yu T, Du R, et al. Clinical course and risk factors for mortality of adult inpatients with COVID-19 in Wuhan, China: a retrospective cohort study. Lancet 2020;395(10229):10541062. Doi:10.1016/S0140-6736(20)30566-3.

35. Uciechowski P, Dempke WCM. Interleukin-6: A Masterplayer in the Cytokine Network. Oncology. 2020;98(3):131-137. doi:10.1159/000505099

36. Qin C, Zhou L, Hu Z, et al. Dysregulation of Immune Response in Patients With Coronavirus 2019 (COVID-19) in Wuhan, China. Clin Infect Dis. 2020;71(15):762-768. Doi:10.1093/cid/ciaa248.

37. Liao Y, Wang X, Huang M, Tam JP, Liu DX. Regulation of the p38 mitogen-activated protein kinase and dual-specificity phosphatase 1 feedback loop modulates the induction of interleukin 6 and 8 in cells infected with coronavirus infectious bronchitis virus. Virology. 2011;420(2):106-116. Doi:10.1016/j.virol.2011.09.003.

38. Zhou Y, et al. Aberrant pathogenic GM-CSF+ T cells and inflammatory CD14+CD16+ monocytes in severe pulmonary syndrome patients of a new coronavirus. BioRxiv. 2020.

39. Wang D, Hu B, Hu C, Zhu F, Liu X. Clinical characteristics of 138 hospitalized patients with 2019 novel coronavirusinfected pneumonia in Wuhan, China. JAMA 2020;10.

40. Channappanavar R, Perlman S. Pathogenic human coronavirus infections: causes and consequences of cytokine storm and immunopathology. Semin Immunopathol. 2017;39(5):529539. doi:10.1007/s00281-017-0629-x.

41. Guan WJ, Ni ZY, Hu Y, Liang WH,Ou CQ. Clinical characteristics of coronavirus disease 2019 in China. The New England Journal of Medicine 2020;10.

42. Mihai C, Dobrota R, Schroder M, Garaiman A, Jordan S. COVID-19 in a patient with systemic sclerosis treated with tocilizumab for SSc-ILD. Annals of the Rheumatic Diseases 2020.

43. Ferro F, Elefante E, Baldini C, Bartoloni E, Puxeddu I. The new challenge for rheumatologists. Clinical and Experimental Rheumatology 2020;19:175-180. 
44. Fu BX, Xiaoling, Wei, Haiming. Why tocilizumab could be an effective treatment for severe COVID-19? J Transl Med. 2020.Chinese Clinical Trial. A multicenter, randomized controlled trial for the efficacy and safety of tocilizumab in the treatment of new coronavirus pneumonia (COVID-19). Chinese Clinical Trial Registry. http://www.chictr.org.cn/ showprojen.aspx?proj=49409.

45. Clinical Trial. Evaluation of the efficacy and safety of sarilumab in hospitalized patients with COVID-19. https:// ClinicalTrials.gov/show/ NCT04315298.

46. Medicine USNLo. ClinicalTrials.gov. US National Library of Medicine. 2020 Mar 31.doi:(https://clinicaltrials.gov/ct2/resu lts? cond $=$ COVID $19 \&$ term $=$ ascorbic + acid $\&$ cntry $=\&$ state $=\&$ city $=\&$ dist $=$.

47. Walmrath D, Schneider T, Pilch J, Grimminger F, Seeger W. Aerosolised prostacyclin in adult respiratory distress syndrome. Lancet (Lond Engl) 1993;342(8877):961-2. https://doi.org/10. 1016/0140-6736(93)92004-d.

48. Tardif JC, Kouz S, Waters DD, Bertrand OF, Diaz R. Efficacy and safety of low-dose colchicine after myocardial infarction. The New England Journal of Medicine 2019;381:2497-2505.

49. Deftereos SG, Siasos G, Giannopoulos G, Vrachatis DA, Angelidis C. The GReek study in the Effects of Colchicine in COVID-19 complications prevention (GRECCO-19 study): rationale and study design. Hellenic Journal of Cardiology 2020;10.

50. Omer Gendelman, et al., Autoimmunity Reviews April 2020. https://doi.org/10.1016/j.autrev.2020.102566.

51. Fragoulis GE, McInnes IB, Siebert S. JAK-inhibitors. New players in the field of immune-mediated diseases, beyond rheumatoid arthritis. Rheumatology 2019;58:i43-i54.

52. Richardson P, Griffin I, Tucker C, Smith D, Oechsle O. Baricitinib as potential treatment for 2019-nCoV acute respiratory disease. Lancet (London, England) 2020;395:e30-e31.

53. Xu Z, Shi L, Wang Y, Zhang J, Huang L, Zhang C. Pathological findings of COVID-19 associated with acute respiratory distress syndrome. Lancet Respirat Med 2020;S2213600(20)30076-X.

54. Leuschner F, Courties G, Dutta P, Mortensen LJ, Gorbatov $\mathrm{R}$, Sena B. Silencing of CCR2 in myocarditis. Eur Heart J 2015;36(23):1478-1488

55. Leuschner F, Dutta P, Gorbatov R, Novobrantseva TI, Donahoe JS, Courties G. Therapeutic siRNA silencing in inflammatory monocytes in mice. Nature Biotechnol 2011;29(11):1005-1010.

56. Qiu P, Cui X, Sun J, Welsh J, Natanson C, Eichacker PQ. Antitumor necrosis factor therapy is associated with improved survival in clinical sepsis trials: a meta-analysis. Critical Care Med 2013;41(10):2419-2429.

57. Udalova I, Monaco C, Nanchahal J, Feldmann M. Anti-TNF Therapy. Microbiol Spect 2016;4(4).

58. McKee DL, Sternberg A, Stange U, Laufer S, Naujokat C, Candidate drugs against SARS-CoV-2 and COVID-19, Pharmacological Research (2020), doi: https://doi. org/10.1016/j.phrs.2020.104859.

59. Bertram S, Heurich A, Lavender H, Gierer S, Danisch S, Perin P, et al. Influenza and SARS-coronavirus activating proteases TMPRSS2 and HAT are expressed at multiple sites in human respiratory and gastrointestinal tracts PLoS One, 2012;7(4):e:35876
60. Yamaya M, Shimotai Y, Hatachi Y, et al., The serine protease inhibitor camostat inhibits influenza virus replication and cytokine production in primary cultures of human tracheal epithelial cells, Pulm. Pharmacol. Ther 2015;33:66-74.

61. Matsuyama S, Nagata N, Shirato K, et al. Efficient activation of the severe acute respiratory syndrome coronavirus spike protein by the transmembrane protease TMPRSS2. J Virol 2010;84(24):12685-12664-I.

62. Glowacka SB, M.A. Müller PA, Soilleux E, Pfefferle S, et al., Evidence that TMPRSS2 activates the severe acute respiratory syndrome coronavirus spike protein for membrane fusion and reduces viral control by the humoral immune response. J Virol 2011;85(9):4122-4134

63. Hoffmann M, Kleine-Weber H, Schroeder S, et al. SARSCoV-2 cell entry depends on ACE2 and TMPRSS2 and is blocked by a clinically proven protease receptor, Cell 2020;(4). https://doi.org/10.1016/j.cell.2020.02.052 pii: S0092-8674(20)30229-4.

64. Kawase M, Shirato K, van der Hoek L, Taguchi F, Matsuyama S. Simultaneous treatment of human bronchial epithelial cells with serine and cysteine protease inhibitors prevents severe acute respiratory syndrome coronavirus entry. J Virol 2012;86(12):6537-6545.

65. Ohkoshi M, Fujji S. Effect of the synthetic protease inhibitor [N,N-dimethylcarbamoyl-methyl 4-(4-guanidinobenzoyloxy)phenylacetate] methanesulfate on carcinogenesis by 3-methylcholanthrene in mouse skin, J Natl Cancer Inst 1983;71(5):1053-1057.

66. Ikeda S, Manabe M, Muramatsu T, Takamori K, Ogawa $\mathrm{H}$, Protease inhibitor therapy for recessive dystrophic epidermolysis bullosa. In vitro effect and clinical trial with camostat mesylate, J Am Acad Dermatol 1988;18(16):12461252.

67. Adler G, MüllenhoffA, Koop I, et al., Stimulation of pancreatic secretion in man by a protease inhibitor (camostate). Eur $\mathrm{J}$ Clin Invest 2020;18(1).

68. Sai JK, Suyama M, Kubokawa Y, et al. Efficacy of camostat mesilate against dyspepsia associated with non-alcoholic mild pancreatic disease, J Gastroenterol 2010;45(3):335-341. 1988 98-104-NCT02693093, ClinicalTrials.gov, (2016), Feb 26.

69. Ramsey ML, Nuttall J, Hart PA. A phase $1 / 2$ trial to evaluate the pharmacokinetics, safety, and efficacy of NI-03 in patients with chronic pancreatitis: study protocol for a randomized controlled trial on the assessment of camostat treatment in chronic pancreatitis (TACTIC). Trials 2019;20(1):501. NCT02693093, ClinicalTrials.gov, (2016), Feb 26.

70. Iwako M, Ino Y, Motoyoshi A, et al., Pharmacological studies of FUT-175, nafamostat mesilate. V. Effects on the pancreatic enzymes and experimental acute pancreatitis in rats, Jpn. J Pharmacol 1986;41(2):155-162.

71. Yamamoto M, Matsuyama S, Li X, Takeda M, Kawaguchi $\mathrm{Y}$, Inoue JI, et al. Identification of nafamostat as a potent inhibitor of middle east respiratory syndrome coronavirus $\mathrm{S}$ protein-mediated membrane fusion using the splitproteinbased cell-cell fusion assay, Antimicrob. Agents Chemother 2016;60(11):6532-6539.

72. Lu X, Zhao J, Li P, Niu B, Wang H, et al. Genomic characterisation and epidemiology of 2019 novel coronavirus: implications for virus origins and receptor binding, Lancet 395 (10224) (2020) 565-574. 
73. Walls AC, Park YJ, Tortorici MA, et al. Structure, function, and antigenicity of the SARS-CoV-2 spike glycoprotein. Cell 2020;(6). https://doi.org/10.1016/j.cell.2020.02.058 pii: S0092-8674(20)30262-2.

74. Hirota M, Shimosegawa T, Kitamura K, Takeda K, et al. Continuous regional arterial infusion versus intravenous administration of the protease inhibitor nafamostat mesilate for predicted severe acute pancreatitis: a multicenter, randomized, open-label, phase 2 trial, J. Gastroenterol. 55 (3) (2020) 342-352.

75. Li W, Moore MJ, Vasilieva N, et al., Angiotensin-converting enzyme 2 is a functional receptor for the SARS coronoavirus. Nature 2003;426(6965):450-454.

76. Song W, Gui M, Wang X, Xiang Y. Cryo-EM structure of the SARS coronavirus spike glycoprotein in complex with its host cell receptor ACE2. PLoS Pathol 2018;14(8):e1007236.

77. Turner AJ, Tipnis SR, Guy JL, et al. ACEH/ACE2 is a novel mammalian metallocarboxypeptidase and a homologue of angiotensin-converting enzyme insensitive to ACE inhibitors. Can J Physiol Pharmacol 2002;80(4):346-353.

78. McCreary, Erin K, and Jason M Pogue. "Coronavirus Disease 2019 Treatment: A Review of Early and Emerging Options." Open forum infectious diseases vol. 7,4 ofaa105. 23 Mar. 2020, doi:10.1093/ofid/ofaa105.

79. Keyaerts E, Vijge L, Maes P, Neyts J, Van Ranst M. In vitro inhibition of severe acute respiratory syndrome coronavirus by chloroquine, Biochem Biophys Res Commun 2004;323(1):264-268.

80. Savarino A, Di Trani L, Donatelli I, Cauda R, Cassone A, New insights into the antiviral effects of chloroquine, Lancet Infect Dis 2006;6(2):67-69.

81. Yan Y, Zou Z, Sun Y, Li X, Xu KF, Wei Y, et al. Antimalaria drug chloroquine is highly effective in treating avian influenza A H5N1 virus infection in an animal model. Cell Res 2013;32(2):300-302.

82. Wang M, Cao R, Zhang L, Yang X, Liu J, Xu M, et al. Remdesivir and chloroquine effectively inhibit the recently emerged novel coronavirus (2019-nCoV) in vitro. Cell Res 2020;30(3):269-271.

83. Gao J, Tian Z, Yang X. Breakthrough: chloroquine phosphate has shown apparent efficacy in treatment of COVID-19 associated pneumonia in clinical studies, Biosci Trends 2020;14(1).

84. Lim H.S., Im J.S., Cho J.Y., Bae K.S., Klein T.A., Yeom J.S., Kim T.S., Choi J.S., Jang I.J., Park J.W. Pharmacokinetics of hydroxychloroquine and its clinical implications in chemoprophylaxis against malaria caused by Plasmodium vivax. Antimicrob. Agents Chemother. 2009;53:1468-1475.

85. Liu J., Cao R., Xu M., Wang X., Zhang H., Hu H., Li Y., Hu Z., Zhong W., Wang M. Hydroxychloroquine, a less toxic derivative of chloroquine, is effective in inhibiting SARSCoV-2 infection in vitro. Cell Discov. 2020;6:16.

86. Savarino A., Boelaert J.R., Cassone A., Majori G., Cauda R. Effects of chloroquine on viral infections: an old drug against today's diseases? Lancet Infect. Dis. 2003;3:722-727.

87. Van den Borne B.E., Dijkmans B.A., de Rooij H.H., le Cessie S., Verweij C.L. Chloroquine and hydroxychloroquine equally affect tumor necrosis factor-alpha, interleukin 6, and interferon-gamma production by peripheral blood mononuclear cells. J. Rheumatol. 1997;24:55-60.
88. Ben-Zvi I, Kivity S, Langevitz P, Shoenfeld Y. Hydroxychloroquine: from malaria to autoimmunity. Clin Rev Allergy Immunol 2012;42(2):145-153.

89. Vincent MJ, Bergeron E, Benjannet S, Erickson BR, Rollin PE, et al. Chloroquine is a potent inhibitor of SARS coronavirus infection and spread. Virol J 2005;2(August 22):69.

90. Al-Bari MAA. Targeting endosomal acidification by chloroquine analogs as a promising strategy for the treatment of emerging viral diseases. Pharmacol Res Perspect 2017;5(1):e00293.

91. Keyaerts E, Vijge L, Maes P, Neyts J, Van Ranst M. In vitro inhibition of severe acute respiratory syndrome coronavirus by chloroquine, Biochem Biophys Res Commun 2004;323(1):264-268.

92. FDA. Coronavirus (COVID-19) Update: FDA Revokes Emergency Use Authorization for Chloroquine and Hydroxychloroquine. Release:June 15, 2020.

93. Bergman SJ. Treatment of Coronavirus Disease 2019 (COVID-19): Investigational Drugs and Other Therapies. Medscape 2020 August 102020.

94. Yao X, Ye F, Zhang M, Cui C, Huang B, Nui P, et al., In vitro antiviral activity and projection of optimized dosing design of hydroxychloroquine for the treatment of severe acute respiratory syndrome coronavirus 2 (SARS-CoV-2), Clin. Infect. Dis. (March 9) (2020), https://doi.org/10.1093/cid/ciaa237 pii: ciaa237.

95. Horby P. Statement of the ChiefInvestigators of the Randomised Evaluation of COVID-19 Rherapy (RECOVERY) Trial on hydroxichloroquine - Recoverytrial.net June 2020.

96. Cavalcanti AB, Zampieri FG, Rosa RG, et al. Hydroxychloroquine with or without azythromycin in mildto-moderate COVID-19. N Engl Med 2020;Jul 23.

97. Ip A, Berry DA, Hensen E. Hydroxychloroquine and tocilizumab therapy in COVID-19 ptients - na observational study medRxiv May 25, 2020.

98. WHO. Solidarity clinical trial for COVID-19 treatments Who 2020;July 4.

99. FDA. Coronavirus (COVID-19) Update: FDA Revokes Emergency Use Authorization for Chloroquine and Hydroxychloroquine. Release:June 15, 2020.

100. Renyi Wu \& Lujing Wang \& Hsiao-Chen Dina Kuo \& Ahmad Shannar \& Rebecca Peter \& Pochung Jordan Chou \& Shanyi Li \& Rasika Hudlikar \& Xia Liu \& Zhigang Liu1,3 \& George J. Poiani \& Louis Amorosa \& Luigi Brunetti \& Ah-Ng Kong. An Update on Current Therapeutic Drugs Treating COVID-19. Current Pharmacology Reports 2020. https://doi.org/10.1007/ s40495-020-00216-7.

101. Wagstaff KM, Rawlinson SM, Hearps AC, Jans DA. An AlphaScreen ${ }^{\circledR}$-based assay for high-throughput screening for specific inhibitors of nuclear import. J Biomol Screen. 2011;16(2):192 - 200. https://doi.org/10.1177/ 1087057110390360 .

102. Wagstaff KM, Sivakumaran H, Heaton SM, Harrich D, Jans DA. Ivermectin is a specific inhibitor of importin $\alpha / \beta$-mediated nuclear import able to inhibit replication of HIV-1 and dengue virus. Biochem J. 2012;443(3):851-6.

103. Yang SNY, Atkinson SC, Wang C, Lee A, Bogoyevitch MA, Borg NA, et al. The broad spectrum antiviral ivermectin targets the host nuclear transport importin alpha/beta1 heterodimer. Antivir Res. 2020;177:104760. https://doi. org/10.1016/j.antiviral.2020.104760 
104. Caly L, Druce JD, Catton MG, Jans DA, Wagstaff KM. The FDAapproved drug ivermectin inhibits the replication of SARS-CoV-2 in vitro. Antivir Res. 2020;104787:104787. https://doi.org/10.1016/j.antiviral.2020.104787.

105. Leon Caly, Julian D. Druce, Mike G. Catton, David A. Jans, Kylie M. Wagstaff. The FDA-approved drug ivermectin inhibits the replication of SARS-CoV-2 in vitro. Antiviral Research 2020;178:104787. https://doi.org/10.1016/j. antiviral.2020.104787.

106. Georgi Momekov, Denitsa Momekova. Ivermectin as a potential COVID-19 treatment from the pharmacokinetic point of view: antiviral levels are not likely attainable with known dosing regimens. medRxiv 2020.04.11.20061804; doi: https://doi.org/10.1101/2020.04.11.20061804.

107. Carlos Chaccour, et al. Ivermectin and COVID-19: Keeping Rigor in Times of Urgency. Am. J. Trop. Med. Hyg., 102(6), 2020, pp. 1156-1157 doi:10.4269/ajtmh.20-0271.

108. Juliana Cepelowicz Rajter, Michael Sherman, Naaz Fatteh, Fabio Vogel, Jamie Sacks, Jean-Jacques Rajter. ICON (Ivermectin in COvid Nineteen) study: Use of Ivermectin is Associated with Lower Mortality in Hospitalized Patients with COVID19. medRxiv preprint doi: https://doi.org/10.110 1/2020.06.06.20124461.

109. Bailly C. Cepharanthine: An update of its mode of action, pharmacological properties and medical applications. Phytomedicine 2019;62(September):152956. https://doi. org/10.1016/j.phymed.2019.152956.

110. Tickell-Painter M, Maayan N, Saunders R, Pace C, Sinclair D. Mefloquine for preventing malaria during travel to endemic áreas. Cochrane Database Syst Rev 2017;10 (October 30). https://doi.org/10.1002/14651858.CD006491. pub4 CD006491.

111. Fan HH, Wang LQ, Liu WL, Na XP, et al., Repurposing of clinically approved drugs for treatment of coronavirus disease 2019 in a 2019novel coronavirus (2019-nCoV) related coronavirus model. Chin Med J 2020;(March 6). https://doi. org/10.1097/CM9.0000000000000797.

112. Jiang S, Hillyer C, Du L. Neutralizing Antibodies against SARS-CoV-2 and Other Human Coronaviruses. Trends in Immunology, May 2020, Vol. 41, No. 5 https://doi. org/10.1016/j.it.2020.03.007.

113. Zhou, P. et al. (2020) A pneumonia outbreak associated with a new coronavirus of probable bat origin. Nature 579, 270-273.

114. Tian, X. et al. Potent binding of 2019 novel coronavirus spike protein by a SARS coronavirus-specific human monoclonal antibody. Emerg Microbes Infect 2020;9:382-385.

115. Tai W, et al. Characterization of the receptor-binding domain (RBD) of 2019 novel coronavirus: implication for development of RBD protein as a viral attachment inhibitor and vaccine. Cell. Mol. Immunol. Published online March 19, 2020. https://doi.org/10.1038/s41423-020-0400-4.

116. Kumar S, et AL. Repurposing antiviral protease inhibitors using extracellular vesicles for potential therapy of COVID-19. Viruses 2020;12:486. Doi:10.3390/v12050486

117. Shen C, Wang Z, Zhao F, Yang Y, et al. Treatment of 5 critically ill patients with COVID-19 with convalescent plasma. JAMA 2020. Doi: 10.1001/jama.2020.4783.

118. Chen L, Xiong J, Bao L, Shi Y. Convalescent plasma as a potential therapy for COVID-19. Lancet Infect Dis 2020;20:398-400. Doi: 10.1016/S1473-3099(20)30141-9.
119. Piechotta V, Chai KL, Valk SJ, Doree C, Monsef I, Wood EM, Lamikanra A, Kimber C, McQuilten Z, So-Osman C, Estcourt LJ, Skoetz N. Convalescent plasma or hyperimmune immunoglobulin for people with COVID-19: a living systematic review. Cochrane Database of Systematic Reviews 2020, Issue 7. Art. No.: CD013600. DOI: 10.1002/14651858. CD013600.pub2.

120. Mengyao S, et al. A potentially effective treatment for COVID-19: A systematic review and meta-analysis of convalescent plasma therapy in treating severe infectious disease. International Journal of Infectious Diseases 98 (2020) 334-346

121. Li L, Zhang W, Hu Y, et al. Effect of convalescente plasma therapy on time to clinical improvement in patients with severe and life-threatening COVID-19: a randomized clinical trial. JAMA 2020: june 3.

122. Liu STD, et al. Convalescent plasma treatment of severe COVID-19: a matched control study. medRxiv 2020; May 22.

123. Alwisa R, Chena S, Gana ES, Ooia EE. Impact of immune enhancement on COVID-19 polyclonal hyperimmune globulin therapy and vaccine development. EBioMedicine 2020;55:102-768. Doi: 10.1016/j.ebiom.2020.102768.

124. Liu L, Wei Q, Lin Q, et al. Anti-spike IgG causes severe acute lung injury by skewing macrophage responses during acute SARS-CoV infection. JCI Insight 2019;4(4).

125. Kasturi SP, Skountzou I, Albrecht RA, et al. Programming the magnitude and persistence of antibody responses with innate immunity. Nature 2011;470 (7335):543-7.

126. Querec TD, Pulendran B. Understanding the role of innate immunity in the mechanism of action of the live attenuated Yellow Fever Vaccine 17D. Adv Exp Med Biol 2007;590:4353.

127. Querec TD, Akondy RS, Lee EK, et al. Systems biology approach predicts immunogenicity of the yellow fever vaccine in humans. Nat Immunol 2009;10(1):116-25.

128. Chan KR, Wang X, Saron WA, et al. Cross-reactive antibodies enhance live attenuated virus infection for increased immunogenicity. Nat Microbiol 2016:16164.

129. Duong V, Lambrechts L, Paul RE, et al. Asymptomatic humans transmit dengue virus to mosquitoes. Proc Natl Acad Sci U S A 2015;112(47):14688-93.

130. Rauh LW, Schmidt R. Measles immunization with killed virus vaccine. Serum antibody titers and experience with exposure to measles epidemic. Am J Dis Child 1965;109:232-7.

131. Nimmerjahn F, Ravetch JV. The antiinflammatory activity of IgG: the intravenous IgG paradox. J Exp Med 2007;204(1):115 .

132. Srivastava R, Ramakrishna C, Cantin E. Anti-inflammatory activity of intravenous immunoglobulins protects against West Nile virus encephalitis. J Gen Virol 2015;96(Pt 6):134757.

133. Dhodapkar KM, Banerjee D, Connolly J, et al. Selective blockade of the inhibitory Fcgamma receptor (FcgammaRIIB) in human dendritic cells and monocytes induces a type I interferon response program. J Exp Med 2007;204(6):135969 ,

134. Chan KR, Zhang SL, Tan HC, et al. Ligation of Fe gamma receptor IIB inhibits antibody-dependent enhancement of dengue virus infection. Proc Natl Acad Sci USA 2011;108(30):12479-84. 
135. Nagelkerke SQ, Kuijpers TW. Immunomodulation by IVIg and the role of Fcgamma receptors: classic mechanisms of action after all. Front Immunol 2014;5:674.

136. Nagelkerke SQ, Dekkers G, Kustiawan I, et al. Inhibition of FcgR-mediated phagocytosis by IVIg is independent of IgGFc sialylation and FcgRIIB in human macrophages. Blood 2014;124(25):3709-18

137. Galeotti C, Kaveri SV, Bayry J. IVIG-mediated effector functions in autoimmune and inflammatory diseases. Int Immunol 2017;29(11):491-8.

138. Russell CD Millar JE Baillie JK Clinical evidence does not support corticosteroid treatment for 2019-nCoV lung injury. Lancet. 2020;395:473-475.

139. Arabi YM Fowler R Hayden FG Critical care management of adults with community-acquired severe respiratory viral infection. Intensive Care Medicine. 2020;46:315-328.

140. Peiris JS Chu CM Cheng VC Chan KS Hung IF Clinical progression and viral load in a community outbreak of coronavirus-associated SARS pneumonia: a prospective study. Lancet (London, England) 2003;361:1767-1772.

141. Zha L Li S Pan L Tefsen B Li Y Corticosteroid treatment of patients with coronavirus disease 2019 (COVID-19) The Medical Journal of Australia. 2020;10.

142. Lu X Chen T Wang Y Wang J Zhang B Adjuvant corticosteroid therapy for critically ill patients with COVID-19. 2020;10.

143. Xu K Chen Y Yuan J Yi P Ding C Factors associated with prolonged viral RNA shedding in patients with COVID-19. Clinical Infectious Diseases: an official publication of the Infectious Diseases Society of America. 2020;10.

144. Zhou W Liu Y Tian D Wang C Wang S Potential benefits of precise corticosteroids therapy for severe 2019-nCoV pneumonia. Signal Transduction and Targeted Therapy. 2020;5:18-18.

145. Villar J, Belda J, Anon JM, Blanco J, Perez-Mendez L, Ferrando C, et al. Evaluating the efficacy of dexamethasone in the treatment of patients with persistent acute respiratory distress syndrome: study protocol for a randomized controlled trial. Trials. 2016;17:342. https://doi.org/10.1186/s13063016-1456-4.

146. Lamontagne F, Rochwerg B, Lytvyn L, Guyatt GH, Møller $\mathrm{MH}$, Annane D, et al. Corticosteroid therapy for sepsis: a clinical practice guideline. BMJ. 2018;362:k3284. https://doi. org/10.1136/bmj.k3284.

147. Wu C, Chen X, Cai Y, Xia J, Zhou X, Xu S, et al. Risk factors associated with acute respiratory distress syndrome and death in patients with coronavirus disease 2019 pneumonia in Wuhan, China. JAMA Intern Med. 2020. https://doi. org/10.1001/jamainternmed.2020.0994.

148. Wang Y, Jiang W, He Q, Wang C, Wang B, Zhou P et al. Early, low-dose and short-term application of corticosteroid treatment in patients with severe COVID-19 pneumonia: single-center experience from Wuhan, China. medRxiv. 2020:2020.03.06.20032342. https://doi.org/10.1101/2020.03 .06 .20032342 .

149. Shang L, Zhao J, Hu Y, Du R, Cao B. On the use of corticosteroids for 2019-nCoV pneumonia. Lancet. 2020;395(10225):683-4. https://doi.org/10.1016/S01406736(20)30361-5.

150. JF. Internet Book of Critical Care. From EMCrit Project website. 2020 Apr 7. doi:https://emcrit.org/ibcc/COVID19.
151. Bhimraj A, Morgan RL, Shumaker AH, Lavergne V, Baden L, Cheng VC-C, et al. Infectious Diseases Society of America guidelines on the treatment and management of patients with COVID-19. Infect Dis Soc Am. 2020.

152. Alhazzani W, Møller MH, Arabi YM, Loeb M, Gong MN, Fan E, et al. Surviving Sepsis campaign: guidelines on the management of critically ill adults with coronavirus disease 2019 (COVID-19). Intensive Care Med. 2020. https://doi.org/10.1007/s00134-02006022-5.

153. Villar J, Ferrando C, Martinez D, Ambros A, Munoz T, Soler JA, et al. Dexamethasone treatment for the acute respiratory distress syndrome: a multicentre, randomised controlled trial. Lancet Respir Med. 2020;8(3):267-76. https://doi.org/10.1016/S22132600(19)30417-5.

154. Group RC, Horby P, Lim WS, et al. Dexamethasone in hospitalized patients with COVID-19-preliminar report. N Engl J Med. 2020. Available at: https://www.ncbi.nlm.nih.gov/ pubmed $/ 32678530$

155. Sodhi M, Etminan M. Safety of Ibuprofen in Patients with COVID-19: causal or confounded? Chest 2020. doi: 10.1016/j. chest.2020.03.040.

156. Amici C, Di Caro A, Ciucci A, Chiappa L, Castilletti C et al. Indomethacin has a potent antiviral activity against SARS coronavirus. Antiviral Therapy 2006; 11 (8): 1021-1030

157. Behnood Bikdeli, Mahesh V. Madhavan, David Jimenez, et al. COVID-19 and Thrombotic or Thromboembolic Disease: Implications for Prevention, Antithrombotic Therapy, and Follow-Up. JACC State-of-the-Art Review. DOI: 10.1016/j. jacc.2020.04.031.

158. Thygesen K, Alpert JS, Jaffe AS, et al. Fourth Universal Definition of Myocardial Infarction. J Am Coll Cardiol 2018;72:2231-64.

159. Amsterdam EA, Wenger NK, Brindis RG, et al. 2014 AHA/ACC guideline for the management of patients with non-ST-elevation acute coronary syndromes: executive summary: a report of the American College of Cardiology/American Heart Association Task Force on Practice Guidelines. Circulation 2014;130:2354 94.

160. Roffi M, Patrono C, Collet JP, et al. 2015 ESC guidelines for the management of acute coronary syndromes in patients presenting without persistent ST-segment elevation: Task Force for the Management of Acute Coronary Syndromes in Patients Presenting without Persistent STSegment Elevation of the European Society of Cardiology (ESC). Eur Heart J 2016;37:267-315.

161. Uyeki TM, Bernstein HH, Bradley JS, et al. Clinical practice guidelines by the Infectious Diseases Society of America: 2018 update on diagnosis, treatment, chemoprophylaxis, and institutional outbreak management of seasonal influenza. Clin Infect 2018.

162. Wu R, Wang L, Kuo HSD, et al. An Update on Current Therapeutic Drugs Treating COVID-19. Current Pharmacology Reports 2020, https://doi.org/10.1007/s40495-020-00216-7.

163. Peters DH, Friedel HA, McTavish D. Azithromycin. A review of its antimicrobial activity, pharmacokinetic properties and clinical efficacy. Drugs. 1992;44(5):750-99. https://doi. org/10.2165/00003495-199244050-00007.

164. Retallack H, Di Lullo E, Arias C, Knopp KA, Laurie MT, Sandoval-Espinosa C, et al. Zika virus cell tropism in the developing human brain and inhibition by azithromycin. Proc Natl Acad Sci U S A. 2016;113(50):14408-13. https://doi. org/10.1073/pnas.1618029113. 
165. Madrid PB, Panchal RG, Warren TK, Shurtleff AC, Endsley AN, Green CE, et al. Evaluation of Ebola virus inhibitors for drug repurposing. ACS Infect Dis. 2015;1(7):317-26. https://doi.org/10.1021/acsinfecdis.5b00030.

166. Gautret P, Lagier JC, Parola P, Hoang VT, Meddeb L, Mailhe $\mathrm{M}$, et al. Hydroxychloroquine and azithromycin as a treatment of COVID-19: results of an open-label non-randomized clinical trial. Int J Antimicrob Agents. 2020;105949:105949. https://doi.org/10.1016/j.ijantimicag.2020.105949.

167. Ishaqui AA, Khan AH, Sulaiman SAS, Alsultan MT, Khan I, Naqvi AA. Assessment of efficacy of oseltamivirazithromycin combination therapy in prevention of influenza-A (H1N1)pdm09 infection complications and rapidity of symptoms relief. Expert Rev Respir Med. 2020:1-9. https://doi.org/10.1080/17476348.2020.1730180

168. Molina JM, Delaugerre C, Le Goff J, Mela-Lima B, Ponscarme D, Goldwirt L, et al. No evidence of rapid antiviral clearance or clinical benefit with the combination of hydroxychloroquine and azithromycin in patients with severe COVID-19 infection. Med Mal Infect. 2020. https:// doi.org/10.1016/j.medmal.2020.03.006.

169. Razonable, R.R., 2011. Antiviral drugs for viruses other than human immunodeficiencyvirus. Mayo Clin. Proc. 86, 1009 1026.https://doi.org/10.4065/mcp.2011.0309.

170. De Clercq, E., 2007. Three decades of antiviral drugs. Nat. Rev. Drug Discov. 6, 941.https://doi.org/10.1038/nrd2485.

171. Elfiky AA. Anti-HCV, nucleotide inhibitors, repurposing against COVID-19. Life Sci 2020; 248:117477.

172. Cheema, S.U.R., Rehman, M.S., Hussain, G., Cheema, S.S., Gilani, N., 2019. Efficacy and tol-erability of sofosbuvir and daclatasvir for treatment of hepatitis $\mathrm{C}$ genotype 1 \& 3 inpatients undergoing hemodialysis-a prospective interventional clinical trial. BMCNephrol. 20, 438.https:// doi.org/10.1186/s12882-019-1631-4.

173. Williamson BN, Feldmann F, Schwarz B, et al. Clinical benefit of remdesivir in rhesus macaques infected with SARS-CoV-2. Nature. 2020; Published online ahead of print. Available at: https://www.ncbi.nlm.nih.gov/ pubmed/32516797.

174. FDA. Coronavirus (COVID-19) Update: FDA issues emergency use authorization for potential COVID-19 treatment. May 2020. www.fda.gov.

175. FDA. Fact sheet for health care providers emergency use authorization (EUA) of Remdesivir (GS-5734TM). June 15, 2020. www.fda.gov.

176. O’Day D. An open letter. Gilead Sciences. June 2020.

177. Mulangu S, Dodd LE, Davey RT, et al. A randomized controlled trial of Ebola virus disease therapeutics. N Engl J Med 2019;381(24):2293-2303.

178. Martinez A. Compounds with therapeutic potential against novel respiratory 2019 coronavirus. Antimicrob Agents Chemother 2020.

179. Beigel JH, Tomashek KM, Dodd LE, et al. Remdesivir for the treatment of COVID-19-preliminary report. N Engl J Med. 2020. Available at: https://www.ncbi.nlm.nih.gov/ pubmed/32445440

180. Wang Y, Zhang D, Du G, et al. Remdesivir in adults with severe COVID-19: a randomised, double-blind, placebo-controlled, multicentre trial. Lancet. 2020;395(10236):1569-1578. Available at: https://pubmed.ncbi.nlm.nih.gov/32423584/.
181. Olender, et al. Remdesivir for severe COVID-19 versus a cohort receiving standard of care. Clin Infect Dis 2020; Jul 24.

182. Goldman JD, Lye DCB, Hui DS, et al. Remdesivir for 5 or 10 days in patients with severe COVID-19. N Engl J Med. 2020; Published online ahead of print. Available at: https:// www.ncbi.nlm.nih.gov/pubmed/32459919.

183. Gilead Sciences. Remdesivir (GS-5734) investigator's brochure. Edition 5. February 21, 2020.

184. Grein J, Ohmagari N, Shin D, et al. Compassionate use of remdesivir for patients with severe COVID-19. N Engl J Med. 2020;382(24):2327-2336. Available at: https://www. ncbi.nlm.nih.gov/pubmed/32275812.

185. Delang L, Abdelnabi R, Neyts J. Favipiravir as a potential countermeasure against neglected and emerging RNA viruses. Antivir Res. 2018; 153:85-94.

186. Cai Q, Yang M, Liu D. Experimental treatment with favipiravir for COVID-19: An open-label control study. Engineering. 2020.

187. Sandoiu A. Is the anti-flu drug Avigan effective in treating COVID-19? https://www.medicalnewstoday.com/articles/ anti-flu-drug-effective-in-treating-COVID-19.

188. Chen C, Zhang Y, Huang J, Yin P, Cheng Z, Wu J, Chen S, Zhang Y, Chen B, Lu M, Luo Y, Ju L, Zhang J, Wang X. Favipiravir versus arbidol for COVID-19: A randomized clinical trial. medRxiv. 2020.

189. Timothy P. Sheahan, Amy C. Sims, Shuntai Zhou, et al. An orally bioavailable broad-spectrum antiviral inhibits SARSCoV-2 in human airway epithelial cell cultures and multiple coronaviruses in mice. Science Translational Medicine 29 Apr 2020:Vol. 12, Issue 541, eabb5883. Doi: 10.1126/ scitranslmed.abb5883.

190. News: arbidol and darunavir can effectively inhibitcoronavirus. http://www.sd.chinanews.com/2/2020/0205/70145.html.

191. ClinicalTrials.gov, Bethesda (MD): National Library of Medicine (US). 2020 Mar.

192. ClinicalTrials.gov, Bethesda (MD): National Library of Medicine (US). 2020 Mar 12 - Identifier NCT04255017, A prospective, randomized controlled clinical study of antiviral therapy in the 2019-nCoV pneumonia. https://www. clinicaltrials.gov/ct2/show/NCT04255017.

193. ClinicalTrials.gov, Bethesda (MD): National Library of Medicine (US). 2020 Mar.

194. Treatment of SARS-CoV-2: How far have we reached? Waquar Ahsan1, Shamama Javed, Mohammed Al Bratty, Hassan A. Alhazmi1, Asim Najmi1 Drug Discoveries \& Therapeutics. 2020; 14(2):67-72. DOI: 10.5582/ddt.2020.03008.

195. Tan EL, Ooi EE, Lin CY, et al. Inhibition of SARS coronavirus infection in vitro with clinically approved antiviral drugs. Emerg Infect Dis 2004; 10:581-6.

196. McCreary EK, Pogue JM. Coronavirus disease 2019 treatment: a review of early and emerging options. Open forum infectious diseases 2020;7(4):ofaa105. 23 Mar. 2020. Doi:10.1093/ofid/ofaa105.

197. Rossignol JF. Nitazoxanide, a new drug candidate for the treatment of Middle East respiratory syndrome coronavirus. J Infect Public Health 2016; 9:227-30.

198. Haffizulla J,HartmanA,Hoppers M, etal.Effect of nitazoxanide in adults and adolescents with acute uncomplicated influenza: a double-blind, randomised, placebo-controlled, phase $2 \mathrm{~b} / 3$ trial. Lancet Infect Dis 2014;14:609-18. 
199. Gamiño-Arroyo AE, Guerrero ML, McCarthy S, et al. Efficacy and safety of nitazoxanide in addition to standard of care for the treatment of severe acute respiratory illness. Clin Infect Dis 2019; 69:1903-11.

200. Barragan P., Podzamczer D. Lopinavir/ritonavir: a protease inhibitor for HIV-1 treatment. Expert Opin. Pharmacother. 2008;9:2363-2375.

201. Chu C.M., Cheng V.C., Hung I.F., Wong M.M., Chan K.H., Chan K.S., Kao R.Y., Poon L.L., Wong C.L., Guan Y., Peiris J.S., Yuen K.Y. Role of lopinavir/ritonavir in the treatment of SARS: initial virological and clinical findings. Thorax. 2004;59:252-256.

202. Chu C.M., Cheng V.C., Hung I.F., Wong M.M., Chan K.H., Chan K.S., Kao R.Y., Poon L.L., Wong C.L., Guan Y., Peiris J.S., Yuen K.Y. Role of lopinavir/ritonavir in the treatment of SARS: initial virological and clinical findings. Thorax. 2004;59:252-256.

203. Kim U.J., Won E.J., Kee S.J., Jung S.I., Jang H.C. Combination therapy with lopinavir/ritonavir, ribavirin and interferon- $\alpha$ for middle east respiratory syndrome. Antivir. Ther. 2016;21:455-459. [PubMed] [Google Scholar]

204. Cao B., Wang Y., Wen D., Liu W., Wang J., Fan G., Ruan L., Song B., Cai Y., Wei M., Li X., Xia J. et. al. A trial of lopinavirritonavir in adults hospitalized with severe COVID-19. N. Engl. J. Med. 2020 doi: 10.1056/NEJMoa2001282.

205. Deng L., Li C., Zeng Q., Liu X., Li X., Zhang H., Hong Z., Xia J. Arbidol combined with LPV/r versus LPV/r alone against Corona Virus Disease 2019: A retrospective cohort study. J. Infect. 2020 doi: 10.1016/j.jinf.2020.03.002. [PMC free article] [PubMed] [CrossRef] [Google Scholar].

206. Johnson and Johnson. https://www.jnj.com/lack-of-evidenceto-support-darunavir-based-hiv-treatments-forcoronavirus.

207. ClinicalTrials.gov, Bethesda (MD): National Library of Medicine (US). 2020 Mar 12 - Identifier NCT04252274. Efficacy and safety of darunavir and cobicistat for treatment of pneumonia caused by 2019-nCoV (DACOnCoV). https:// clinicaltrials.gov/ct2/show/NCT04252274]

208. Xu Z, Peng C, Shi Y, et al. Nelfinavir was predicted to be a potential inhibitor of 2019-nCov main protease by an integrative approach combining homology modelling, molecular docking and binding free energy calculation. 2010; DOI: 10.1101/2020.01.27.921627.

209. Ye Q, Wang B, Mao J. The pathogenesis and treatment of the 'Cytokine Storm' in COVID- 19, Journal of Infection 2020. https://doi.org/10.1016/j.jinf.2020.03.037.

210. Uccelli A, de Rosbo NK. The immunomodulatory function of mesenchymal stem cells: mode of action and pathways. Ann NY Acad Sci 2015;1351(1):114-126.

211. Ben-Mordechai T, Palevski D, Glucksam-Galnoy Y, ElronGross I, Margalit R, Leor J. Targeting macrophage subsets for infarct repair. J Cardiovascular Pharmacol Therapeut 2014;20(1):36-51. 2015/01/01.

212. Lee JW, Fang X, Krasnodembskaya A, Howard JP, Matthay MA. Concise review: Mesenchymal stem cells for acute lung injury: role of paracrine soluble factors. Stem Cells 2011;29(6):913-919.

213. Chen C, Qi F, Shi K, Li Y, Li J, Chen Y, Pan J, Zhou T, Lin X, Zhang J. Thalidomide combined with low-dose glucocorticoid in the treatment of COVID-19 pneumonia. Preprints 2020.
214. Wang Q, Guo H, Li Y, et al. Efficacy and safety of leflunomide for refractory COVID-19: an open-label controlled study. Doi: https://doi.org/10.1101/2020.05.29.20114223.

215. Raj VS, Mou H, Smits SL, et al. Dipeptidyl peptidase 4 is a functional receptor for the emerging human coronavirusEMC. Nature 2013;495:251-254.

216. Qing E, Hantak M, Perlman S, Gallagher T. Distinct roles for sialoside and protein receptors in coronavirus infection. mBio 2020, 11, e02764-19.

217. Li W, Hulswit RJG, Kenney SP, et al. Broad receptor engagement of an emerging global coronavirus may potentiate its diverse cross-species transmissibility. Proc Natl Acad. Sci. USA 2018;115:E5135-E5143.

218. Haraguchi N, Ishii H, Mimori K, Tanaka F, et al. CD13 is a therapeutic target in human liver cancer stem cells. J Clin Invest 2010;120:3326-3339.

219. Toshiyama R, Konno M, Eguchi H, et al. Poly(ethylene glycol)-poly(lysine) block copolymer-ubenimex conjugate targets aminopeptidase $\mathrm{N}$ and exerts an antitumor effect in hepatocellular carcinoma stem cells. Oncogene 2019;38: 244-260.

220. H W, B L, Y T, P C, L Y, B H, et al. Improvement of sepsis prognosis by Ulinastatin: a systematic review and metaanalysis of randomized controlled trials. Frontiers Pharmacol 2019;10:1370 PubMed PMID: 31849646

221. M J, H H, S C, Y L, Y L, S P, et al. Ulinastatin ameliorates LPS-induced pulmonary inflammation and injury by blocking the MAPK/NF- $\kappa$ B signaling pathways in rats. Molecul Med Rep 2019;20(4):3347-54 PubMed PMID: 31432172.

222. Seto B. Rapamycin and mTOR: a serendipitous discovery and implications for breast cancer. Clin Transl Med. 2012;1(1):29. https://doi.org/10.1186/2001-1326-1-29.

223. Kindrachuk J, Ork B, Hart BJ, Mazur S, Holbrook MR, Frieman MB, et al. Antiviral potential of ERK/MAPK and $\mathrm{PI} 3 \mathrm{~K} / \mathrm{AKT} / \mathrm{mTOR}$ signaling modulation for Middle East respiratory syndrome coronavirus infection as identified by temporal kinome analysis. Antimicrob Agents Chemother. 2015;59(2):1088-99. https://doi.org/10.1128/AAC.0365914

224. Sirolimus treatment in hospitalized patients with COVID-19 pneumonia. https://ClinicalTrials.gov/show/NCT04341675.

225. Wang CH, Chung FT, Lin SM, Huang SY, Chou CL, Lee $\mathrm{KY}$, et al. Adjuvant treatment with a mammalian target of rapamycin inhibitor, sirolimus, and steroids improves outcomes in patients with severe H1N1 pneumonia and acute respiratory failure. Crit Care Med. 2014;42(2):313-21. https://doi.org/10.1097/CCM. 0b013e3182a2727d.

226. Jia X, Liu B, Bao L, Lv Q, Li F, Li H, et al. Delayed oseltamivir plus sirolimus treatment attenuates H1N1 virus-induced severe lung injury correlated with repressed NLRP3 inflammasome activation and inflammatory cell infiltration. PLoS Pathog. 2018;14(11):e1007428. https:// doi.org/10.1371/journal.ppat. 1007428.

227. Adjunctive sirolimus and oseltamivir versus oseltamivir alone for treatment of influenza. https:/ClinicalTrials.gov/ show/NCT03901001.

228. Zhou Y, Hou Y, Shen J, Huang Y, Martin W, Cheng F. Networkbased drug repurposing for novel coronavirus 2019nCoV/SARS-CoV-2. Cell Discov. 2020;6:14. https://doi. org/10.1038/s41421-020-0153-3. 
229. Maceyka M., Harikumar K.B., Milstien S., Spiegel S. Sphingosine-1-phosphate signaling and its role in disease. Trends Cell Biol. 2012;22(1):50-60. PubMed PMID: 22001186. Epub 2011/10/14. Eng.

230. Walsh K.B., Teijaro J.R., Rosen H., Oldstone M.B.A. Quelling the storm: utilization of sphingosine-1-phosphate receptor signaling to ameliorate influenza virus-induced cytokine storm. Immunol Res. 2011;51(1):15. 2011/09/08.

231. Teijaro J.R., Walsh K.B., Cahalan S., Fremgen D.M., Roberts E., Scott F. Endothelial cells are central orchestrators of cytokine amplification during influenza virus infection. Cell. 2011;146(6):980-991. PubMed PMID: 21925319. Eng

232. Walsh K.B., Teijaro J.R., Wilker P.R., JatzekA., Fremgen D.M., Das S.C. Suppression of cytokine storm with a sphingosine analog provides protection against pathogenic influenza virus. Proc Natl Acad Sci USA. 2011;108(29):12018-12023. PubMed PMID: 21715659. Epub 2011/06/29. eng

233. Imai Y, Kuba K, Neely GG, Yaghubian-Malhami R, Perkmann T, van Loo G. Identification of oxidative stress and Toll-like receptor 4 signaling as a key pathway of acute lung injury. Cell 2008;133(2):235-249. PubMed PMID: 18423196. Eng.

234. Shirey KA, Perkins DJ, Lai W, Zhang W, Fernando LR, Gusovsky F. Influenza "Trains" the host for enhanced susceptibility to secondary bacterial infection. mBio 2019;10(3):e00810-e00819. PubMed PMID: 31064834. Eng.

235. Russell B, Moss C, George G, Santaolalla A, Cope A. Associations between immune-suppressive and stimulating drugs and novel COVID-19-a systematic review of current evidence. Ecancermedicalscience 2020;14:1022-1022.

236. Al Ghamdi M, Alghamdi KM, Ghandoora Y, Alzahrani A, Salah F. Treatment outcomes for patients with Middle Eastern respiratory syndrome coronavirus (MERS-CoV) infection at a coronavirus referral center in the Kingdom of Saudi Arabia. BMC Infectious Diseases 2016;16:174-174.

237. Schönbeck U, Lilly P. Inflammation, immunity and HMGCoA reductase inhibitors: statins as antiinflammatory agentes? Circulation 2004:109:II18-26.

238. Virani SS. Is there a role for statin therapy in acute viral infections? Cardiology Magazine - American College of Cardiology 2020; March 18.

239. Carr AC, Maggini S. Vitamin C and immune function. Nutrients. 2017;9(11). https://doi.org/10.3390/nu9111211.

240. Kim Y, Kim H, Bae S, Choi J, Lim SY, Lee N, et al. Vitamin $\mathrm{C}$ is an essential factor on the anti-viral immune responses through the production of interferon-alpha/beta at the initial stage of influenza A virus (H3N2) infection. Immune Netw. 2013;13(2):70-4. https://doi.org/10.4110/in.2013.13.2.70.

241. van Gorkom GNY, Klein Wolterink RGJ, Van Elssen C, Wieten L, Germeraad WTV, Bos GMJ. Influence of Vitamin $\mathrm{C}$ on lymphocytes: an overview. Antioxidants (Basel). 2018;7(3). https://doi.org/10.3390/antiox7030041.

242. Medicine USNLo. ClinicalTrials.gov. US National Library of Medicine. 2020 Mar 31.doi:(https://clinicaltrials.gov/ct2/resu lts? cond $=$ COVID $19 \&$ term $=$ ascorbic + acid \& cntry $=\&$ state $=\&$ city $=\&$ dist $=$.

243. Cheng R. Can early and high intravenous dose of vitamin C prevent and treat coronavirus disease 2019 (COVID-19)? Med Drug Discov. 2020;100028. https://doi.org/10.1016/j. medidd.2020.100028.
244. Cheng R. Can early and high intravenous dose of vitamin C prevent and treat coronavirus disease 2019 (COVID-19)? Med Drug Discov. 2020;100028. https://doi.org/10.1016/j. medidd.2020.100028, Institute NC. High-dose vitamin C (PDQ ${ }^{\circledR)}$-Health professional version. National Cancer Institute. 2020 Feb 9. doi:https://www.cancer.gov/aboutcancer/treatment/cam/hp/vitamin-c-pdq.

245. Alessandri F, Pugliese F, Ranieri VM. The role of rescue therapies in the treatment of severe ARDS. Respir Care. 2018;63(1):92-101. https://doi.org/10.4187/respcare.05752.

246. Khan TA, Schnickel G, Ross D, Bastani S, Laks H, Esmailian F, et al. A prospective, randomized, crossover pilot study of inhaled nitric oxide versus inhaled prostacyclin in heart transplant and lung transplant recipients. J Thorac Cardiovasc Surg. 2009;138(6):1417-24. https://doi.org/10.1016/j. jtcvs.2009.04.063.

247. Åkerström S, Mousavi-Jazi M, Klingström J, Leijon M, Lundkvist $\AA$, Mirazimi A. Nitric oxide inhibits the replication cycle of severe acute respiratory syndrome coronavirus. J Virol. 2005;79(3):1966. ～https://doi.org/10.1128/JVI.79.3.19661969.2005.

248. Cherian SV, Kumar A, Akasapu K, Ashton RW, Aparnath M, Malhotra A. Salvage therapies for refractory hypoxemia in ARDS. Respir Med. 2018;141:150-8. https://doi. org/10.1016/j.rmed.2018.06.030.

249. Walmrath D, Schneider T, Pilch J, Grimminger F, Seeger W. Aerosolised prostacyclin in adult respiratory distress syndrome. Lancet (Lond Engl).1993;342(8877):961-2. https://doi.org/10. 1016/0140-6736(93)92004-d.

250. Searcy RJ, Morales JR, Ferreira JA, Johnson DW. The role of inhaled prostacyclin in treating acute respiratory distress syndrome. Ther Adv Respir Dis. 2015;9(6):302-12. https:// doi.org/10.1177/1753465815599345.

251. Chen L, Liu P, Gao H, Sun B, Chao D, Wang F, et al. Inhalation of nitric oxide in the treatment of severe acute respiratory syndrome: a rescue trial in Beijing. Clin Infect Dis. 2004;39(10):1531-5. https://doi.org/10.1086/425357

252. Medicine USNLo. U.S. National Library of Medicine. ClinicalTrialsgov. 2020 Apr 2. doi: https://clinicaltrials.gov, Biospace. Mallinckrodt evaluates the potential role for inhaled nitric oxide to treat COVID-19 associated lung complications, engages with scientific, governmental and regulatory agencies. From the Biospace website. 2020 Mar 24.

253. Grunberger D, Banerjee R, Eisinger K, et al. Preferential cytotoxicity on tumor cells by caffeic acid phenethyl ester isolated from propolis. Experientia 1988;44:230-2.

254. Xu JW, Ikeda K, Kobayakawa A, Ikami $\mathrm{T}$, et al. Downregulation of Rac1 activation by caffeic acid in aortic smooth muscle cells. Life Sci 2005;76:2861-72.

255. Nguyen BC, Yoshimura K, Kumazawa S, Tawata S, Maruta H. Frondoside A from Sea Cucumber and Nymphaeols from Okinawa Propolis: Natural anti-cancer agents that selectively inhibit PAK1 in vitro, Drug Discov. Ther 2017;11:110-4].

256. Maruta H. Herbal therapeutics that block the oncogenic kinase PAK1: a practical approach towards PAK1-dependent diseases and longevity. Phytother Res 2014;28: 360 656-72.

257. Huynh N, Wang K, Yim M, et al. Depletion of p21-activated kinase 1 (PAK1) upregulates the immune system of APC $\Delta 14 /+$ mice and inhibits intestinal tumorigenesis. BMC Cancer 2017; 17:431. 
258. Maruta H, Ahn MR. From bench (laboratory) to bed (hospital/ home): How to explore effective natural and synthetic PAK1blockers/Longevity-promoters for cancer therapy. Fig. 3. Eur J Med Chem 2017;142:229.

259. H. Maruta, H. He / Medicine in Drug Discovery xxx (xxxx) xxx 4 UNCORRECTED PROOF.

260. Reiter R, Robinson J. Melatonin: Your Body's Natural Wonder Drug. New York: Bantan Books; 1995.

261. Be Tu PT, Nguyen BC, Tawata S, et al. The serum/PDGFdependent "melanogenic" role of the minute level of the oncogenic kinase PAK1 in melanoma cells proven by the highly sensitive kinase assay. Drug Discov Ther 2017;10:314-22.

262. Zhang R, Wang X, Ni L, et al. COVID-19: Melatonin as a potential adjuvant treatment. Life Sci. 2020;250:117583. doi:10.1016/j.lfs.2020.117583.

263. Maruta H. Herbal therapeutics that block the oncogenic kinase PAK1: a practical approach towards PAK1-dependent diseases and longevity. Phytother Res 2014;28: 360 656-72.

264. Allen JD, Jaffer ZM, Park SJ, et al. (2009). p21-activated kinase regulates mast cell degranulation via effects on calcium mobilization and cytoskeletal dynamics. Blood. 19; 113(12):2695-705.

265. Choi HS, Kim SL, Kim JH, Lee DS (2020). The FDAApproved Anti-Asthma Medicine Ciclesonide Inhibits Lung Cancer Stem Cells through Hedgehog Signaling-Mediated SOX2 Regulation. Int J Mol Sci, 21(3). pii: E1014.

266. Maruta $\mathrm{H}$. Tackling the Coronaviral Infection: Blocking Either the "Pathogenic" Kinase PAK1 or RNA-dependent RNA Polymerase (RdRP). J Infect Dis Ther 2020;8(2): 357418. https://writening.net/page?FC3QPm.

267. Maruta H, Ahn MR. From bench (laboratory) to bed (hospital/ home): How to explore effective natural and synthetic PAK1blockers/Longevity-promoters for cancer therapy. Fig. 3. Eur J Med Chem 2017;142:229.

268. Liou JT, Chen ZY, Ho LJ, et al. Differential effects of triptolide and tetrandrine on activation of COX-2, NF-kappaB, and AP-1 and virus production in dengue virus-infected human lung cells. Eur J Pharmacol 2008;589:288-98.

269. Patil S, Lis LG, Schumacher RJ, et al. Phosphonooxymethyl Prodrug of Triptolide (Minnelide): Synthesis, Physicochemical Characterization, and Efficacy in Human Colon Adenocarcinoma and Ovarian Cancer Xenografts. J Med Chem 2015;58:9334- 44.

270. Hashimoto H, Messerli SM, Sudo T, Maruta H. Ivermectin inactivates the kinase PAK1 and blocks the PAK1-dependent growth of human ovarian cancer and NF2 tumor cell lines. Drug Discov Ther 2009;3:243-6.

271. Caly L, Druce JD, Catton MG, Jans DA, Wagstaff KM. The FDA-approved drug ivermectin inhibits the replication of SARS-CoV-2 in vitro. Antiviral Res. 2020;178:104787. doi:10.1016/j.antiviral.2020.104787.

272. Hashimoto H, Messerli SM, Sudo T, Maruta H. Ivermectin inactivates the kinase PAK1 and blocks the PAK1-dependent growth of human ovarian cancer and NF2 tumor cell lines. Drug Discov Ther 2009;3:243-6.

273. Chen H, Sun B, Pan S, Jiang H, et al. Dihydroartemisinin inhibits growth of pancreatic cancer cells in vitro and in vivo. Anticancer Drugs 2009;20:131-40.

274. Sicard A, Semblat JP, Doerig C, Hamelin R, et al. Activation of a PAK-MEK signalling pathway in malaria parasiteinfected erythrocytes. Cell Microbiol 2011;13:836-45.
275. Wang JX, Tang W, Shi LP, Wan J, et al. Investigation of the immune-suppressive activity of artemether on T-cell activation and proliferation. Brit J Pharmacol 2007;150:652-61.

276. Hirokawa Y, Nheu T, Grimm K, et al. Sichuan pepper extracts block the PAK1/cyclin D1 pathway and the growth of NF1-deficient cancer xenograft in mice. Cancer Biol Ther 2006;5:305-9.

277. Hirokawa Y, Arnold M, Nakajima H, Zalcberg J, Maruta H. Signal therapy of breast cancer xenograft in mice by the HDAC inhibitor FK228 that blocks the activation of PAK1 and abrogates the tamoxifen-resistance. Cancer Biol Ther 2005;4:956-60.

278. Guo Y, Kenney Jr SR, Muller CY, et al. R-ketorolac Targets Cdc42 and Rac1 and Alters Ovarian Cancer Cell Behaviors Critical for Invasion and Metastasis. Mol Cancer Ther 2015;14:2215-27.

279. Nguyen BC, Takahashi H, Uto Y, Shahinozzaman MD, Tawata S, Maruta H. 1,2,3-Triazolyl ester of Ketorolac: A "Click Chemistry"-based highly potent PAK1-blocking cancer-killer. Eur J Med Chem 2016;126:270-6.

280. Hennig R, Albawardi A, Almarzooqi S, et al. 1,2,3-Triazolyl Ester of Ketorolac $(15 \mathrm{~K})$, a Potent PAK1-Blocker. Inhibits Both Growth and Metastasis of Human Pancreatic Cancer Orthotopic Xenografts in Mice Drug DiscovTher 2019;13:24855.

281. Eisman JA, Barkla DH, Tutton PJ. Suppression of in vivo growth of human cancer solid tumor xenografts by 1,25-dihydroxyvitamin D3. Cancer Res 1987;47:21-5.

282. Flanagan JN, Zheng S, Chiang KC, et al. Evaluation of 19-nor2alpha-(3-hydroxypropyl)-1alpha,25-dihydroxyvitamin D3 (MART-10) as a therapeutic agent for androgen-dependent prostate cancer. Anticancer Res 2009;29:3547-53.

283. Zeng N, Salker MS, Zhang S, et al. $1 \alpha, 25(\mathrm{OH}) 2 \mathrm{D} 3$ Induces Actin Depolymerization in Endometrial Carcinoma Cells by Targeting RAC1 and PAK1. Cell Physiol Biochem 2016; 40:1455-64.

284. Chiang KC, Yeh TS, Chen SC, et al. The Vitamin D analog, MART-10, attenuates triple negative breast cancer cells metastatic potential. Int J Mol Sci 2020;17:pii: E606.

285. Dwivedi PP, Omdahl JL, Kola I, Hume DA, May BK. Regulation of rat cytochrome P450C24 (CYP24) gene expression. Evidence for functional cooperation of Rasctivated Ets transcription factors with the vitamin $\mathrm{D}$ receptor in 1,25-dihydroxyvitamin 44

286. Lim H, Min DS, Park H, Kim HP. Flavonoids interfere with NLRP3 inflammasome activation. Toxicol Appl Pharmacol 2018;355:93-102.

287. Chen IY, Moriyama M, Chang MF, Ichinohe T. Severe acute respiratory syndrome coronavirus viroporin $3 \mathrm{a}$ activates the NLRP3 inflammasome, Front. Microbiol 2019;10(50). https:// doi.org/10.3389/fmicb.2019.00050.

288. B.C. Zhang, Z. Li, W. Xu, C.H. Xiang, Y.F. Ma, Luteolin alleviates NLRP3 inflammasome activation and directs macrophage polarization in lipopolysaccharide-stimulated RAW264.7 cells Am J Transl Res 2018;10(1):265-273.

289. Chen H, Lin H, Xie S, et al. Myricetin inhibits NLRP3 inflammasome activation via reduction of ROS-dependent ubiquitination of ASC and promotion of ROS-independent NLRP3 ubiquitination. Toxicol Appl Pharmacol 2019;365:1929. 
290. Yamagata K, Hashiguchi K, Yamamoto H, Tagami M. Dietary apigenin reduces induction of LOX-1 and NLRP3 expression, leukocyte adhesion, and acetylated low-density lipoprotein uptake in human endothelial cells exposed to trimethylamine-N-oxide. J Cardiovasc Pharmacol 2019;74(6):558-565.

291. Choe JY, Kim SK. Quercetin and ascorbic acid suppress fructose-induced NLRP3 inflammasome activation by blocking intracellular shuttling of TXNIP in human macrophage cell lines. Inflammation 2017;40(3):980-994.

292. Lim H, Min DS, Park H, Kim HP. Flavonoids interfere with NLRP3 inflammasome activation, Toxicol Appl Pharmacol 2018;355:93-102.

293. Fu S, Xu L, Li S, Qiu Y, Liu Y, Wu Z. Baicalin suppresses NLRP3 inflammasome and nuclear factor-kappa B (NF- $\kappa B$ ) signaling during haemophilus parasuis infection. Vet Res 2016;47(1):80.

294. Sun Y, Zhao Y, Yao J, et al. Wogonoside protects against dextran sulfate sodium-induced experimental colitis in mice by inhibiting NF- $\kappa \mathrm{B}$ and NLRP3 inflammasome activation, Biochem. Pharmacol 2015;94(2):142-154.

295. Dai W, Bi J, Li F, Wang S, Huang X, Meng X. Antiviral efficacy of lavonoids against enterovirus 71 infection in vitro and in newborn mice. Viruses 2019;11(7):625.
296. Moghaddam E, Teoh BT, Sam SS, et al. Baicalin, a metabolite of baicalein with antiviral activity against dengue virus. Sci Rep 2014;4:5452.

297. Ho TY, Wu SL, Chen JC, Li CC, Hsiang CY. Emodin blocks the SARS coronavirus spike protein and angiotensin-converting enzyme 2 interaction, Antiviral Res 2007;74(2):92-101.

298. Lin SC, Ho CT, Chuo WH, et al. Effective inhibition of MERS-CoV infection by resveratrol, BMC Infect Dis 2017;17(1):144.

299. KX, HC, YS, QN, YC, SH. Management of corona virus disease-19 (COVID-19): the Zhejiang experience. Zhejiang da xue xue bao Yi xue ban. 2020;49(1):0.

300. $\mathrm{Xu} \mathrm{Z}$, Shi L, Wang Y, Zhang J, Huang L, Zhang C. Pathological findings of COVID-19 associated with acute respiratory distress syndrome. Lancet Respirat Med 2020 S2213-600(20)30076-X. PubMed PMID: 32085846. Eng.

301. Leuschner F, Courties G, Dutta P, Mortensen LJ, Gorbatov R, Sena B. Silencing of CCR2 in myocarditis. Eur Heart J. 2015;36(23):1478-1488. PubMed PMID: 24950695. Epub 2014/06/20. Eng.

302. Leuschner F, Dutta P, Gorbatov R, et al. Therapeutic siRNA silencing in inflammatory monocytes in mice. Nature Biotechnol 2011;29(11):1005-1010. PubMed PMID: 21983520. Eng. 